\title{
Grain Growth Behavior, Tensile Impact Ductility, and Weldability of Cerium- Doped Iridium Alloys
}

June 2002

C. G. McKamey, E. P. George, E. H. Lee, J. L. Wright, and E.K. Ohriner 


\title{
DOCUMENT AVAILABILITY
}

Reports produced after January 1, 1996, are generally available free via the U.S. Department of Energy (DOE) Information Bridge:

Web site:http://www.osti.gov/bridge

Reports produced before January 1, 1996, may be purchased by members of the public from the following source:

\author{
National Technical Information Service \\ 5285 Port Royal Road \\ Springfield, VA 22161 \\ Telephone: 703-605-6000 (1-800-553-6847) \\ TDD: 703-487-4639 \\ Fax: 703-605-6900 \\ E-mail:info@ntis.fedworld.gov \\ Web site: http://www.ntis.gov/support/ordernowabout.htm
}

Reports are available to DOE employees, DOE contractors, Energy Technology Data Exchange (ETDE) representatives, and International Nuclear Information System (INIS) representatives from the following source:

Office of Scientific and Technical Information

P.O. Box 62

Oak Ridge, TN 37831

Telephone: 865-576-8401

Fax: 865-576-5728

E-mail:reports@adonis.osti.gov

Web site: http://www.osti.gov/contact.html

\begin{abstract}
This report was prepared as an account of work sponsored by an agency of the United States Government. Neither the United States government nor any agency thereof, nor any of their employees, makes any warranty, express or implied, or assumes any legal liability or responsibility for the accuracy, completeness, or usefulness of any information, apparatus, product, or process disclosed, or represents that its use would not infringe privately owned rights. Reference herein to any specific commercial product, process, or service by trade name, trademark, manufacturer, or otherwise, does not necessarily constitute or imply its endorsement, recommendation, or favoring by the United States Government or any agency thereof. The views and opinions of authors expressed herein do not necessarily state or reflect those of the United States Government or any agency thereof.
\end{abstract}


ORNL/TM-2002/114

RADIOISOTOPE POWER SYSTEMS PROGRAM

\title{
GRAIN GROWTH BEHAVIOR, TENSILE IMPACT DUCTILITY, AND WELDABILITY OF CERIUM-DOPED IRIDIUM ALLOYS
}

C. G. McKamey, E. P. George, E. H. Lee, J. L. Wright, and E.K. Ohriner

June 2002

Prepared for the Department of Energy

Office of Space and Defense Power Systems (NE-50)

Under Budget and Reporting Classification AF 7010200

\author{
Prepared by \\ OAK RIDGE NATIONAL LABORATORY \\ Oak Ridge, Tennessee 37831-6285 \\ managed by \\ UT-BATTELLE, LLC \\ for the \\ U.S. DEPARTMENT OF ENERGY \\ under contract DE-AC05-00OR22725
}




\section{CONTENTS}

Page

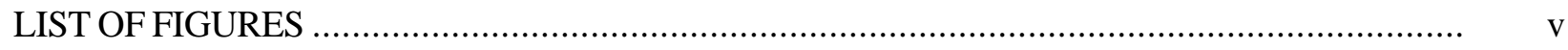

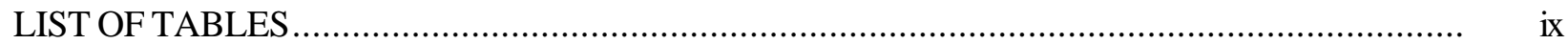

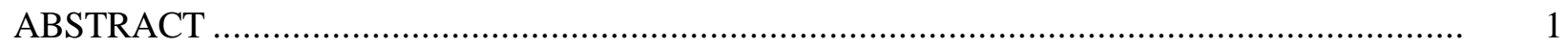

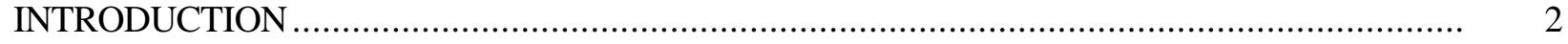

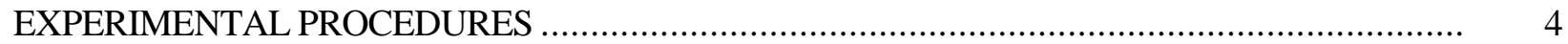

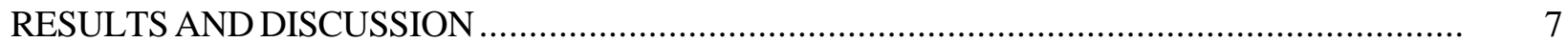

GRAIN GROWTH BEHAVIOR IN VACUUM............................................................

GRAIN GROWTH BEHAVIOR IN LOW PRESSURE OXYGEN ENVIRONMENTS ........... 13

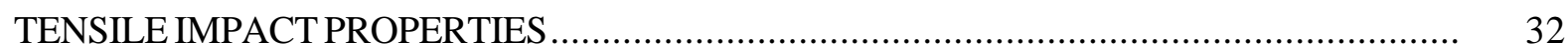

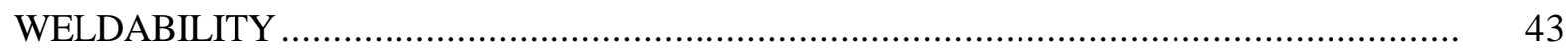

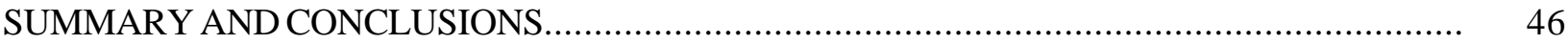

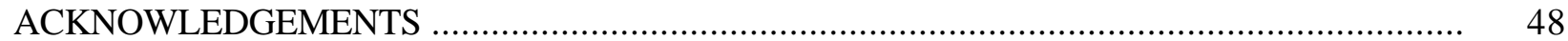

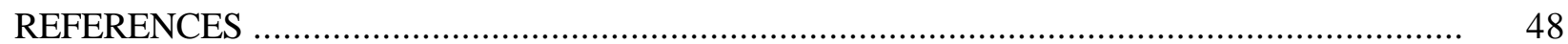




\section{LIST OF FIGURES}

Figure

Page

1 Schematic diagram of the Sigmajig weldability test

2 Temperature dependence of the grain size of the cerium-doped iridium alloys Ce-2 through $\mathrm{Ce}-7$.

3 Microstructures of (a) Ce-2, (b) Ce-3, (c) Ce-4, (d) Ce-6, (e) Ce-7, and (f) DOP-26

after a $1-\mathrm{h}$ vacuum anneal at $1500 \mathrm{EC}$

4 Average grain size as a function of time of annealing at 1300, 1400, and 1500EC for old-process DOP-26 (ZR heat) and Ce/Th-doped heat Ce-2

5 Effect of annealing temperature on the (a) short transverse (ST) and (b) long transverse (LT) direction grain sizes of the I-1 heat of DOP-40 iridium

6 Grain size of heat I- 1 as a function of time in vacuum at 1400EC for both the ST and LT directions with respect to the rolling direction

7 Optical micrographs showing grain size of the I-1 heat of DOP-40 (a) in the as-recrystallized $\left(1 \mathrm{~h}\right.$ at $\left.1375^{\circ} \mathrm{C}\right)$ condition and after heat treating in vacuum at $1400 \mathrm{EC}$ for (b) $4 \mathrm{~h}$ and (c) $565 \mathrm{~h}$.

8 Grain size of heat I-1 in the ST direction as a function of time in vacuum at 1500EC

9 Effect of annealing temperature on the grain growth of DOP-40 iridium alloys

10 Optical micrographs showing typical microstructures of Ce/Th-doped iridium: $(a, b)$ heat I-102 and (c,d) heat I-106 after 1-h anneals at 1500 and 1800EC, respectively

11 Optical micrographs of (a) the ZR heat of DOP-26 and the DOP-40 heats (b) Ce-2, (c) Ce-3, and (d) Ce-7 in the as-recrystallized condition (1 $\mathrm{h}$ at 1375EC)

12 Comparison of grain sizes in the (a) ST direction and (b) LT direction for iridium heats $\mathrm{ZR}, \mathrm{Ce}-3$, and $\mathrm{Ce}-7$ after exposure to $1.3 \mathrm{mPa}$ oxygen at $1230^{\circ} \mathrm{C}$

13 Optical micrographs showing microstructures of iridium heats (a) ZR (with only thorium), (b) Ce-3 (with only cerium), and (c) Ce-7 (with both thorium and cerium) after $3000 \mathrm{~h}$ of exposure to $1.3 \mathrm{mPa}$ oxygen at $1230 \mathrm{EC}$

14 Grain size as a function of depth below the surface for samples of the cerium-doped heats (a) Ce-3 and (b) Ce-7 and for (c) the old-process DOP-26 ZR heat after exposure to $1.3 \mathrm{mPa}$ oxygen at $1230 \mathrm{EC}$.

15 Grain size as a function of time of exposure to $1.3 \mathrm{mPa}$ oxygen at $1280 \mathrm{EC}$ for the old-process ZR heat and the cerium-doped Ce-3 heat 
16 Grain size as a function of depth below the surface for samples of (a) the cerium-doped heat Ce-3 and (b) old-process DOP-26 ZR heat after exposure to $1.3 \mathrm{mPa}$ oxygen at $1280 \mathrm{EC}$

17 Effect of annealing time on the grain size of the Ce-3 alloy annealed at 1230 and 1280EC in $1.3 \mathrm{mPa}$ oxygen, (a) ST direction and (b) LT direction

18 Grain size as a function of depth below the surface for samples of the Ce-3 alloy annealed at 1230 and $1280 \mathrm{EC}$ in $1.3 \mathrm{mPa}$ oxygen

19 Grain size as a function of time of exposure to $1.3 \mathrm{mPa}$ oxygen at $1330 \mathrm{EC}$ for the old-process ZR heat and the Ce/Th-doped Ce-2 heat

20 Optical micrographs showing grain size of iridium heat $\mathrm{Ce}-2$ after exposure to $1.3 \mathrm{mPa}$ oxygen at $1330 \mathrm{EC}$ for (a) 760, (b) 1524, and (c) $3000 \mathrm{~h}$

21 Grain size as a function of depth below the surface for samples of (a) the cerium-doped heat Ce-2 and (b) the DOP-26 ZR heat after exposure to $1.3 \mathrm{mPa}$ oxygen at $1330 \mathrm{EC}$.

22 Comparison of grain size as a function of time of exposure at three different temperatures in an oxygen partial pressure of $13.3 \mathrm{mPa}$ for the Ce/Th-doped I-1 heat and the new-process DOP-26 D2 heat in the (a) ST and (b) LT direction with respect to the rolling direction

23 Optical micrographs of Ce/Th-doped heat I-1 after (a) 696 and (b) $3000 \mathrm{~h}$ of exposure to $13.3 \mathrm{mPa}$ oxygen at $1280 \mathrm{EC}$

24 Optical micrographs of (a) the DOP-26 D2 heat and (b) the DOP-40 I-1 heat after $3000 \mathrm{~h}$ of exposure to $13.3 \mathrm{mPa}$ oxygen at $1330 \mathrm{EC}$

25 Grain size in the LT direction as a function of temperature and depth below the surface of the sample for the (a) Ce/Th-doped I-1 and (b) new-process D2 alloy annealed for $3000 \mathrm{~h}$ at $1230 \mathrm{EC}$ in an oxygen partial pressure of $13.3 \mathrm{mPa}$

26 Comparison of grain size as a function of time of exposure at 1330EC in an oxygen partial pressure of $1.3 \mathrm{mPa}$ for the new-process DOP-26 D2 heat and for Ce/Th-doped heats I-102 through I-105 in the (a) ST and (b) LT direction with respect to the rolling direction

27 Comparison of grain size as a function of time of exposure at 1330EC in an oxygen partial pressure of $13.3 \mathrm{mPa}$ for the new-process DOP-26 D2 heat and for Ce/Th-doped heats I-102 through I-105 in the (a) ST and (b) LT direction with respect to the rolling direction

28 Optical micrographs of iridium heat I-103 (a) in the as-recrystallized condition and after (b) $666 \mathrm{~h}$ and (c) $3000 \mathrm{~h}$ exposure to $13.3 \mathrm{mPa}$ oxygen at $1330 \mathrm{EC}$

29 Optical micrographs of iridium heat I-105 (a) in the as-recrystallized condition and after (b) $666 \mathrm{~h}$ and (c) $3000 \mathrm{~h}$ exposure to $13.3 \mathrm{mPa}$ oxygen at 1330EC 
30 Comparison of grain size as a function of time of exposure at 1230 and $1330 \mathrm{EC}$ in an oxygen partial pressure of $13.3 \mathrm{mPa}$ for the new-process DOP-26 D2 heat and for cerium-doped heat I-103 in the (a) ST and (b) LT direction with respect to the rolling direction

31 Grain size in the LT direction as a function depth below the surface of the samples for the new-process DOP-26 D2 heat and for Ce/Th-doped heats I-102 through I-105 annealed for $3000 \mathrm{~h}$ at $1330 \mathrm{EC}$ in an oxygen partial pressure of $13.3 \mathrm{mPa}$

32 Comparison of grain size as a function of depth below the surface of samples of the $\mathrm{Ce} / \mathrm{Th}$-doped I-103 heat annealed for $3000 \mathrm{~h}$ in $13.3 \mathrm{mPa}$ oxygen at $1230 \mathrm{EC}$ and at $1330 \mathrm{EC}$ in 1.3 and $13.3 \mathrm{mPa}$ oxygen

33 Variation of impact ductility with annealing temperature (impact test temperature was $980 \mathrm{EC}$ )

34 Variation of impact ductility with grain size (impact test temperature was 980EC)

35 Fracture surfaces of (a) Ce-2, (b) Ce-3, (c) Ce-4, (d) Ce-6, (e) Ce-7, and (f) DOP-26 annealed for $1 \mathrm{~h}$ at $1500 \mathrm{EC}$ and impact tested at $980 \mathrm{EC}$

36 Amount of transgranular fracture area as a function of impact ductility

37 Variation of impact ductility with test temperature for cerium-, thorium-, and Ce/Th-doped alloys (all alloys possess a similar grain size of 30 to $35 \mathrm{Fm}$ )

38 Fracture surfaces of (a,b) Ce-3, (c,d) Ce-4, (e,f) Ce-6, and (g,h) DOP-26 at low and high test temperatures, all annealed $1 \mathrm{~h}$ at $1500 \mathrm{EC}$

39 Amount of transgranular fracture area as a function of test temperature

40 Temperature dependence of the yield and ultimate tensile strengths of Ce/Th-doped alloy I-1 (squares) and DOP-26 (circles), tensile tested at a conventional strain rate $\left(\sim 10^{-3} \mathrm{~s}^{-1}\right) \ldots$

41 Temperature dependence of the ductilities of Ce/Th-doped alloy I-1 (squares) and DOP-26 (circles) compared to Ir- $0.3 \mathrm{~W}$ and pure iridium, tensile tested at a conventional strain rate $\left(\sim 10^{-3} \mathrm{~s}^{-1}\right)$.

42 Fracture surface of I-1 alloy tensile tested at the conventional strain rate $\left(\sim 10^{-3} \mathrm{~s}^{-1}\right)$ at (a) 400 and (b) $700 \mathrm{EC}$

43 Temperature dependence of the ductilities of DOP-40 alloys and DOP-26 tensile tested at the high strain rate $\left(\sim 10^{3} \mathrm{~s}^{-1}\right)$

44 Fracture surfaces of the I-106 alloy tensile tested at high strain rate $\left(\sim 10^{3} \mathrm{~s}^{-1}\right)$ at (a) 800 , (b) 1000, and (c) 1300EC

45 Effect of annealing temperature on the ductility of DOP-40 alloys and DOP-26 tensile tested at $1000 \mathrm{EC}$ at a strain rate of $\sim 10^{3} \mathrm{~s}^{-1}$ 
46 Tensile ductility of DOP-26 and the Ce-2 through Ce-7 Ce-doped iridium alloys as a function of the inverse square root of grain size (tensile tested at $1000 \mathrm{EC}$ and a strain rate

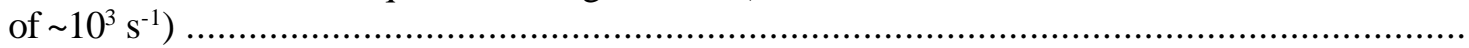

47 Tensile ductility of the I-101 through I-107 DOP-40 alloys and DOP-26 as a function of the inverse square root of grain size (tensile tested at 1000EC and a strain rate of $\sim 10^{3} \mathrm{~s}^{-1}$ ) ........

48 Phase diagrams of (a) Ir-Ce and (b) Ir-Th .

49 Effect of doping with cerium and thorium, individually and together, on weldability of iridium alloys 


\section{LIST OF TABLES}

Table

Page

I Nominal dopant levels of DOP-26 and DOP-40 alloys ......................................... 4

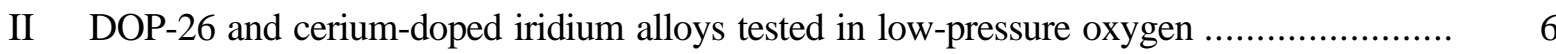

III Average grain size of thorium-, cerium-, and Ce/Th-doped iridium alloys after 1-h vacuum anneals at various temperatures compared to data for DOP-26 alloys ZR and D2

IV Average grain sizes of ZR (old process), D2 (new process), and Ce-2 iridium alloys as a function of annealing time at $1300-1500^{\circ} \mathrm{C}$

$\mathrm{V}$ Effect of annealing temperature (for 1-h anneals) on grain sizes of DOP-26 and the I-1 heat of DOP-40

VI Effect of annealing time at temperatures of 1400 and $1500^{\circ} \mathrm{C}$ on grain sizes of DOP-26 and the I-1 heat of DOP-40

VII Grain size of DOP-40 alloys annealed for $1 \mathrm{~h}$ at different annealing temperatures

VIII Grain size of the Th/Ce-doped Ce-2, Ce-3, and Ce-7 alloys as a function of exposure time and temperature in an oxygen partial pressure of $1.3 \mathrm{mPa}$.....

IX Average grain size (in Fm) as a function of depth below the surface for Ce-2, Ce-3, and Ce-7 specimens exposed to an oxygen partial pressure of $1.3 \mathrm{mPa}$

$\mathrm{X}$ Grain size of the Ce/Th-doped I-1 heat as a function of exposure time at 1230, 1280, and $1330^{\circ} \mathrm{C}$ in an oxygen partial pressure of $13.3 \mathrm{mPa}$

XI Average grain size (in $\mathrm{Fm}$ ) as a function of depth below the surface for specimens of the DOP-40 I-1 heat exposed to an oxygen partial pressure of $13.3 \mathrm{mPa}$

XII Grain size of Th/Ce-doped DOP-40 alloys as a function of exposure time at $1330^{\circ} \mathrm{C}$ in an oxygen partial pressure of $1.3 \mathrm{mPa}$

XIII Grain size of Th/Ce-doped DOP-40 alloys as a function of exposure time at $1330^{\circ} \mathrm{C}$ in an oxygen partial pressure of $13.3 \mathrm{mPa}$.

XIV Grain size of the cerium-doped I-103 alloy as a function of exposure time at $1230^{\circ} \mathrm{C}$ in an oxygen partial pressure of $13.3 \mathrm{mPa}$.

XV Average grain size (in Fm) as a function of depth below the surface for DOP-40 specimens exposed to an oxygen partial pressure of $1.3 \mathrm{mPa}$ at $1330^{\circ} \mathrm{C}$ 
XVI Average grain size (in $\mathrm{Fm}$ ) as a function of depth below the surface for DOP-40 specimens exposed to an oxygen partial pressure of $13.3 \mathrm{mPa}$ at $1330^{\circ} \mathrm{C}$

XVII Average grain size (in Fm) as a function of depth below the surface for I-103 specimens exposed to an oxygen partial pressure of $13.3 \mathrm{mPa}$ at $1230^{\circ} \mathrm{C}$.....

XVIII Effect of annealing temperature on tensile impact ductility of $\mathrm{Ce} / \mathrm{Th}$-doped heats Ce-2 through Ce-7

XIX Effect of test temperature on tensile impact ductility of $\mathrm{Ce} / \mathrm{Th}$-doped alloys

XX Effect of test temperature on tensile impact ductility of Ce/Th-doped heats I-101 through I-107

XXI Effect of annealing temperature on tensile impact ductility of $\mathrm{Ce} / \mathrm{Th}$-doped heats I-101 through I-107

XXII Results from impact testing of Ce/Th-doped iridium alloys

XXIII Results of Auger analysis of grain boundaries in various iridium alloys

XXIV Threshold stresses for weld cracking in cerium- and Ce/Th-doped iridium alloys 


\title{
GRAIN GROWTH BEHAVIOR, TENSILE IMPACT DUCTILITY, AND WELDABILITY OF CERIUM-DOPED IRIDIUM ALLOYS*
}

\author{
C. G. McKamey, E. P. George, E. H. Lee, J. L. Wright, and E. K. Ohriner
}

\begin{abstract}
An iridium alloy doped with small amounts of cerium and thorium is being developed as a potential replacement for the iridium-based DOP-26 alloy (doped with thorium only) that is currently used by the National Aeronautics and Space Administration (NASA) for cladding and post-impact containment of the radioactive fuel in radioisotope thermoelectric generator (RTG) heat sources which provide electric power for interplanetary spacecraft. This report summarizes results of studies conducted to date under the Iridium Alloy Characterization and Development subtask of the Radioisotope Power System Materials Production and Technology Program to characterize the properties of the iridium-based alloy (designated as DOP-40) containing both cerium and thorium. Included within this report are data on grain growth of sheet material in vacuum and low-pressure oxygen environments, grain growth in vacuum of the clad vent set cup material, weldability, and the effect of grain size and test temperature on tensile properties. Where applicable, data for the DOP-26 alloy are included for comparison.

Both grain size and grain-boundary cohesion affect the ductility of iridium alloys. In this study it was found that cerium and thorium, when added together, refine grain size more effectively than when thorium is added by itself (especially at high temperatures). In addition, the effect of cerium additions on grain-boundary cohesion is similar to that of thorium. Mechanical testing at both low $\left(\sim 10^{-3} \mathrm{~s}^{-1}\right)$ and high $\left(\sim 10^{3} \mathrm{~s}^{-1}\right)$ strain rates showed that the Ce/Thdoped alloys have tensile ductilities that are as good or better than the DOP-26 alloy. The general conclusion from these studies is that cerium can be used to replace some of the radioactive thorium currently used in DOP-26 while maintaining or improving its metallurgical properties. The current DOP-26 alloy meets all requirements for cladding the radioactive fuel in the RTG heat source, but the new DOP-40 alloy could serve as a back-up alloy to be used if the costs of refining, handling, and transporting DOP-26 become prohibitively high.
\end{abstract}

\footnotetext{
* Research sponsored by the Office of Space and Defense Power Systems at the Oak Ridge National Laboratory, managed by UT-Battelle, LLC for the U.S. Department of Energy under contract number DE-AC05-00OR22725.
} 


\section{INTRODUCTION}

Iridium is a face centered cubic metal with a high melting point ( 2442EC), the highest shear modulus of any metal [1], the second-highest elevated-temperature strength among the refractory metals [2], good oxidation resistance [3], and the highest corrosion resistance of any element [4]. It is, therefore, attractive for high-temperature structural applications - especially in hostile environments. Unfortunately, it has a few drawbacks. Iridium is the heaviest element in the periodic table (density, $22.7 \mathrm{~g} / \mathrm{cc}$ ) and is relatively expensive. Other disadvantages include mechanical properties that are strain-rate sensitive and a brittle-to-ductile transition [5], features usually associated with bcc and not fcc metals.

Monocrystalline iridium cleaves at room temperature and polycrystals undergo mixed intergranular/ transgranular fracture at temperatures to $1000 \mathrm{EC}$, even at moderate strain rates [6-9]. At higher strain rates, the brittle-to-ductile transition temperature (BDTT) shifts up; e.g., at strain rates on the order of $10^{3}$ $\mathrm{s}^{-1}$, brittle intergranular fracture persists to $1500 \mathrm{EC}$ [5]. The brittleness of iridium is intriguing given that it deforms in the 'normal' fcc way, i.e., slip occurs on $\{111\}<110>[10-13]$ which provides five independent slip systems. Impurities were implicated in early studies [14,15], but it was shown later that, while some impurities exacerbated brittleness [16], even high-purity iridium with no detectable impurities on its grain boundaries exhibited brittle intergranular fracture [5,16-20]. This is similar to the situation in $\mathrm{Ni}_{3} \mathrm{Al}$, which has the 'ordered fcc' structure, and in which brittle intergranular fracture occurs even though the grain boundaries are clean [21,22]. However, unlike in $\mathrm{Ni}_{3} \mathrm{Al}$ where the atomic hydrogen and oxygen generated from ordinary ambient air are the cause of grain-boundary brittleness at low [23-26] and high temperatures [25,27,28], respectively, no environmental factors have so far been implicated in the brittle fracture of iridium.

Liu and Inouye [17] discovered that doping with 'ppm levels' of thorium suppressed grain-boundary fracture and increased the ductility of iridium alloys, especially at high-strain rates. This made it possible to use iridium in some high-temperature structural applications. Thus, during the last three decades, iridium alloys have been used successfully as fuel cladding material in radioisotope thermoelectric generators, the major source of onboard electric power in spacecraft sent to explore the outer planets [29]. The iridium alloy that is currently used for space-power applications is designated DOP-26 [5,30]; it has the nominal composition $\mathrm{Ir}-0.3 \mathrm{~W}-0.006 \mathrm{Th}-0.005 \mathrm{Al}$ (all compositions by weight, unless otherwise noted). The role of tungsten is to provide solid-solution strength and to raise the recrystallization temperature so that the alloy can be warm rolled without inducing recrystallization (its formability is better in the wrought state than in the recrystallized state, another bcc-like feature). Aluminum is thought to promote thorium segregation to the grain boundaries $[17,19,20]$, while thorium serves two purposes: (i) it forms fine, highly stable $\mathrm{Ir}_{5}$ Th precipitates [31] which pin the boundaries and refine grain size [5] and (ii)

it segregates to the grain boundaries [18] where it enhances cohesion [5], both of which contribute to improved ductility at high strain rates [5]. Maximum ductility is obtained when thorium is present at a 
level of about $200 \mathrm{ppm}$. Unfortunately, this level of thorium is harmful to weldability because it promotes hot cracking by the formation of a low-melting $\operatorname{Ir}_{-} \mathrm{Ir}_{5} \mathrm{Th}$ eutectic at the fusion-zone grain boundaries [32]. The currently used DOP-26 alloy contains nominally only $60 \mathrm{ppm}$ Th. This lower level of thorium results in improved weldability but somewhat lower high-temperature impact ductility than the maximum obtainable.

Since thorium is also a radioactive element, there are several potential problems in using this element as an alloying addition. Refining of the element is expensive, and if the scrap cannot be refined commercially the cost of recovery will continue to increase. Additionally, the increasingly strict environmental, safety, and health regulations may make it more costly to work with DOP-26 in the future. Currently, the $60 \pm 30$ ppm specification for thorium in DOP-26 is just under the limit at which this alloy would be designated as radioactive. If these limits were to become stricter in the future, DOP-26 would have to be handled as a radioactive material and its manufacturing and handling costs would dramatically increase. From these standpoints it is prudent to search now for a suitable alternative alloying element to replace thorium in DOP-26, so that back-up alloys will be available when needed.

This report presents results of an ongoing research program aimed at finding substitutes for thorium that are not radioactive and that improve weldability without reducing high-temperature impact ductility. Physical metallurgy principles were used to select potential alloying elements as follows: To be beneficial, the selected dopant should segregate to the grain boundaries, improve grain boundary cohesion, and refine the grain size of iridium. A driving force for grain boundary segregation is the large atomic size misfit between the dopant and the matrix [33]. This size mismatch also causes low solid solubility of the dopant, which results in second-phase precipitation. The second-phase particles, if they are stable at elevated temperatures, are expected to refine the grain size by pinning the grain boundaries. Once a dopant segregates, it must enhance the grain boundary cohesion if it is to be beneficial. Cerium, yttrium, and lutetium were chosen as promising elements [34-36] based on the above reasoning.

In earlier studies [35,37] it was found that, of these three elements, cerium segregated most strongly to the grain boundaries in iridium. Based on these results, cerium was selected as a replacement for thorium. The original goal was to replace all of the radioactive thorium in DOP-26 iridium with nonradioactive cerium. However, our studies showed that, although cerium was effective in refining the grain size of iridium, it was not as effective as thorium in enhancing grain-boundary cohesion [35]. Since grain size and grain-boundary cohesion both influence high-temperature impact ductility [5], our alloy design strategy then changed to replacing only part of the thorium with cerium, with the former serving mainly as a grain-boundary strengthener and the latter as the grain refiner.

The new Ce/Th-doped alloys have been designated as DOP-40 and contain 15-40 ppm Ce and 0-60 ppm Th, levels which fall within their allowable ranges in the current DOP-26 specification: $60 \pm 30 \mathrm{ppm}$ for Th and <50 ppm for Ce. One additional alloy with 73 ppm Ce (equivalent to 100 appm Ce) containing no thorium was also included in these studies. This report summarizes the results of studies to 
determine how the grain growth behavior, tensile impact properties, and weldability of DOP-40 iridium change with small changes in the thorium and cerium concentrations.

\section{EXPERIMENTAL PROCEDURES}

Several Ir-0.3 wt $\% \mathrm{~W}$ alloys, doped with the microalloying additions listed in Table I, were prepared as follows. [Note that aluminum, which is a dopant in DOP-26 iridium [5], was not added to any of the DOP-40 alloys used in this study. When the first cerium-doped alloys were being designed, there was a possibility that the arc melting and drop casting steps in the iridium blank production process would be eliminated and replaced with electron beam melting. The addition of aluminum to iridium would then pose a problem because of extensive evaporative losses during electron beam melting. It was therefore decided to develop the new DOP-40 alloys without any aluminum additions.] Heats Ce-2 through Ce-7, E818 through E820, and heats I-101 through I-107 were made using the so-called 'old-process.' Heat I-1 was made using the so-called 'new-process.' Both processes have been discussed in detail elsewhere [30,38-40], so they will be described only briefly here. The old-process alloys were produced by arc melting and drop casting into copper chill molds measuring 19 x 19 x $63 \mathrm{~mm}$. The resulting 500-g ingots

Table I. Nominal dopant levels of DOP-26 and DOP-40 alloys

\begin{tabular}{|c|c|c|c|c|c|}
\hline \multirow{2}{*}{$\begin{array}{c}\text { Heat } \\
\text { designation }\end{array}$} & \multicolumn{2}{|c|}{ Ce concentration } & \multicolumn{2}{|c|}{ Th concentration } & \multirow{2}{*}{$\begin{array}{c}\text { Other } \\
\text { (appm) }\end{array}$} \\
\hline & wppm & appm & wppm & appm & \\
\hline ZR & 0 & 0 & 60 & 50 & -- \\
\hline $\mathrm{D} 2$ & 0 & 0 & 60 & 50 & -- \\
\hline $\mathrm{Ce}-2(13935)$ & 36 & 50 & 60 & 50 & -- \\
\hline Ce-3 (E809) & 36 & 50 & 0 & 0 & -- \\
\hline Ce-4 (E808) & 73 & 100 & 0 & 0 & -- \\
\hline Ce-6 (E814) & 29 & 40 & 12 & 10 & -- \\
\hline Ce-7 (E815) & 22 & 30 & 24 & 20 & -- \\
\hline E818 & 22 & 30 & 24 & 20 & $100 \mathrm{~B}$ \\
\hline E819 & 15 & 20 & 24 & 20 & $10 \mathrm{Y}$ \\
\hline E820 & 15 & 20 & 24 & 20 & $10 \mathrm{Y}, 100 \mathrm{~B}$ \\
\hline $\mathrm{I}-1$ & 29 & 40 & 18 & 15 & -- \\
\hline I-101 & 20 & 27 & 30 & 25 & -- \\
\hline I-102 & 20 & 27 & 40 & 33 & -- \\
\hline I-103 & 30 & 41 & 30 & 25 & -- \\
\hline I-104 & 30 & 41 & 40 & 33 & -- \\
\hline $\mathrm{I}-105$ & 30 & 41 & 50 & 41 & -- \\
\hline I-106 & 40 & 55 & 40 & 33 & -- \\
\hline $\mathrm{I}-107$ & 40 & 55 & 50 & 41 & -- \\
\hline
\end{tabular}


were individually clad in molybdenum plates and warm rolled at temperatures of 1200-1000EC with a $20 \%$ reduction in thickness per pass to a final thickness of $\sim 1 \mathrm{~mm}$. The sheets were electrolytically cleaned in a $\mathrm{KCN}$ bath and acid-cleaned in a solution containing 3 parts $\mathrm{HCl}, 1$ part $\mathrm{HF}$ and 1 part water to remove impurities and oxide scales from the surface. In the new process, arc-melting and drop-casting were performed as in the old-process, after which the 500-g ingots were electron-beam welded together to make an electrode for vacuum arc remelting (VAR). The VAR process produced an ingot approximately $63 \mathrm{~mm}$ in diameter and $64 \mathrm{~mm}$ long, weighing $\sim 4 \mathrm{~kg}$. The ingot was encased in molybdenum and extruded at 1475EC to produce bar stock approximately $40 \times 13 \mathrm{~mm}$ in cross-section. The extruded bar was cut into sections, rolled to sheet, and cleaned as in the old process. The final thickness of both the oldand new-process sheet was approximately $0.75 \mathrm{~mm}$. In Table I and in many of the results presented below, results for the old-process ZR and new-process D2 heats of DOP-26 are included for comparison purposes [30].

Specimens for grain growth studies were cut by electrical discharge machining from the rolled sheets. Approximately $0.1 \mathrm{~mm}$ was ground from the edges of the specimens to remove any damage produced by the machining. To determine general grain growth characteristics, specimens were annealed in a vacuum of better than $7 \times 10^{-4} \mathrm{~Pa}\left(5 \times 10^{-6}\right.$ torr $)$ for various times at temperatures ranging from 1300 to $1800 \mathrm{EC}$. Studies were also conducted to determine the tendency of cerium-doped iridium alloys to experience anomalous grain growth of near-surface grains during exposure to low-oxygen environments, a type of grain growth that has been observed in DOP-26 iridium alloys [30,41]. For heat treatments in low pressure oxygen, samples were first recrystallized for $1 \mathrm{~h}$ at $1375 \mathrm{EC}$ in vacuum $\left(10^{-4} \mathrm{~Pa}\right.$ range $)$. Oxygen anneals for times up to $3000 \mathrm{~h}$ were then performed in a dynamically pumped tube furnace having a base pressure of better than $10^{-4} \mathrm{~Pa}$ at the test temperatures. Oxygen anneals were performed at two different oxygen partial pressures, 1.3 and $13.3 \mathrm{mPa}$, and at temperatures of 1230, 1280, and 1330EC. The compositions tested and the test conditions for the oxygen anneals are listed in Table II. Specimens of the iridium DOP-26 ingots designated as ZR (fabricated by the old process) or D2 (fabricated by the new process) were included in each oxygen anneal for comparison purposes.

After annealing, the specimens were mounted in epoxy, metallographically polished, and then electrolytically etched in a solution of $400 \mathrm{ml} \mathrm{H}_{2} \mathrm{O}, 100 \mathrm{ml} \mathrm{HCl}$, and . $2.5 \mathrm{~g} \mathrm{NaCl}$, using a current of $0.9 \mathrm{~A}$ at an applied potential of approximately $10 \mathrm{~V} \mathrm{AC}$ for 4-5 min. Grain sizes were measured by the linear intercept method in a plane transverse to the rolling direction. In this plane, grain diameters were determined in the short transverse (ST) direction (i.e., perpendicular to the plane of the sheet) and occasionally also in the long transverse (LT) direction (i.e., parallel to the plane of the sheet). In the oxygen-annealed specimens, grain sizes were also measured in the LT direction as a function of depth from the specimen surface. Grain size measurements were recorded as the average values obtained from 2-4 fields in each specimen. In most cases, the confidence limits of the data are indicated by the number of intercepts counted for each data point and are recorded in parentheses in the data tables. 
Table II. DOP-26 and Ce-doped iridium alloys tested in low-pressure oxygen

\begin{tabular}{ccccc}
\hline $\begin{array}{c}\text { Oxygen pressure } \\
(\mathrm{mPa})\end{array}$ & $\begin{array}{c}\text { Temperature } \\
\left({ }^{\circ} \mathrm{C}\right)\end{array}$ & $\begin{array}{c}\text { DOP-26 } \\
(\text { old process })\end{array}$ & $\begin{array}{c}\text { DOP-26 } \\
(\text { new process })\end{array}$ & Ce-doped \\
\hline 1.3 & 1330 & $\mathrm{ZR}$ & $\mathrm{D} 2$ & $\mathrm{Ce}-2$ \\
& 1280 & $\mathrm{ZR}$ & $\mathrm{D} 2$ & $\mathrm{Ce}-3$ \\
& 1230 & $\mathrm{ZR}$ & $\mathrm{D} 2$ & $\mathrm{Ce}-3, \mathrm{Ce}-7$ \\
13.3 & 1330 & $\mathrm{ZR}$ & $\mathrm{D} 2$ & $\mathrm{I}-1$ \\
& 1280 & $\mathrm{ZR}$ & $\mathrm{D} 2$ & $\mathrm{I}-1$ \\
& 1230 & $\mathrm{ZR}$ & $\mathrm{D} 2$ & $\mathrm{I}-1, \mathrm{I}-103$ \\
13.3 & 1330 & -- & $\mathrm{D} 2$ & $\mathrm{I}-102, \mathrm{I}-103$, \\
& & & $\mathrm{D} 2$ & $\mathrm{I}-104, \mathrm{I}-105$ \\
& & -- & & $\mathrm{I}-102, \mathrm{I}-103$, \\
& 1330 & & & \\
\end{tabular}

Tensile testing was performed to study the effect of grain size and test temperature on strength and ductility of the Ce/Th-doped alloys. Specimens were first machined from the rolled sheets (after a stress relief heat treatment of $1 \mathrm{~h}$ at $900 \mathrm{EC}$ ) with gage length parallel to the rolling direction. The specimen gage section had dimensions of $11.4 \times 2.5 \times 0.63 \mathrm{~mm}$. Some of the specimens were then vacuum annealed for $1 \mathrm{~h}$ at temperatures between 1300 and 1800EC to produce a range of grain sizes for a study of the influence of grain size on tensile properties. In addition, selected specimens of both Th-doped DOP26 and Ce/Th-doped DOP-40 heats were annealed for $1 \mathrm{~h}$ at 1500EC to produce grain sizes of between 30 and $35 \mathrm{Fm}$. These specimens were used to study the effect of test temperature on tensile properties. Grain sizes were measured in the ST direction, as described above.

Tensile tests were conducted at two different strain rates $\left(\sim 10^{-3} \mathrm{~s}^{-1}\right.$ and $\left.\sim 10^{3} \mathrm{~s}^{-1}\right)$, at temperatures ranging from -196 to $1200 \mathrm{EC}$ at the slower strain rate, and 800 to $1300 \mathrm{EC}$ at the higher strain rate. The slow-strain-rate tests were performed on a screw-driven Instron machine. The high-strain-rate tests were performed using a specially designed gas-powered 'impact gun' [5,17] consisting of four components: (1) a $7.62-\mathrm{cm}$ diameter gas gun to accelerate the projectile and its carrier at velocities to $85 \mathrm{~m} / \mathrm{s}$, (2) an impact chamber with a controlled argon atmosphere, (3) an induction heating system to heat the specimens to $1673 \mathrm{~K}$, and (4) a specimen rig to load the impact specimens. The details of the setup and the loading arrangement have been given elsewhere [5,17]. Impact testing was conducted at a constant bullet velocity of $61 \pm 3 \mathrm{~m} / \mathrm{s}$ (which corresponds to a tensile stain rate of approximately $5 \times 10^{3} \mathrm{~s}^{-1}$ ) and the specimen temperature was controlled to within $\pm 10 \mathrm{C}$. The impact gun was not instrumented to measure loads, so yield and ultimate strengths are not reported for the high-strain-rate tests. Uniform tensile elongation was used as a measure of ductility in this study. It was obtained by making eight uniformly spaced Vicker's hardness indents along the specimen gage length with a $500 \mathrm{~g}$ load. The distance between pairs of indents was measured before and after fracture, and the results averaged to obtain uniform elongation. 
Reduction in area was difficult to measure because during impact the sheet specimens were often damaged or distorted in the vicinity of the fracture location. The technique used for measuring uniform elongation avoided this problem because it did not include the segment where fracture occurred.

After testing, the fracture surfaces of the samples were examined in a scanning electron microscope. Quantitative analysis of the fracture surfaces was conducted using a two-dimensional systematic pointcount method, and estimates for the area fraction of transgranular fracture were obtained.

For Sigmajig weldability testing, blanks (approximately $52 \mathrm{~mm}$ in diameter and $0.65 \mathrm{~mm}$ thick) were machined from the rolled sheet and subsequently recrystallized by annealing in vacuum for $1 \mathrm{~h}$ at 1300EC. The Sigmajig test (see schematic diagram in Fig. 1) is a hot cracking test in which a transverse stress $(F)$ is applied to a sheet specimen of the alloy to be characterized, and a weld line is produced down the center of the specimen using autogenous gas tungsten arc (GTA) welding [42]. The magnitude of the transverse stress is increased progressively from one specimen to the next, until a specimen cracks completely (i.e., into two pieces). The stress at which such cracking occurs is called the threshold stress for cracking $\left(F_{o}\right)$. Studies on stainless steels have shown that such threshold stresses can be used to quantitatively rank different heats in terms of their propensity for hot cracking [42]. Thus, the Sigmajig test is a useful tool to compare the weldablity of DOP-40 to that of the currently produced DOP-26.

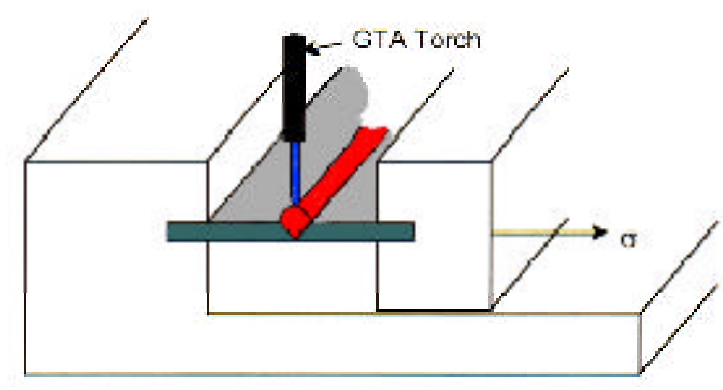

Fig. 1. Schematic diagram of the Sigmajig weldability test.

\section{RESULTS AND DISCUSSION}

\section{GRAIN GROWTH BEHAVIOR IN VACUUM}

Table III and Fig. 2 show the effect of annealing temperature on the grain size of the cerium-containing heats Ce-2, $-3,-4,-6$, and -7 annealed in a vacuum of better than $\sim 10^{-4} \mathrm{~Pa}$. Data for the ZR and D2 heats of DOP-26 iridium are included for comparison [30]. All five cerium-containing alloys and the two DOP-26 heats exhibited increasing grain size with annealing temperature and had similar grain sizes below about 1500EC (see Fig. 3). At higher temperatures, the observed grain growth behavior can be divided into three different groups. Alloys doped with thorium (DOP-26) and alloys doped with cerium plus thorium (Ce-2, -6, and -7) had the smallest grain growth, whereas Ce-3 containing only cerium (36 ppm) exhibited the highest grain growth. The grain growth behavior of Ce-4 (with $73 \mathrm{ppm} \mathrm{Ce}$ ) fell in between the two. Both $\mathrm{Ce}-3$ and $\mathrm{Ce}-4$, which were doped with only cerium, had similar grain sizes 
Table III. Average grain size of thorium-, cerium-, and Ce/Th-doped iridium alloys after 1-h vacuum anneals at various temperatures compared to data for DOP-26 alloys ZR and D2

\begin{tabular}{cccccccc}
\hline \multirow{2}{*}{$\begin{array}{c}\text { Temperature } \\
\left({ }^{\circ} \mathrm{C}\right)\end{array}$} & $\mathrm{ZR}^{b}$ & $\mathrm{D}^{b}$ & $\mathrm{Ce} 2$ & $\mathrm{Ce} 3$ & $\mathrm{Ce} 4$ & $\mathrm{Ce} 6$ & $\mathrm{Ce} 7$ \\
\cline { 2 - 7 } & $15(268)$ & $24(170)$ & 26 & 21 & 17 & 14 & 13 \\
\hline 1300 & $23(204)$ & $29(199)$ & 26 & 25 & 24 & 18 & 16 \\
1400 & $30(201)$ & $33(60)$ & 52 & 35 & 36 & 25 & 19 \\
1500 & $45(182)$ & $48(38)$ & 64 & 75 & 65 & 38 & 32 \\
1600 & $90(124)$ & $69(164)$ & 92 & 163 & 133 & 66 & 58 \\
1700 & $99(107)$ & $117(94)$ & 129 & 329 & 204 & 97 & - \\
1800 & &
\end{tabular}

${ }^{a}$ All grain sizes measured perpendicular to the rolling direction of the sheet. Numbers in parentheses indicate number of intercepts counted for grain size determinations.

${ }^{b} \mathrm{ZR}=$ DOP-26, old process; D2 = DOP-26, new process. Data taken from Ref. 30.

between 1300 and $1600 \mathrm{EC}$, whereas from 1600 to $1800 \mathrm{EC}, \mathrm{Ce}-3$ had larger grain sizes than $\mathrm{Ce}-4$. Increased cerium (from $36 \mathrm{ppm}$ in $\mathrm{Ce}-3$ to $73 \mathrm{ppm}$ in $\mathrm{Ce}-4)$ thus resulted in some grain refinement, possibly due to more precipitation and, hence, more effective pinning of the grain boundaries. In an earlier study [34], the second-phase precipitates formed in an iridium alloy with $36 \mathrm{ppm}$ Ce were identified as $\mathrm{Ir}_{5} \mathrm{Ce}$ by electron diffraction and energy dispersive spectroscopy (EDS). Hence, the grain size refinement in alloys containing only cerium is, most

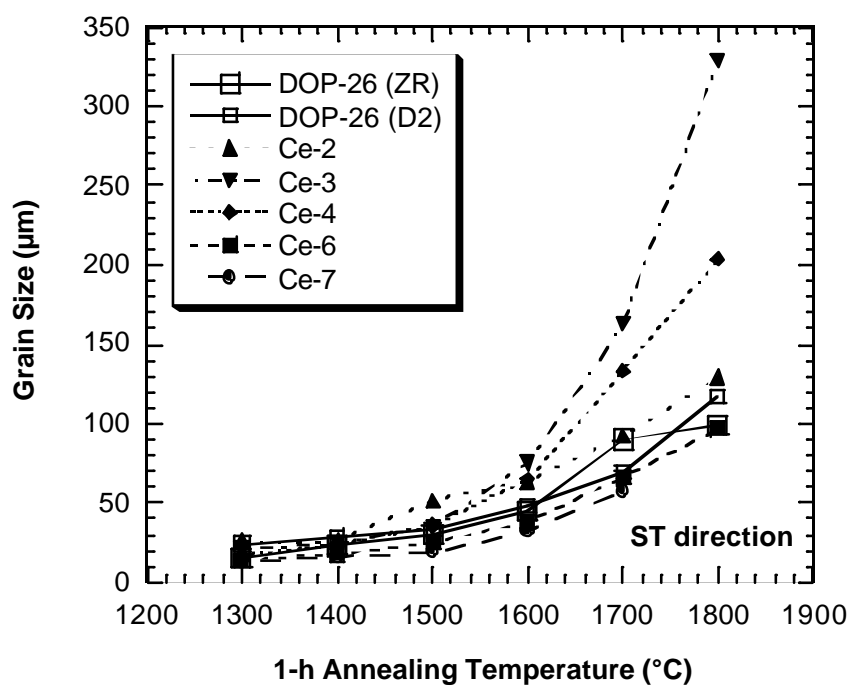

Fig. 2. Temperature dependence of the grain size of the cerium-doped iridium alloys Ce-2 through Ce-7. Data for DOP-26 are from Ref. 30.

likely, due to the grain boundary pinning by these second-phase particles.

Table IV shows the variation in grain size of the Ce-2 heat (with $36 \mathrm{ppm}$ Ce and $60 \mathrm{ppm}$ Th) as a function of annealing time in the temperature range 1300-1500EC and compares it to data for new- (heat D2) and old-process (heat ZR) DOP-26. At all three temperatures, grain size increases with increasing annealing time. There is essentially no difference in the grain size of new- and old-process DOP-26 at all temperatures and times examined [30]. Therefore, in Fig. 4 the grain size of Ce-2 is compared against only the old-process DOP-26. This figure shows that, for the times and temperatures studied, grain growth in Ce-2 (containing $36 \mathrm{ppm}$ Ce and $60 \mathrm{ppm}$ Th) is comparable to that of DOP-26. 

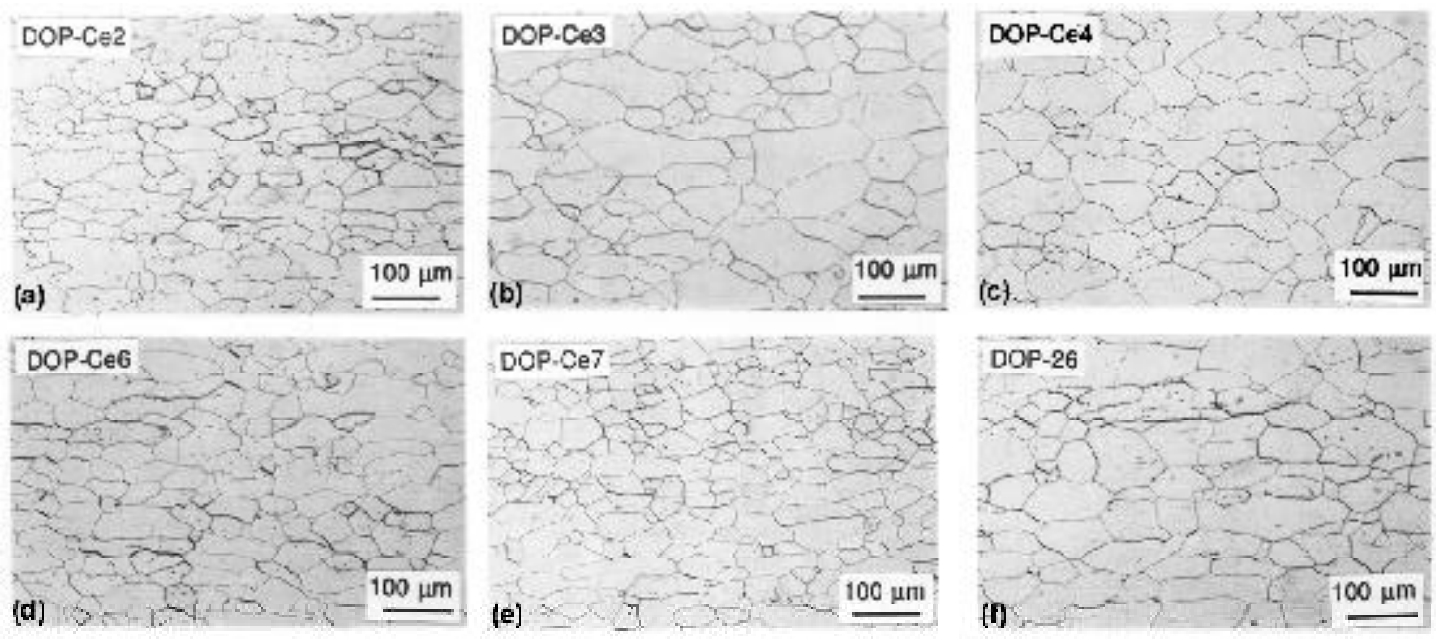

Fig. 3. Microstructures of (a) Ce-2, (b) Ce-3, (c) Ce-4, (d) Ce-6, (e) Ce-7, and (f) DOP-26 after a 1-h vacuum anneal at 1500EC. (From Refs. 35 and 37)

Table IV. Average grain sizes of ZR (old process), D2 (new process), and Ce-2 iridium alloys as a function of annealing time at $1300-1500^{\circ} \mathrm{C}$

\begin{tabular}{|c|c|c|c|c|}
\hline \multirow{2}{*}{ Temperature $\left({ }^{\circ} \mathrm{C}\right)$} & \multirow{2}{*}{ Time (h) } & \multicolumn{3}{|c|}{ Grain size $(\mathrm{Fm})^{a}$} \\
\hline & & $\mathrm{ZR}^{b}$ & $\mathrm{D} 2^{b}$ & $\mathrm{Ce}-2$ \\
\hline \multirow[t]{8}{*}{1300} & 1 & 15 (268) & $24(322)$ & 26 \\
\hline & 2 & 17 (232) & -- & 26 \\
\hline & 4 & 19 (94) & 25 (166) & 28 \\
\hline & 18 & $21(128)$ & 28 (289) & 30 \\
\hline & 70 & 24 (329) & $31(340)$ & 25 \\
\hline & 250 & 34 (223) & $30(404)$ & 38 \\
\hline & 480 & $32(282)$ & 36 (274) & 43 \\
\hline & 1000 & 34 (146) & 42 (138) & 47 \\
\hline \multirow[t]{8}{*}{1400} & 1 & $23(340)$ & 29 (397) & 27 \\
\hline & 2 & 26 (208) & 30 (134) & 28 \\
\hline & 4 & 24 (317) & $34(300)$ & 37 \\
\hline & 16 & $31(310)$ & 39 (283) & 55 \\
\hline & 100 & $52(218)$ & 50 (210) & 52 \\
\hline & 250 & $63(40)$ & $56(153)$ & 61 \\
\hline & 520 & $74(59)$ & 63 (73) & 55 \\
\hline & 1000 & 99 (109) & 72 (159) & 73 \\
\hline \multirow[t]{7}{*}{1500} & 0.2 & 22 (367) & 30 (336) & 39 \\
\hline & 0.5 & $25(331)$ & $32(302)$ & 45 \\
\hline & 1 & $30(225)$ & $33(80)$ & 51 \\
\hline & 2 & $36(310)$ & 39 (123) & 55 \\
\hline & 4 & $39(233)$ & 42 (192) & 48 \\
\hline & 18 & $59(165)$ & 52 (194) & 59 \\
\hline & 100 & 82 (127) & $71(153)$ & 74 \\
\hline
\end{tabular}

${ }^{a}$ All grain sizes were measured in the ST direction. Numbers in parentheses indicate number of intercepts counted for grain size determinations.

${ }^{b}$ Data taken from Ref. 30 . 
Table V and Fig. 5 illustrate the effects of annealing temperature on the grain sizes in both the short transverse (ST) and long transverse (LT) directions of the I-1 heat of DOP-40 (containing 29 ppm Ce and 18 ppm Th) and compares it to data for DOP-26 iridium alloys. In general, for both DOP-40 and DOP-26, the grain size increases with increasing annealing temperature for both orientations. Also, at any given temperature, the grain size in the $\mathrm{ST}$ direction is slightly smaller than that in the LT direction. Within experimental error, in the ST direction, the grain size of the I-1 heat is almost identical to that of DOP-26 for all the

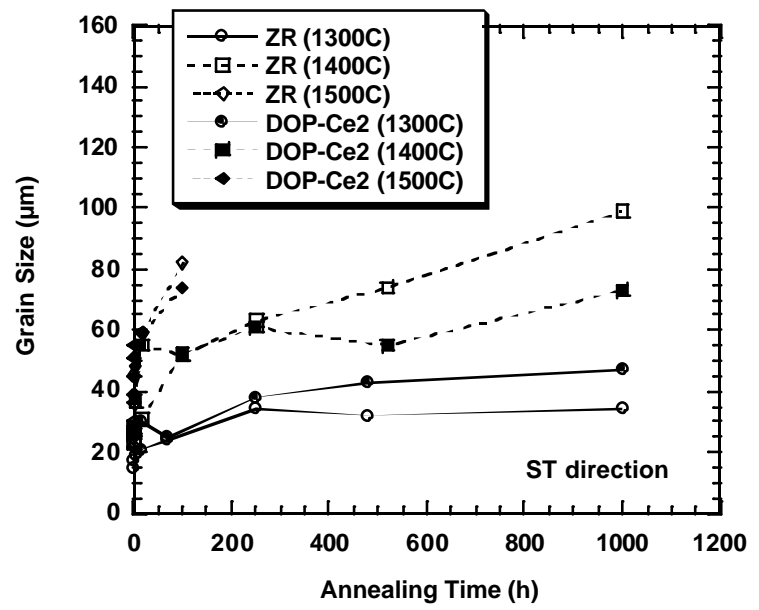

Fig. 4. Average grain size as a function of time of annealing at 1300,1400 , and $1500 \mathrm{EC}$ for oldprocess DOP-26 (ZR heat) [30] and Ce/Th-doped heat Ce-2. temperatures tested. In the LT direction, the grain sizes of the three alloys are similar at temperatures to 1700EC. At the highest test temperature of $1800 \mathrm{EC}$, however, the Ce/Th-doped alloy has a much larger average grain size. The reason for this difference in LT grain size at the very highest temperature is not clear, but it may be related to differences in the distribution of intermetallic stringers or to differences in the diffusion rates of cerium and thorium at this high temperature.

Grain sizes for heat I-1 annealed at 1400EC have been measured for annealing times of up to $565 \mathrm{~h}$. The data are listed in Table VI and plotted in Fig. 6 for both the ST and LT directions. For comparison, similar data for the DOP-26 alloy (D2 ingot) in the ST direction [30] are included. Representative micrographs for the I-1 heat are shown in Fig. 7. The data show that grain growth at $1400 \mathrm{EC}$ of the I-1

Table V. Effect of annealing temperature (for 1-h anneals) on grain sizes of DOP-26 and the I-1 heat of DOP-40

\begin{tabular}{|c|c|c|c|c|c|c|}
\hline \multirow{3}{*}{$\begin{array}{c}\text { Annealing } \\
\text { temperature } \\
\left({ }^{\circ} \mathrm{C}\right)\end{array}$} & \multicolumn{6}{|c|}{ Grain size $(\mathrm{Fm})^{a}$} \\
\hline & \multicolumn{2}{|c|}{ DOP-40 (I-1 ingot) } & \multicolumn{2}{|c|}{ DOP-26 (ZR ingot $)^{b}$} & \multicolumn{2}{|c|}{ DOP-26 (D2 ingot) ${ }^{b}$} \\
\hline & ST direction & LT direction & ST direction & LT direction & ST direction & LT direction \\
\hline 1300 & 16 & 30 & $15(268)$ & $33(126)$ & $24(170)$ & $46(90)$ \\
\hline 1400 & 19 & 42 & $23(204)$ & $39(122)$ & 29 (199) & $59(159)$ \\
\hline 1500 & 36 & 54 & $30(201)$ & $45(102)$ & $33(60)$ & $55(67)$ \\
\hline 1600 & 42 & 60 & 45 (182) & $59(143)$ & $48(38)$ & $70(66)$ \\
\hline 1700 & 65 & 85 & $90(124)$ & $94(98)$ & $69(164)$ & $97(122)$ \\
\hline 1800 & 124 & 184 & 99 (107) & $111(83)$ & $117(94)$ & $156(76)$ \\
\hline
\end{tabular}

${ }^{a}$ Numbers in parentheses indicate number of intercepts counted for grain size determinations.

${ }^{b} \mathrm{ZR}$ and D2 data were taken from Ref. 30. 

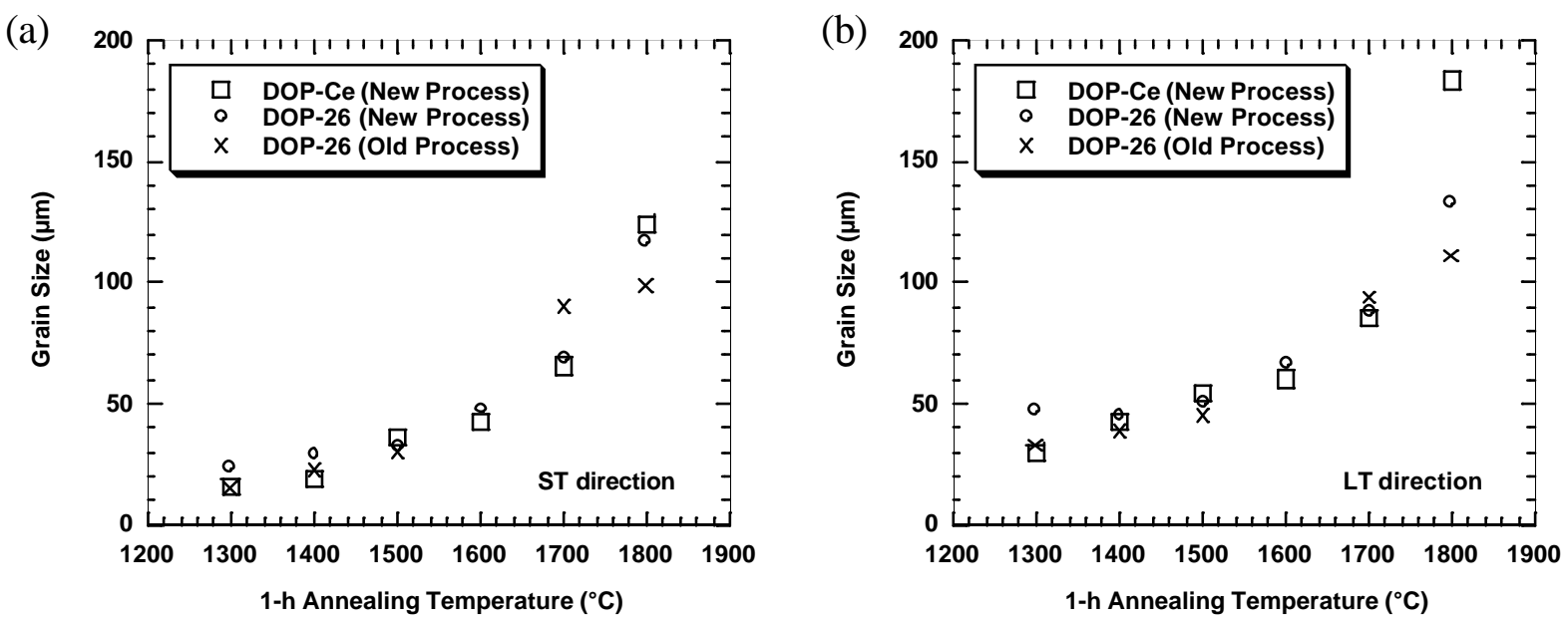

Fig. 5. Effect of annealing temperature on the (a) short transverse (ST) and (b) long transverse (LT) direction grain sizes of the I-1 heat of DOP-40 iridium. Data for DOP-26 are from Ref. 30.

Table VI. Effect of annealing time at temperatures of 1400 and $1500^{\circ} \mathrm{C}$ on grain sizes of DOP-26 and the I-1 heat of DOP-40

\begin{tabular}{|c|c|c|c|c|c|c|}
\hline \multirow{3}{*}{$\begin{array}{l}\text { Annealing } \\
\text { time (h) }\end{array}$} & \multicolumn{6}{|c|}{ Grain size $(\mathrm{Fm})^{a}$} \\
\hline & \multicolumn{2}{|c|}{ DOP-40 (I-1 ingot) } & \multicolumn{2}{|c|}{ DOP-26 (ZR ingot) ${ }^{b}$} & \multicolumn{2}{|c|}{ DOP-26 (D2 ingot) ${ }^{b}$} \\
\hline & $1400^{\circ} \mathrm{C}$ & $1500^{\circ} \mathrm{C}$ & $1400^{\circ} \mathrm{C}$ & $1500^{\circ} \mathrm{C}$ & $1400^{\circ} \mathrm{C}$ & $1500^{\circ} \mathrm{C}$ \\
\hline 1 & 19 & 36 & $23(340)$ & $30(225)$ & 29 (397) & $33(80)$ \\
\hline 4 & $22(458)$ & -- & $24(317)$ & 39 (233) & $34(300)$ & $42(192)$ \\
\hline 16 & $28(356)$ & -- & $31(310)$ & -- & $39(283)$ & -- \\
\hline 18 & -- & 68 & -- & 59 (165) & -- & 52 (194) \\
\hline 100 & -- & 90 & $52(218)$ & 82 (127) & $50(210)$ & $71(153)$ \\
\hline 110 & $35(283)$ & -- & -- & -- & -- & -- \\
\hline 240 & -- & 212 & -- & -- & -- & -- \\
\hline 250 & 45 (223) & -- & $63(40)$ & -- & 56 (153) & -- \\
\hline 520 & -- & -- & $74(59)$ & -- & $63(73)$ & -- \\
\hline 565 & 55 (184) & -- & -- & -- & -- & -- \\
\hline 1000 & -- & -- & 99 (109) & -- & 72 (159) & -- \\
\hline
\end{tabular}

${ }^{a}$ Numbers in parentheses indicate number of intercepts counted for grain size determinations.

${ }^{b} \mathrm{ZR}$ and D2 data were taken from Ref. 30.

heat is comparable to that of the DOP-26 alloy (both fabricated by the new-process) at all annealing times used in this study.

Figure 8 illustrates the effects of annealing time at 1500EC on the grain sizes of the I-1 heat in the ST direction. The data are compared to similar data from new- and old-process DOP-26 iridium alloys [30] and to the Ce-2 heat containing $36 \mathrm{ppm} \mathrm{Ce}$ and $60 \mathrm{ppm}$ Th. In general, for all alloys, the grain size increases with increasing annealing temperature. Within experimental error, grain growth at $1500 \mathrm{EC}$ of the I-1 ingot is comparable to that of the DOP-26 alloy fabricated by either the old- or new-process. The 


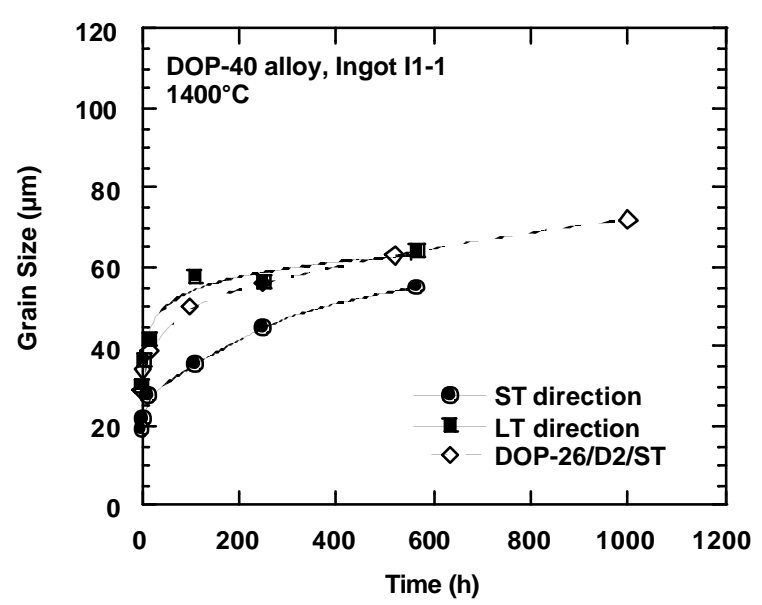

Fig. 6. Grain size of heat I-1 as a function of time in vacuum at $1400 E C$ for both the ST and LT directions with respect to the rolling direction. For comparison, similar data for heat D2 of DOP-26 [30] are included.

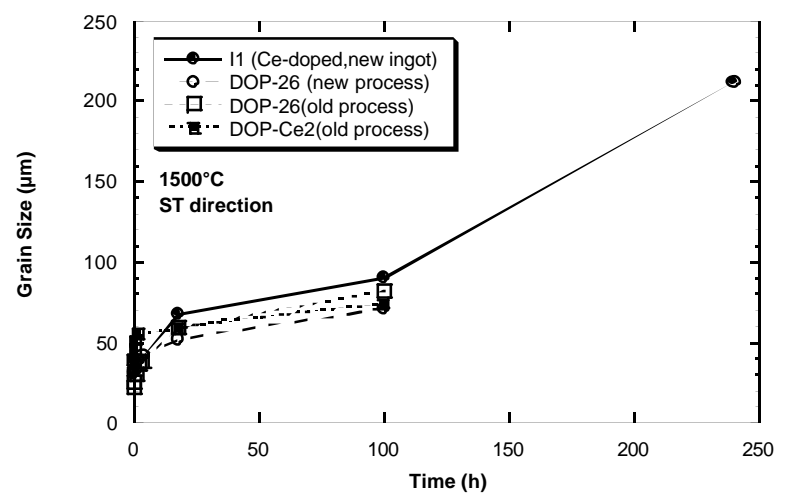

Fig. 8. Grain size of heat I-1 in the ST direction as a function of time in vacuum at 1500EC. For comparison, similar data for the D2 (new process) and ZR (old process) heats of DOP-26 [30] and for the $\mathrm{Ce}-2 \mathrm{Ce} / \mathrm{Th}$-doped heat are included.
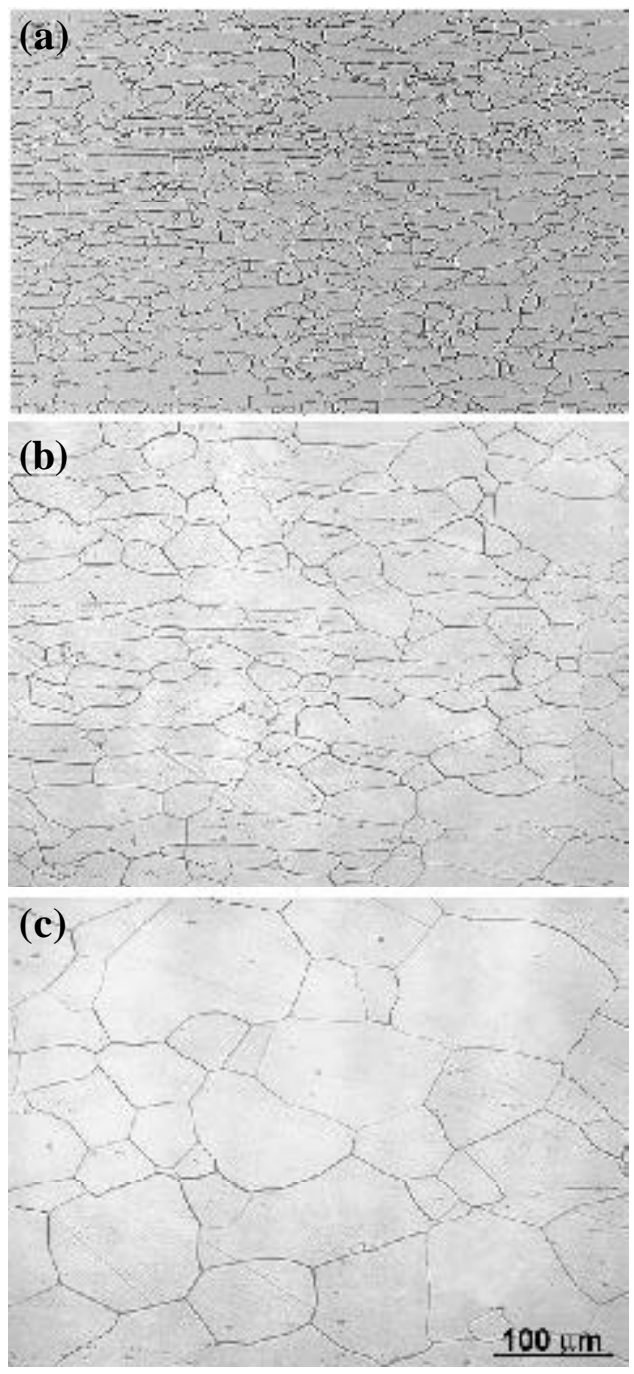

Fig. 7. Optical micrographs showing grain size of the I-1 heat of DOP-40 (a) in the as-recrystallized $\left(1 \mathrm{~h}\right.$ at $\left.1375^{\circ} \mathrm{C}\right)$ condition and after heat treating in vacuum at $1400 \mathrm{EC}$ for (b) $4 \mathrm{~h}$ and (c) $565 \mathrm{~h}$.

slightly larger grain sizes of the I-1 heat compared to Ce-2 and DOP-26 are probably a result of the lower amount of Ce+Th in that alloy (47 ppm for I-1 and 96 ppm for Ce-2).

Table VII and Fig. 9 illustrate the grain growth in vacuum as a function of temperature for alloys I-101 through I-107 which contain various concentrations of cerium plus thorium. For comparison, data for new-process DOP-26 iridium containing thorium but no cerium (from Ref. 30) are included. The data show that, for the range of cerium and thorium additions used in these alloys (20-40 wppm Ce and 30-50 wppm Th, see Table I), no difference in grain growth behavior was observed and grain sizes were comparable to that of DOP-26. One hour at 1300EC resulted in grain sizes of approximately 15-18 Fm. Grain 
Table VII. Grain size of DOP-40 alloys annealed for $1 \mathrm{~h}$ at different annealing temperatures

\begin{tabular}{rcccccr}
\hline & \multicolumn{5}{c}{ Grain Size $(\mathrm{Fm})^{a}$ after annealing at temperatures $\left({ }^{\circ} \mathrm{C}\right)$ of } \\
\cline { 2 - 7 } Alloy & 1300 & 1400 & 1500 & 1600 & 1700 & 1800 \\
\hline I-101 & $15(1234)$ & $18(969)$ & $21(915)$ & $36(1296)$ & $66(773)$ & $126(431)$ \\
I-102 & $17(1140)$ & $20(1331)$ & $22(848)$ & $40(1290)$ & $72(740)$ & $97(545)$ \\
I-103 & $17(1134)$ & $17(1440)$ & $22(882)$ & $41(1240)$ & $78(700)$ & $132(409)$ \\
I-104 & $16(1187)$ & $19(890)$ & $22(869)$ & $40(1267)$ & $70(755)$ & $102(527)$ \\
I-105 & $16(1199)$ & $21(1299)$ & $23(815)$ & $43(1190)$ & $81(645)$ & $117(449)$ \\
I-106 & $18(1069)$ & $22(1543)$ & $22(809)$ & $42(1177)$ & $75(708)$ & $144(430)$ \\
I-107 & $17(1123)$ & $20(1335)$ & $23(823)$ & $38(1299)$ & $70(745)$ & $101(519)$ \\
\hline
\end{tabular}

${ }^{a}$ Numbers in parentheses indicate number of intercepts counted for grain size determinations.

growth was very modest through one hour at 1500EC (up to 21-23 Fm), after which the grain size gradually increased to a range of 97 to 144 Fm. Figure 10 shows micrographs of heats I-102 and I-106 after $1 \mathrm{~h}$ at 1500 and 1800EC. These are typical of this set of $\mathrm{Ce} / \mathrm{Th}$-doped iridium alloys.

\section{GRAIN GROWTH BEHAVIOR IN LOW PRESSURE OXYGEN ENVIRONMENTS}

As the $\mathrm{Ce} / \mathrm{Th}$-doped iridium alloys have been developed, they have been included in oxygen

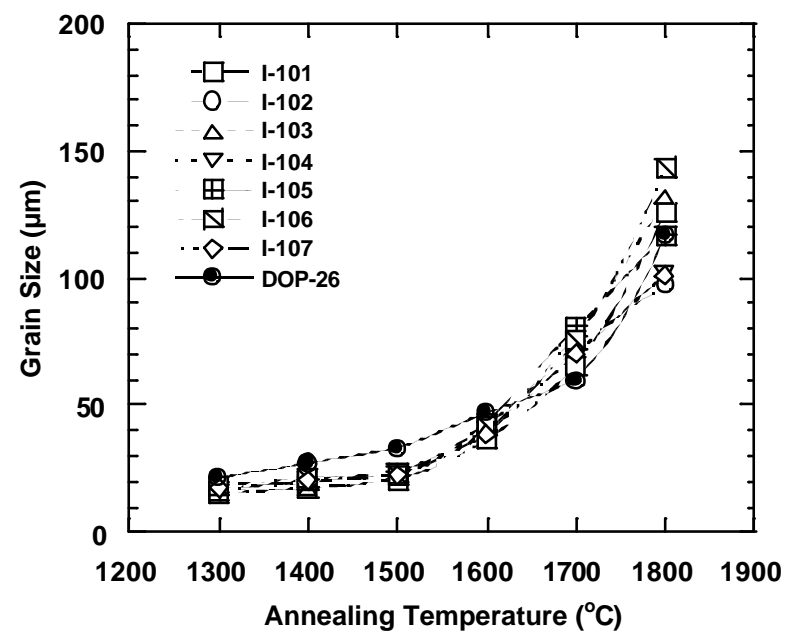

Fig. 9. Effect of annealing temperature on the grain growth of DOP-40 iridium alloys. Data for new-process DOP-26 [30] are included for comparison.

compatibility studies that were being conducted on DOP-26 iridium alloys [30]. These tests indicate whether a tendency exists for the anomalous growth of near-surface grains (NSGs) in low pressure oxygen environments. More rapid growth of near-surface grains indicates that the thorium and/or cerium are diffusing out of the material resulting in dissolution of $\mathrm{Ir}_{5} \mathrm{Th}_{\mathrm{f}}$ or $\mathrm{Ir}_{5} \mathrm{Ce}$ precipitates which therefore become unavailable for pinning of the grain boundaries $[41,43]$. The conditions of the various oxygen compatibility tests conducted to date and the alloys tested are shown in Table II. The earliest cerium-doped alloys produced in this development program were denoted as $\mathrm{Ce}-1$ to -7 , which were fabricated using the old process as described above. From this series of alloys, samples of heats Ce-2, -3 , and -7 were included in the first set of oxygen compatibility studies which was conducted at an oxygen partial pressure of $1.3 \mathrm{mPa}$ at temperatures of 1230, 1280, and 1330EC. The beginning microstructures of these alloys (recrystallized by annealing $1 \mathrm{~h}$ at 1375EC), 

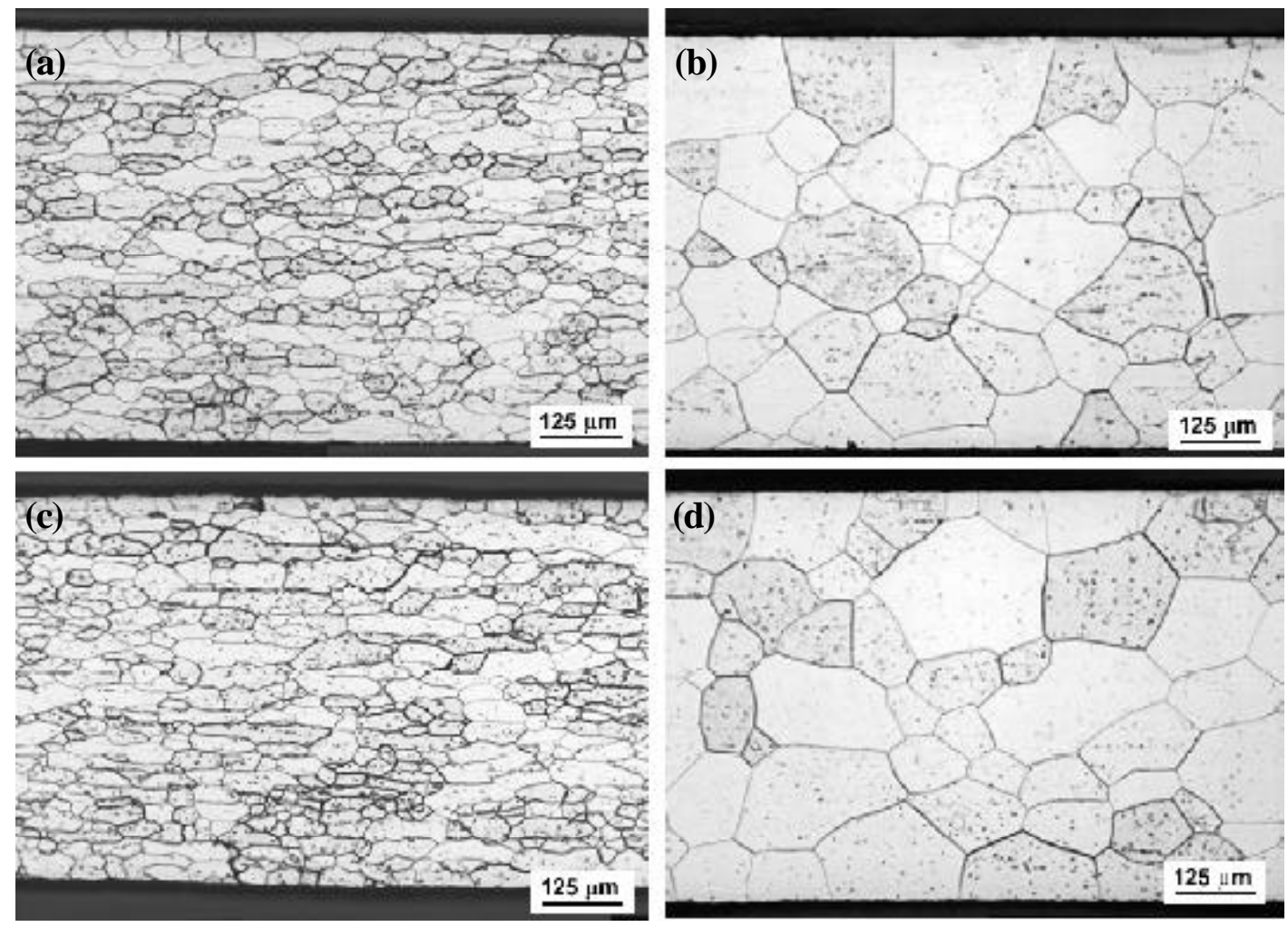

Fig. 10. Optical micrographs showing typical microstructures of Ce/Th-doped iridium: (a,b) heat I-102 and (c,d) heat I-106 after 1-h anneals at 1500 and 1800EC, respectively.
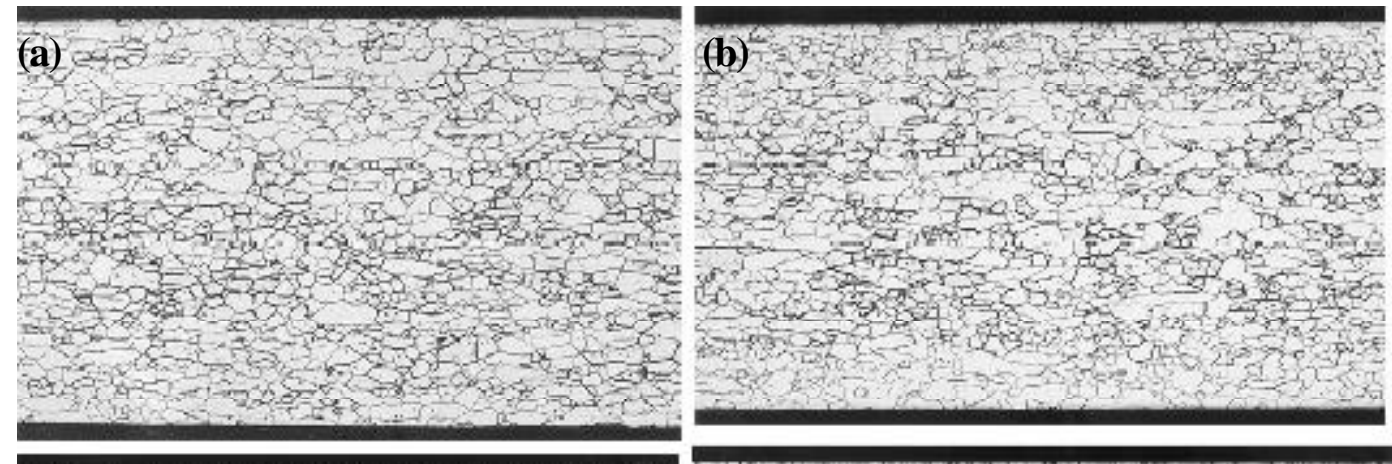

(c)

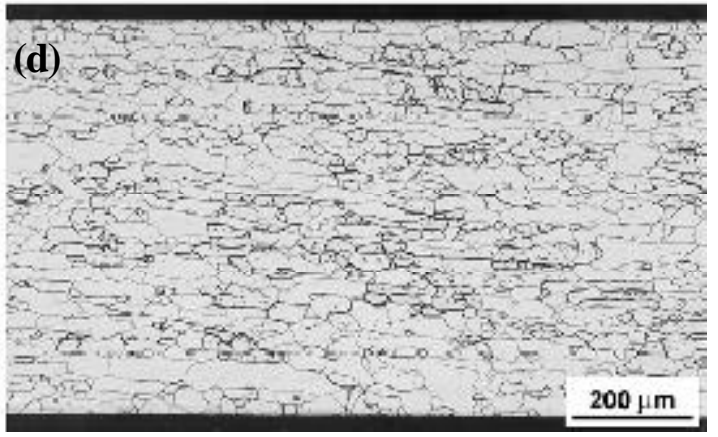

Fig. 11. Optical micrographs of (a) the ZR heat of DOP-26 and the DOP-40 heats (b) Ce-2, (c) Ce-3, and (d) Ce-7 in the as-recrystallized condition ( $1 \mathrm{~h}$ at 1375EC). 
shown in Fig. 11, were very similar to that of the DOP-26 alloys containing no cerium. The starting grain size was 14-16 Fm in the ST direction and 22-35 Fm in the LT direction.

Table VIII shows the grain sizes of these three alloys in both the ST and LT directions as a function of exposure time and temperature. The Ce-3 alloy containing $36 \mathrm{ppm} \mathrm{Ce}$ (no thorium) and the Ce-7 alloy containing $22 \mathrm{ppm} \mathrm{Ce}$ and $24 \mathrm{ppm}$ Th were annealed at 1230EC in $1.3 \mathrm{mPa}$ oxygen. Grain sizes for these alloys as a function of time are plotted in Fig. 12. For comparison purposes, the grain size data for the old-process DOP-26 alloy (ZR) [30] are also included in Fig. 12. These data show no significant difference between the DOP-26 alloy and the cerium-doped alloys in the average grain size perpendicular to the rolling direction (ST direction) as a function of time [Fig. 12(a)]. In the LT direction [Fig. 12(b)], the grains of the Ce-7 alloy started out slightly more elongated than either the Ce-3 or ZR heats (see Fig. 11), but its rate of grain growth was about the same as that of the ZR heat (both ZR and Ce-7 contain thorium.

Table VIII. Grain size of the Th/Ce-doped Ce-2, Ce-3, and Ce-7 alloys as a function of exposure time and temperature in an oxygen partial pressure of $1.3 \mathrm{mPa}$

\begin{tabular}{|c|c|c|c|c|}
\hline \multirow{2}{*}{ Alloy } & \multirow{2}{*}{$\begin{array}{l}\text { Annealing temperature } \\
\qquad\left({ }^{\circ} \mathrm{C}\right)\end{array}$} & \multirow{2}{*}{ Annealing time (h) } & \multicolumn{2}{|c|}{ Grain size $(\mathrm{Fm})^{a}$} \\
\hline & & & ST direction & LT direction \\
\hline \multirow[t]{5}{*}{$\mathrm{Ce}-3$} & 1230 & 0 & $14(1006)$ & $22(1262)$ \\
\hline & & 768 & $24(600)$ & 34 (848) \\
\hline & & 1512 & $30(475)$ & 44 (647) \\
\hline & & 2252 & $27(529)$ & $41(726)$ \\
\hline & & 3000 & 37 (396) & $64(449)$ \\
\hline \multirow[t]{5}{*}{$\mathrm{Ce}-7$} & 1230 & 0 & $16(884)$ & 35 (818) \\
\hline & & 768 & $25(580)$ & $43(658)$ \\
\hline & & 1512 & $27(541)$ & $48(586)$ \\
\hline & & 2252 & $29(502)$ & $49(573)$ \\
\hline & & 3000 & $28(509)$ & $50(567)$ \\
\hline \multirow[t]{7}{*}{$\mathrm{Ce}-3$} & 1280 & 0 & $16(405)$ & $28(1022)$ \\
\hline & & 144 & $26(385)$ & $45(641)$ \\
\hline & & 380 & $30(422)$ & $48(595)$ \\
\hline & & 764 & $40(244)$ & $57(510)$ \\
\hline & & 1508 & $44(277)$ & $62(454)$ \\
\hline & & 2250 & 59 (339) & $79(365)$ \\
\hline & & 3000 & $74(271)$ & $96(307)$ \\
\hline \multirow[t]{7}{*}{$\mathrm{Ce}-2$} & 1330 & 0 & $16(414)$ & $32(868)$ \\
\hline & & 166 & $26(270)$ & 48 (569) \\
\hline & & 340 & $31(228)$ & $61(451)$ \\
\hline & & 760 & 33 (199) & $54(508)$ \\
\hline & & 1524 & $50(256)$ & $64(430)$ \\
\hline & & 2265 & 43 (164) & $66(414)$ \\
\hline & & 3000 & $52(132)$ & $70(390)$ \\
\hline
\end{tabular}

${ }^{a}$ Numbers in parentheses indicate number of intercepts counted for grain size determinations. 

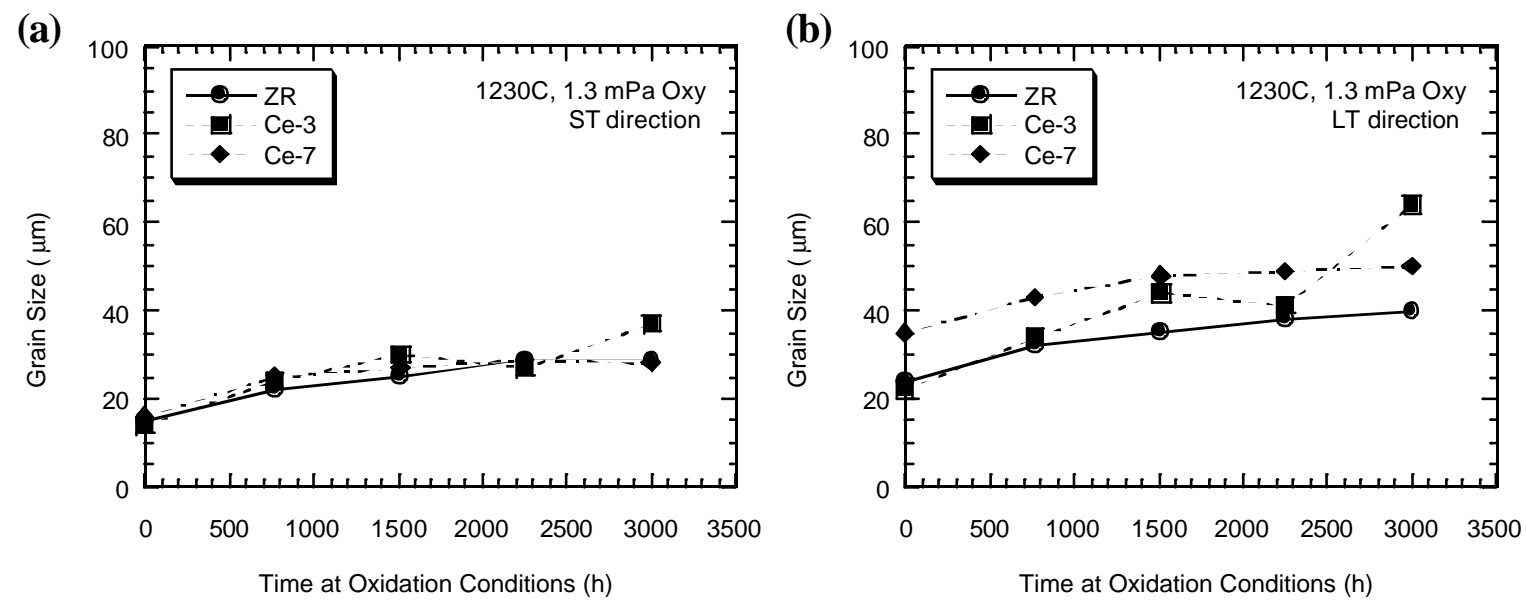

Fig. 12. Comparison of grain sizes in the (a) ST direction and (b) LT direction for iridium heats ZR [from Ref. 30], Ce-3, and Ce-7 after exposure to $1.3 \mathrm{mPa}$ oxygen at $1^{\circ 30} \mathrm{C}$.

The Ce-3 heat containing no thorium, however, exhibited signs of grain growth, especially for the $3000 \mathrm{~h}$ anneal. The difference in the microstructures of these three heats is evident in Fig. 13 which shows ZR, Ce-3, and Ce-7 after $3000 \mathrm{~h}$. This result is substantiated by recrystallization studies that suggest that $\mathrm{Ir}_{5} \mathrm{Ce}$ precipitates may not be as stable as $\operatorname{Ir}_{5}$ Th precipitates at higher temperatures or for longer annealing times [35].

Table IX and Figure 14 show the grain size as a function of depth into the specimen for the Ce-3 and Ce-7 alloys annealed at 1230EC in $1.3 \mathrm{mPa}$ oxygen. In these plots, a larger grain size near the surface (at 50-100 Fm from the surface) would indicate a tendency for growth of anomalous near-surface grains (NSGs). Although the grain size at zero time was slightly larger for Ce-7, grain sizes in that alloy did not increase as much as in the Ce-3 alloy during the $3000 \mathrm{~h}$ of testing. The data indicate that the NSGs of alloy Ce-3 increased from approximately $20 \mathrm{Fm}$ to $80 \mathrm{Fm}$, while the NSGs of Ce-7 increased from approximately $35 \mathrm{Fm}$ to $55 \mathrm{Fm}$. The larger NSGs in alloy Ce-3 doped only with cerium are evident in the microstructure shown in Fig. 13(b). The Ce-7 alloy behaved much like the ZR alloy, whose grain size increased from approximately $25 \mathrm{Fm}$ to $40 \mathrm{Fm}$ [30]. This seems to indicate that the Ce-7 alloy containing both cerium and thorium was more resistant to grain growth, particularly for the near-surface grains (approx. $60 \mathrm{Fm}$ for $\mathrm{Ce}-7$ versus $80 \mathrm{Fm}$ for $\mathrm{Ce}-3$ ). Grain sizes at all depths below the surface in the $\mathrm{Ce}-7$ alloy were almost identical to those of the ZR DOP-26 alloy that was included in this test [30].

Alloy Ce-3 was also exposed to $1.3 \mathrm{mPa}$ oxygen at 1280EC. Grain sizes as a function of time at this temperature are shown in Table VIII and plotted in Fig. 15. At this temperature, grain growth of the Ce-3 alloy in both the ST and LT directions was comparable to that of the ZR DOP-26 alloy for times up to and including $1500 \mathrm{~h}$. In the ST direction both alloys increased from their as-recrystallized grain size of approximately 15-20 Fm to a diameter of about 40-45 Fm. Above $1500 \mathrm{~h}$, the grain size of the Ce-3 alloy increased significantly with time in both the ST and LT directions with respect to the rolling direction. After $3000 \mathrm{~h}$ its average grain size was determined to be about $74 \mathrm{Fm}$ in the ST direction and $96 \mathrm{Fm}$ in 

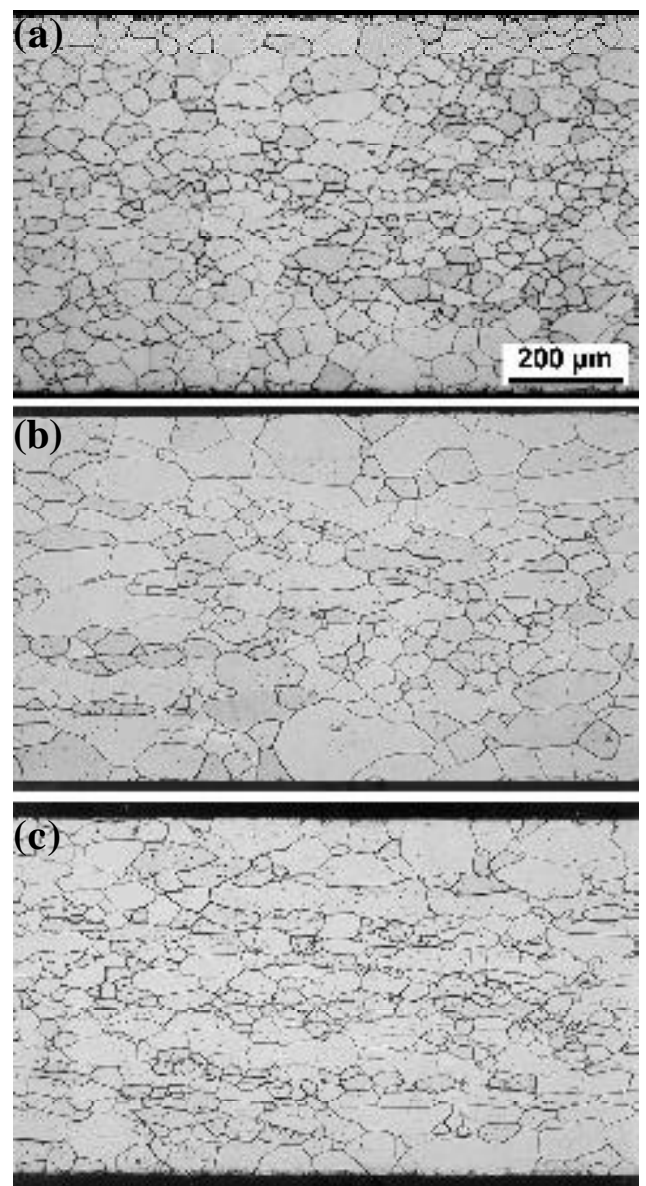

Fig. 13. Optical micrographs showing microstructures of iridium heats (a) ZR (with only thorium), (b) Ce-3 (with only cerium), and (c) Ce-7 (with both thorium and cerium) after $3000 \mathrm{~h}$ of exposure to $1.3 \mathrm{mPa}$ oxygen at 1230EC.

the LT direction. In comparison, very little grain growth was observed in the DOP-26 alloy for times longer than $764 \mathrm{~h}$. After $3000 \mathrm{~h}$, the grain size of the DOP-26 alloy was still only approximately 40-45 Fm. Table IX and Fig. 16 show that as a function of depth into the samples grain growth in the Ce-3 alloy was much more rapid than in the ZR alloy.

The more rapid grain growth in alloy Ce-3 (containing cerium, but no thorium) in comparison to the DOP-26 ZR alloy can be seen more
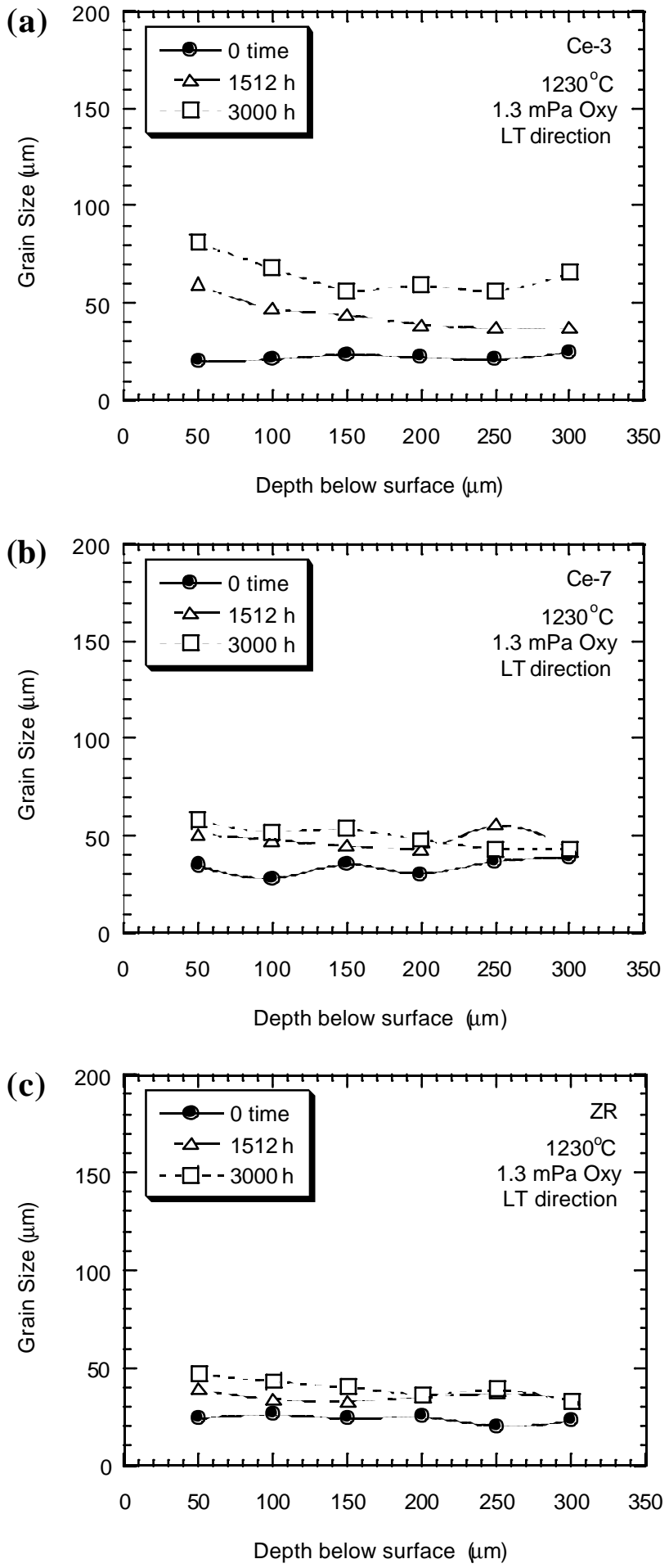

Fig. 14. Grain size as a function of depth below the surface for samples of the cerium-doped heats (a) Ce-3 and (b) Ce-7 and for (c) the old-process DOP-26 ZR heat [30] after exposure to $1.3 \mathrm{mPa}$ oxygen at $1230 \mathrm{EC}$. 
Table IX. Average grain size (in Fm) as a function of depth below the surface for Ce-2, Ce-3, and Ce-7 specimens exposed to an oxygen partial pressure of $1.3 \mathrm{mPa}$

\begin{tabular}{|c|c|c|c|c|c|c|c|c|}
\hline \multirow{2}{*}{ Alloy } & \multirow{2}{*}{$\begin{array}{l}\text { Temp. } \\
\left({ }^{\circ} \mathrm{C}\right)\end{array}$} & \multirow{2}{*}{$\begin{array}{l}\text { Exposure } \\
\text { time (h) }\end{array}$} & \multicolumn{6}{|c|}{ Depth below surface $(\mathrm{Fm})^{a}$} \\
\hline & & & 50 & 100 & 150 & 200 & 250 & 300 \\
\hline \multirow[t]{5}{*}{$\mathrm{Ce}-3$} & 1230 & 0 & $20(236)$ & $21(225)$ & 24 (193) & $22(207)$ & 21 (216) & $25(185)$ \\
\hline & & 768 & 43 (107) & $38(130)$ & $40(123)$ & $31(148)$ & $27(173)$ & $28(159)$ \\
\hline & & 1512 & $60(77)$ & $47(98)$ & $44(106)$ & 39 (118) & $37(124)$ & 37 (159) \\
\hline & & 2252 & $66(70)$ & $46(101)$ & $36(128)$ & $36(128)$ & $31(147)$ & $30(152)$ \\
\hline & & 3000 & $81(57)$ & $68(68)$ & $56(84)$ & $59(83)$ & $56(88)$ & $66(69)$ \\
\hline \multirow[t]{5}{*}{$\mathrm{Ce}-7$} & 1230 & 0 & $35(134)$ & $28(163)$ & $36(126)$ & $30(153)$ & 37 (119) & $39(123)$ \\
\hline & & 768 & $49(94)$ & $42(112)$ & $40(115)$ & $40(113)$ & $45(105)$ & 39 (159) \\
\hline & & 1512 & $51(91)$ & $48(96)$ & $45(102)$ & 43 (107) & $56(81)$ & 43 (159) \\
\hline & & 2252 & $51(90)$ & $50(92)$ & $42(109)$ & 44 (106) & $55(84)$ & $52(92)$ \\
\hline & & 3000 & $58(80)$ & $52(89)$ & $54(87)$ & $48(97)$ & $43(106)$ & $43(108)$ \\
\hline \multirow[t]{7}{*}{$\mathrm{Ce}-3$} & 1280 & 0 & 33 (144) & 37 (127) & 28 (171) & 27 (176) & 25 (190) & $22(212)$ \\
\hline & & 144 & 49 (98) & $51(95)$ & 46 (104) & $36(131)$ & 45 (106) & 42 (114) \\
\hline & & 380 & $62(74)$ & $48(95)$ & $53(86)$ & 37 (124) & 43 (109) & 45 (107) \\
\hline & & 764 & 77 (61) & $64(73)$ & $51(91)$ & 49 (95) & $53(88)$ & 47 (99) \\
\hline & & 1508 & $94(43)$ & $70(60)$ & $59(71)$ & 43 (101) & $56(76)$ & $41(105)$ \\
\hline & & 2250 & $89(54)$ & $102(47)$ & $77(61)$ & $63(74)$ & $69(68)$ & 77 (61) \\
\hline & & 3000 & $107(45)$ & 109 (44) & $92(52)$ & $113(42)$ & $85(56)$ & $67(70)$ \\
\hline \multirow[t]{7}{*}{$\mathrm{Ce}-2$} & 1330 & 0 & 31 (158) & 34 (141) & 32 (147) & $32(147)$ & $32(142)$ & 35 (133) \\
\hline & & 166 & $54(87)$ & $50(91)$ & 43 (106) & 47 (98) & 47 (99) & $56(88)$ \\
\hline & & 340 & $69(67)$ & $65(73)$ & $58(82)$ & $63(73)$ & $59(79)$ & $63(77)$ \\
\hline & & 760 & $74(62)$ & $52(89)$ & $46(100)$ & $61(80)$ & $55(87)$ & $52(90)$ \\
\hline & & 1524 & $85(54)$ & $78(59)$ & $69(68)$ & $53(88)$ & $58(80)$ & $58(80)$ \\
\hline & & 2265 & $108(45)$ & 95 (49) & $68(69)$ & $60(78)$ & $51(91)$ & $57(82)$ \\
\hline & & 3000 & $130(36)$ & $128(38)$ & $94(50)$ & $51(89)$ & 49 (94) & $56(83)$ \\
\hline
\end{tabular}

${ }^{a}$ Numbers in parentheses indicate number of intercepts counted for grain size determinations.

Fig. 15. Grain size as a function of time of exposure to $1.3 \mathrm{mPa}$ oxygen at $1280 \mathrm{EC}$ for the old-process ZR heat [30] and the cerium-doped Ce-3 heat.

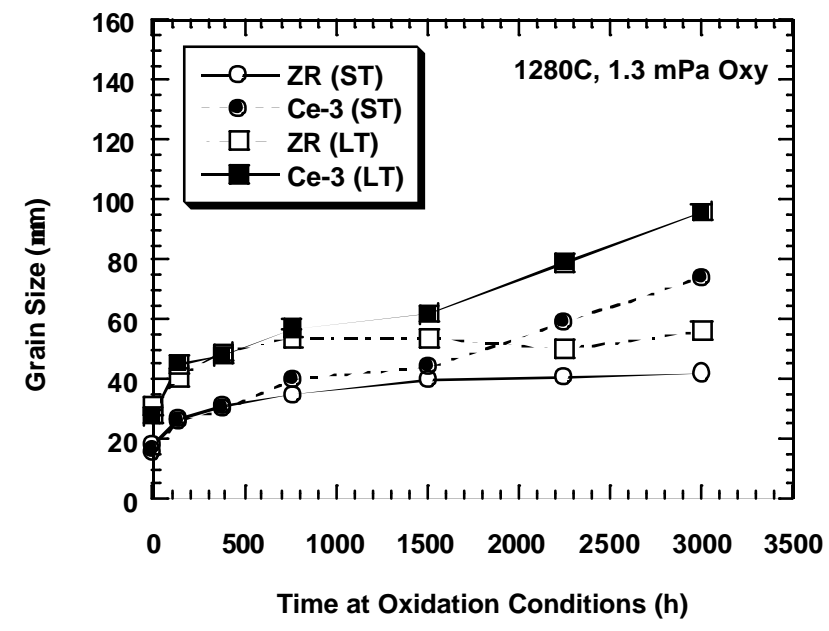



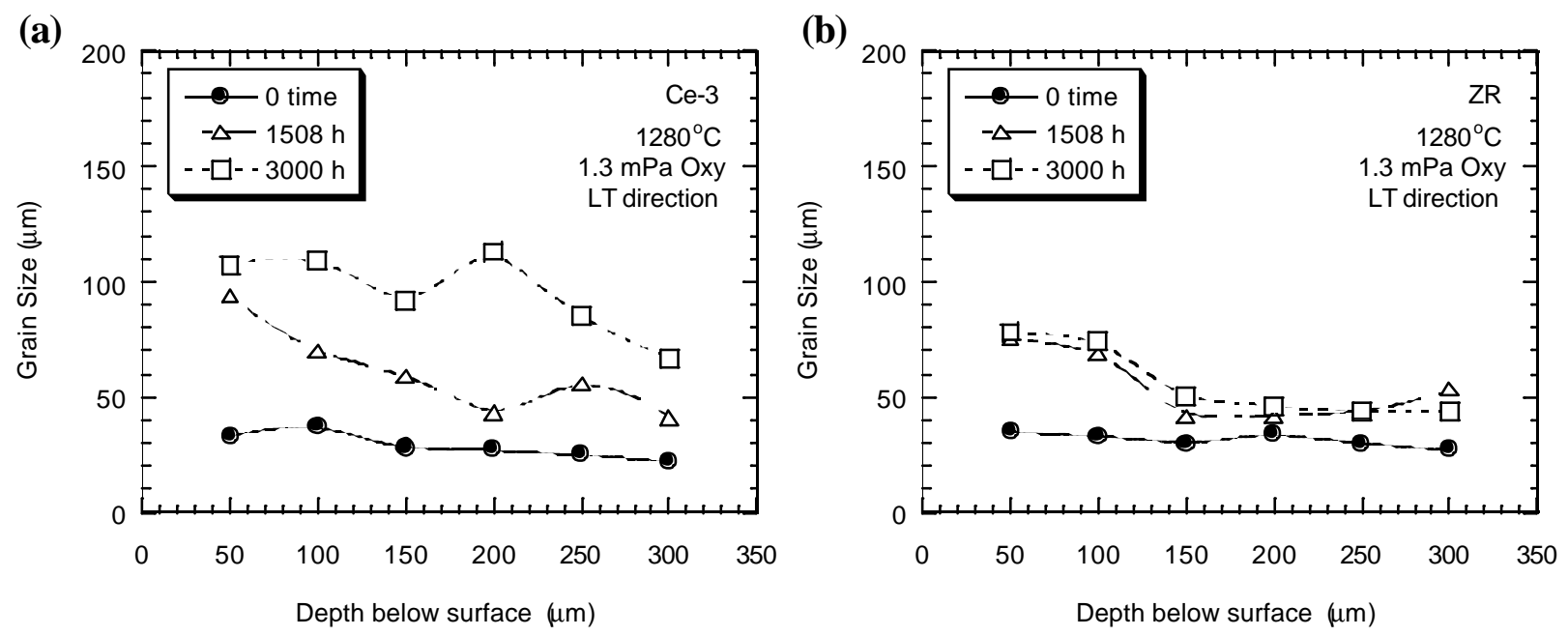

Fig. 16. Grain size as a function of depth below the surface for samples of (a) the cerium-doped heat Ce3 and (b) old-process DOP-26 ZR heat [30] after exposure to $1.3 \mathrm{mPa}$ oxygen at $1280 \mathrm{EC}$.

clearly in Fig. 17. Data for both the Ce-3 and ZR alloys annealed at 1230 and 1280EC in $1.3 \mathrm{mPa}$ oxygen are included. For annealing times longer than approximately $1500 \mathrm{~h}$, the rate of grain growth of the Ce-3 alloy is much higher than for the ZR alloy. A comparison of data from the 1230 and 1280EC anneals for heat Ce-3 as a function of depth into the sample (Fig. 18) shows the larger grain sizes for the higher 1280EC annealing temperature.

The Ce-2 alloy containing $36 \mathrm{ppm}$ Ce and $60 \mathrm{ppm}$ Th was exposed to $1.3 \mathrm{mPa}$ oxygen at 1330EC. The results are shown in Tables VIII and IX. The data plotted in Fig. 19 and the micrographs in Fig. 20 show that as a function of annealing time, grain growth in the Ce-2 alloy was comparable to that of the DOP-26 ZR alloy. At this higher temperature, grain growth was more rapid and pronounced than that
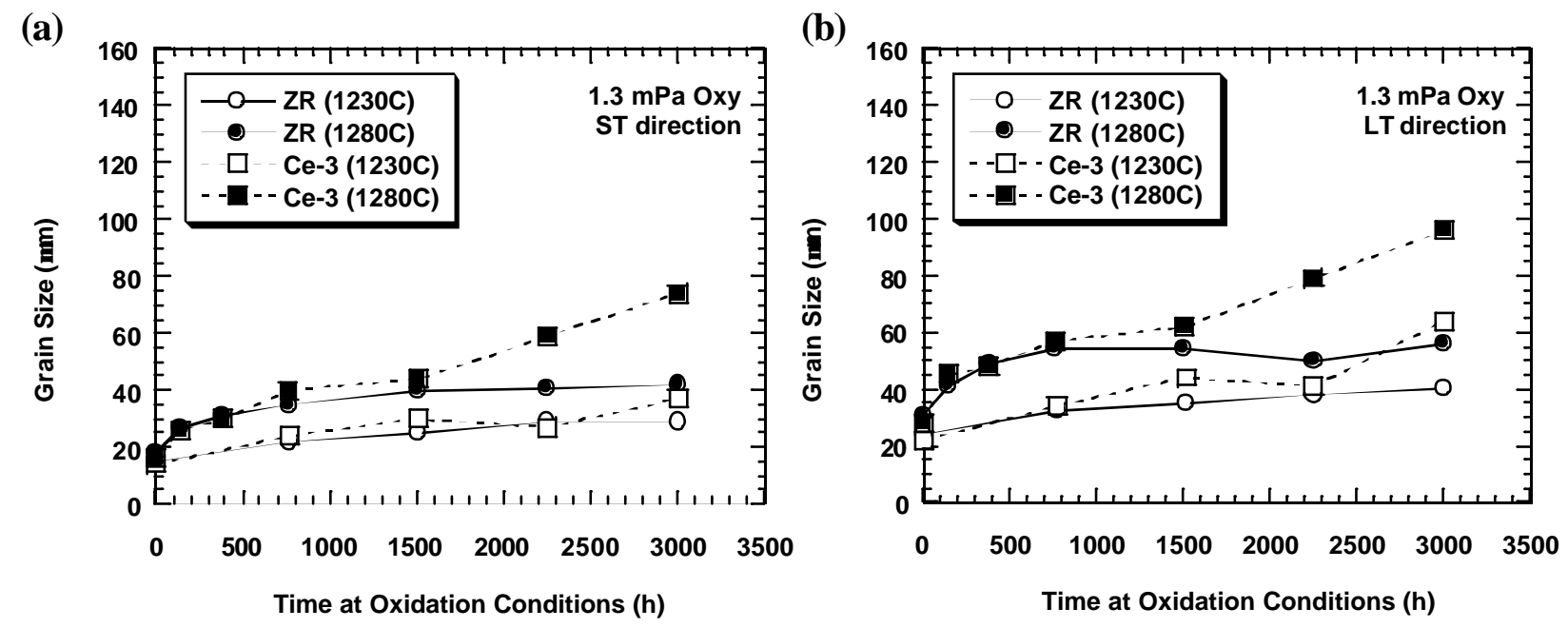

Fig. 17. Effect of annealing time on the grain size of the Ce-3 alloy annealed at 1230 and $1280 \mathrm{EC}$ in 1.3 mPa oxygen, (a) ST direction and (b) LT direction. Data for the ZR alloy are from Ref. 30. 


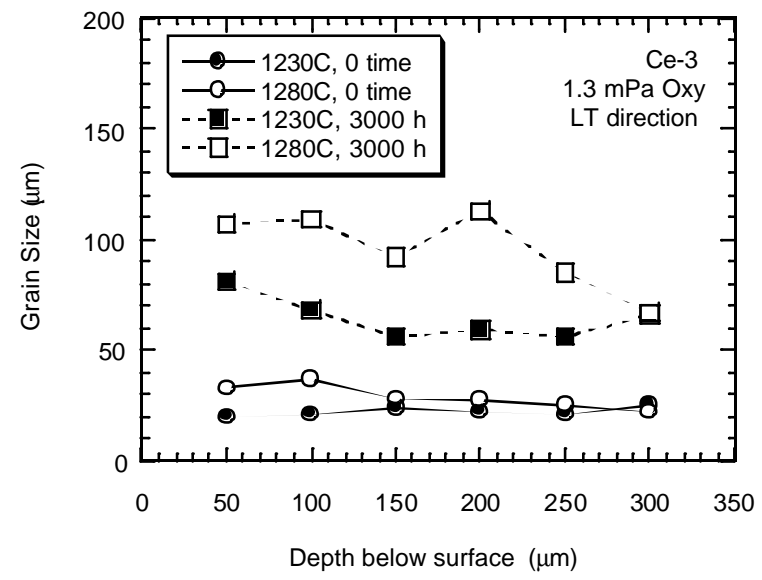

Fig. 18. Grain size as a function of depth below the surface for samples of the Ce-3 alloy annealed at 1230 and 1280EC in $1.3 \mathrm{mPa}$ oxygen.

observed at 1230 or 1280 EC. After $3000 \mathrm{~h}$ of exposure, both alloys had ST grain size of about 50-55 Fm and LT grain diameters of about 70 Fm. Within expected experimental variability, Ce-2 was also comparable to the DOP-26 ZR alloy as a function of depth into the specimen (Fig. 21), indicating that the tendency for anomalous growth of near surface grains (shown for Ce-2 in the micrographs in Fig. 20) was approximately the same for both alloys. This is not unexpected since both alloys contain 60 ppm Th.

The next Ce/Th-doped alloy prepared for testing was designated as the I-1 heat (fabricated using the new-process) and contained 29 ppm Ce and $18 \mathrm{ppm}$ Th. Its grain growth behavior was studied by annealing in a partial pressure of oxygen of $13.3 \mathrm{mPa}$ at temperatures of 1230, 1280, and 1330EC. Table X shows the average grain sizes in both the ST and LT directions for samples of the I1 alloy exposed for up to 3000 h. The data are plotted in Fig. 22 where it is compared with similar data for the

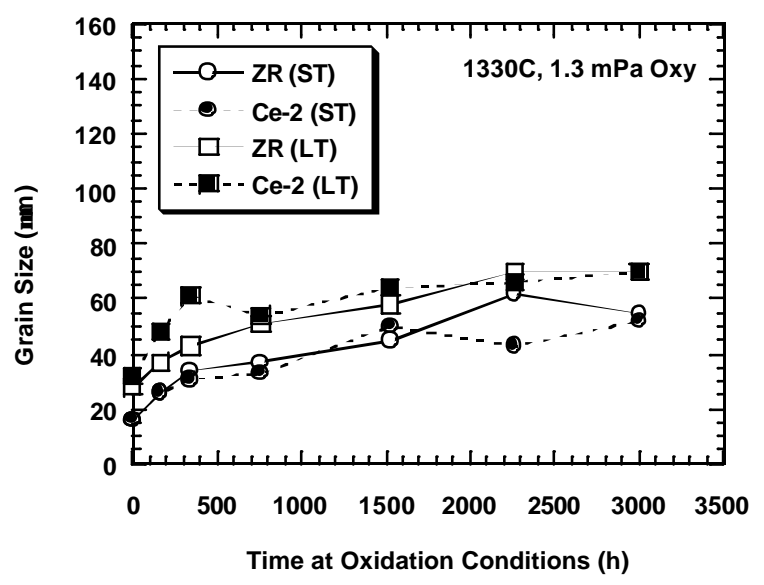

Fig. 19. Grain size as a function of time of exposure to $1.3 \mathrm{mPa}$ oxygen at $1330 \mathrm{EC}$ for the oldprocess DOP-26 ZR heat [30] and the Ce/Th-doped Ce-2 heat.
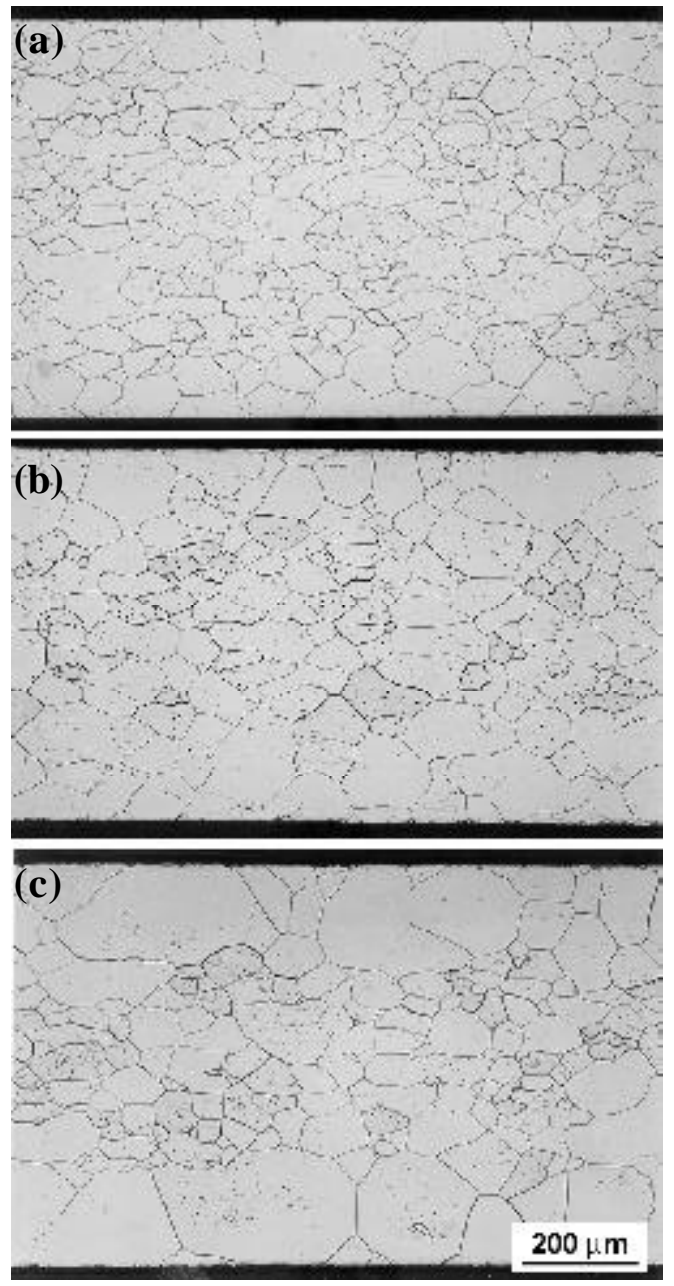

Fig. 20. Optical micrographs showing grain size of iridium heat $\mathrm{Ce}-2$ after exposure to $1.3 \mathrm{mPa}$ oxygen at $1330 \mathrm{EC}$ for (a) 760, (b) 1524, and (c) $3000 \mathrm{~h}$. 

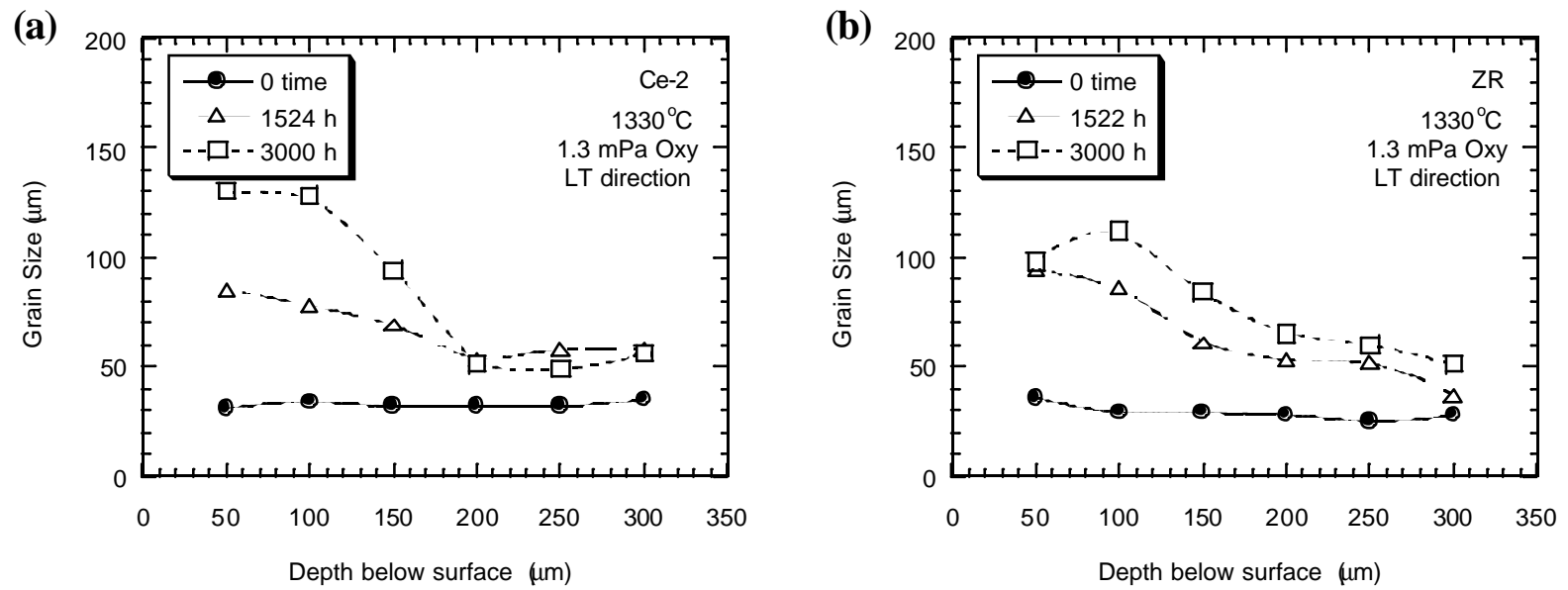

Fig. 21. Grain size as a function of depth below the surface for samples of (a) the cerium-doped heat Ce-2 and (b) the DOP-26 ZR heat [30] after exposure to $1.3 \mathrm{mPa}$ oxygen at $1330^{\circ} \mathrm{C}$.

Table X. Grain size of the Ce/Th-doped I-1 heat as a function of exposure time at 1230,1280, and $1330^{\circ} \mathrm{C}$ in an oxygen partial pressure of $13.3 \mathrm{mPa}$

\begin{tabular}{|c|c|c|c|c|c|c|c|c|}
\hline \multicolumn{3}{|c|}{$1230^{\circ} \mathrm{C}$} & \multicolumn{3}{|c|}{$1280^{\circ} \mathrm{C}$} & \multicolumn{3}{|c|}{$1330^{\circ} \mathrm{C}$} \\
\hline \multirow{2}{*}{$\begin{array}{l}\text { Length of } \\
\text { anneal (h) }\end{array}$} & \multicolumn{2}{|c|}{ Grain size $(\mathrm{F} \mathrm{m})^{a}$} & \multirow{2}{*}{$\begin{array}{l}\text { Length of } \\
\text { anneal (h) }\end{array}$} & \multicolumn{2}{|c|}{ Grain size $(\mathrm{F} \mathrm{m})^{a}$} & \multirow{2}{*}{$\begin{array}{l}\text { Length of } \\
\text { anneal (h) }\end{array}$} & \multicolumn{2}{|c|}{ Grain size $(\mathrm{Fm})^{a}$} \\
\hline & $\mathrm{ST}$ & $\mathrm{LT}$ & & ST & $\mathrm{LT}$ & & ST & LT \\
\hline 0 & $21(686)$ & $50(583)$ & 0 & $19(818)$ & 47 (606) & 0 & $22(661)$ & $59(527)$ \\
\hline 170 & $23(674)$ & -- & 166 & $27(575)$ & $57(487)$ & 170 & $35(411)$ & $71(409)$ \\
\hline 338 & $24(629)$ & -- & 332 & $30(514)$ & $66(471)$ & -- & -- & -- \\
\hline 674 & $28(549)$ & $56(516)$ & 696 & 38 (414) & $70(403)$ & 720 & $54(819)$ & 87 (653) \\
\hline 1370 & $30(518)$ & $54(521)$ & 1494 & $40(348)$ & $74(385)$ & -- & -- & -- \\
\hline 2186 & $31(486)$ & $66(440)$ & 2285 & $38(370)$ & $69(432)$ & -- & -- & -- \\
\hline 3000 & $36(403)$ & $70(404)$ & 3000 & $52(291)$ & $92(335)$ & 3000 & $82(341)$ & $112(520)$ \\
\hline
\end{tabular}

${ }^{a}$ Numbers in parentheses indicate number of intercepts counted for grain size determinations.

D2 DOP-26 material [30] that was also fabricated using the new process. The microstructures of the I-1 heat after oxygen annealing for 696 and $3000 \mathrm{~h}$ at 1280EC are shown in Fig. 23 and can be compared with the as-recrystallized condition shown in Fig. 7(a). In the ST direction, the grain growth rate of the I-1 material appears to be higher than the DOP-26 material only for the test performed at the highest temperature of 1330EC where grain sizes of the I-1 and D2 heats after $3000 \mathrm{~h}$ were 82 and $47 \mathrm{Fm}$, respectively. This difference is easily seen in the micrographs shown in Fig. 24, comparing DOP-26 D2 and DOP-40 I1 after $3000 \mathrm{~h}$ at $1330 \mathrm{EC}$. In the LT direction, the grain sizes were 112 and $65 \mathrm{Fm}$, with the I-1 heat again being larger. Some of this difference in the LT grain sizes can be explained by the different starting grain sizes of the two alloys. Starting grain sizes were measured in both the ST and LT directions on three different I-1 specimens, one for each series at the three different temperatures (see Table X). Averaging that data gives a starting grain size for the I-1 material of $21 \pm 2 \mu \mathrm{m}$ in the ST direction and $52 \pm 6 \mu \mathrm{m}$ in the 

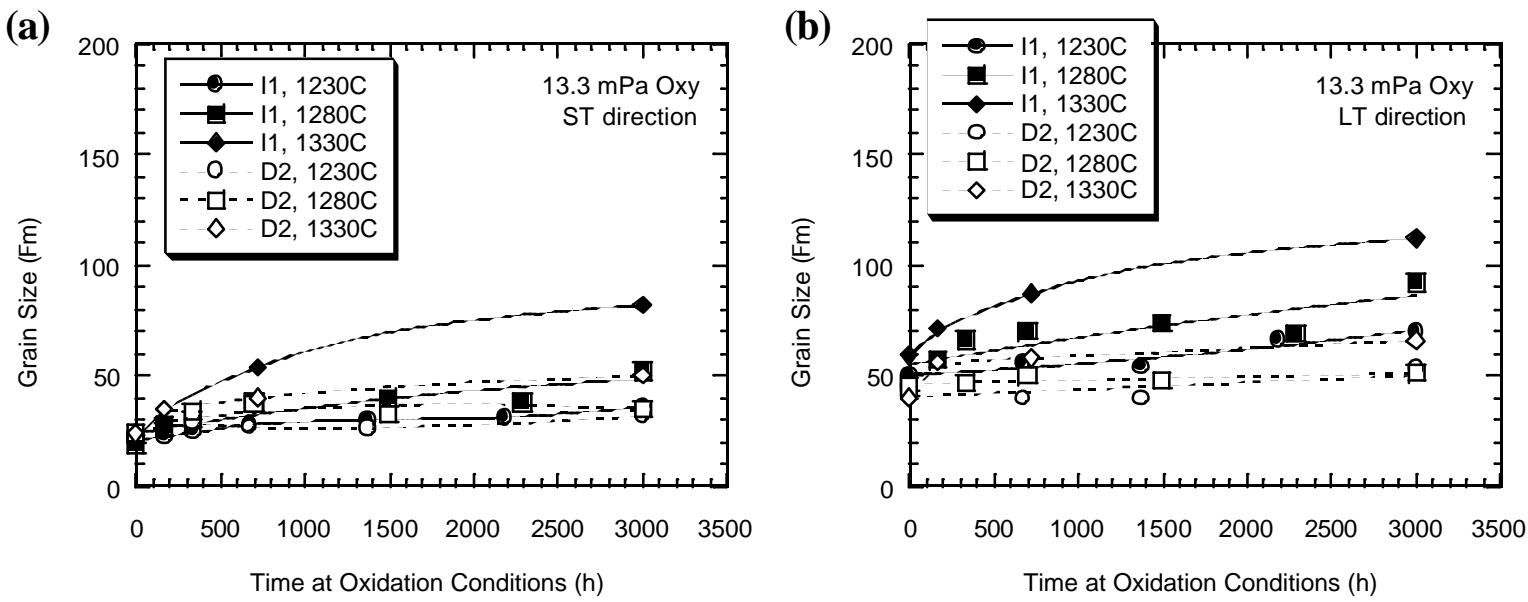

Fig. 22. Comparison of grain size as a function of time of exposure at three different temperatures in an oxygen partial pressure of $13.3 \mathrm{mPa}$ for the Ce/Th-doped I-1 heat and the new-process DOP-26 D2 heat [30] in the (a) ST and (b) LT direction with respect to the rolling direction.
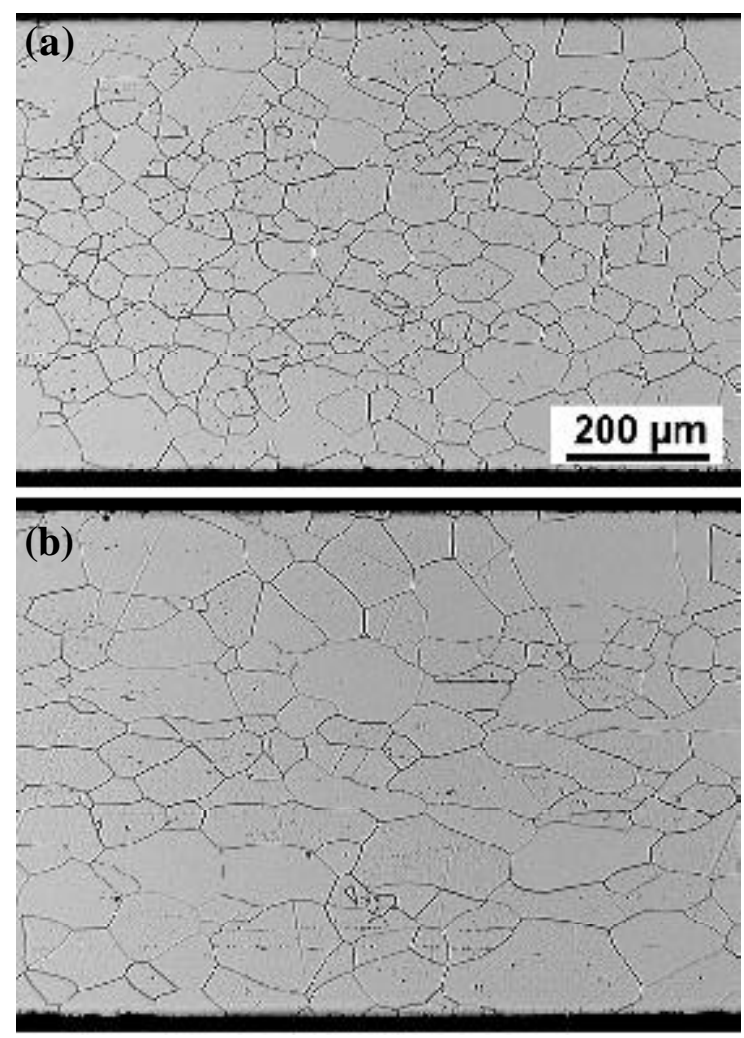

Fig. 23. Optical micrographs of Ce/Th-doped heat I1 after (a) 696 and (b) $3000 \mathrm{~h}$ of exposure to $13.3 \mathrm{mPa}$ oxygen at 1280EC.
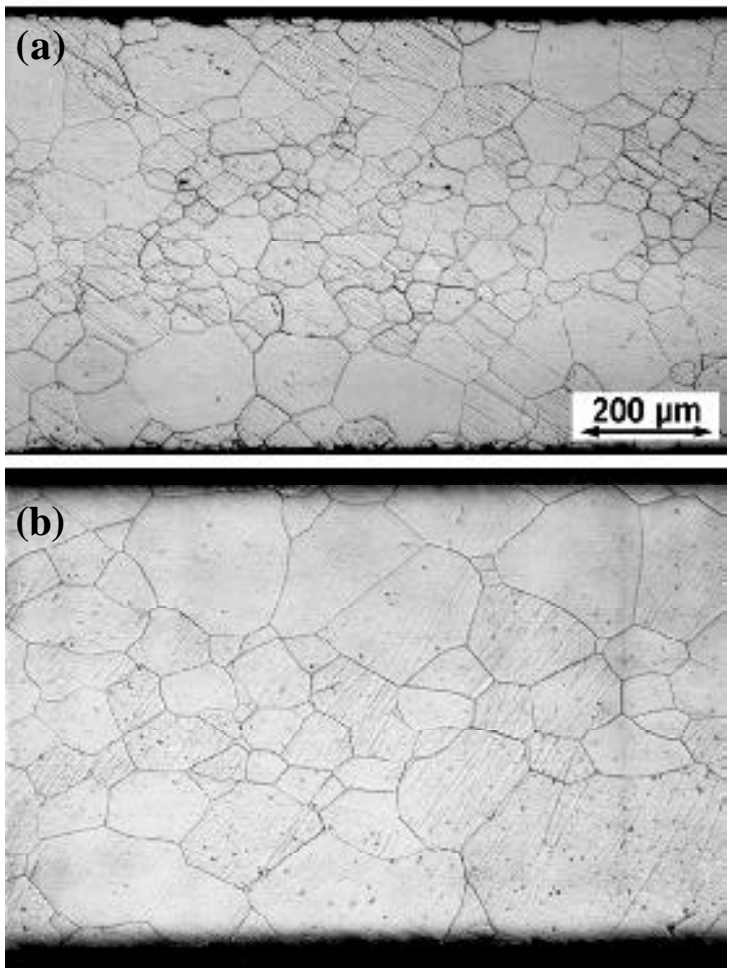

Fig. 24. Optical micrographs of (a) the DOP-26 D2 heat and (b) the DOP-40 I-1 heat after $3000 \mathrm{~h}$ of exposure to $13.3 \mathrm{mPa}$ oxygen at 1330EC. 
LT direction. The starting grain size of the D2 DOP-26 material was $22 \pm 2 \mu \mathrm{m}$ in the ST direction and $38 \pm 2 \mu \mathrm{m}$ in the LT direction [30]. The difference between 38 and $52 \mu \mathrm{m}$ has pushed the data curves for the I-1 heat upward in comparison to the DOP-26 data. The difference in grain size can also be related to the cerium and thorium compositions of the two alloys: D2 has 60 ppm Th and no cerium, while the I-1 heat contains only $18 \mathrm{ppm} \mathrm{Ce}$ and $29 \mathrm{ppm}$ Th.

The grain sizes of I-1 as a function of depth into the specimen for tests at 1230-1330EC in $13.3 \mathrm{mPa}$ of oxygen are shown in Table XI. Figure 25 shows the 0 and $3000 \mathrm{~h}$ data from this table and compares it with the results for the D2 heat of DOP-26 [30]. The scatter in the data for the I-1 heat can be seen in the three sets of data designated as " 0 time". These data indicate the starting grain size in the LT direction and show approximately 10-15\% difference between the three sets. A comparison of the I-1 data in Fig. 25(a) to similar data for the new-process D2 alloy [30] in Fig. 25(b) indicates that the I-1 alloy may have a higher tendency to grow larger grains near the surface, especially at temperatures of 1280-1330EC. A possible reason for this is the smaller mass of cerium relative to thorium which would result in faster diffusion.

Heats I-101 through I-107 were prepared using the old-process as described previously [30,38,39]. They contain various ratios of cerium to thorium with cerium ranging from $20-40 \mathrm{ppm}$ and thorium ranging from 30-50 ppm as shown in Table I. Of this set of heats, oxygen compatibility studies were

Table XI. Average grain size (in Fm) as a function of depth below the surrface for specimens of the DOP-40 I-1 heat exposed to an oxygen partial pressure of $13.3 \mathrm{mPa}$

\begin{tabular}{|c|c|c|c|c|c|c|c|}
\hline \multirow{2}{*}{$\begin{array}{l}\text { Test temp. } \\
\quad\left({ }^{\circ} \mathrm{C}\right)\end{array}$} & \multirow{2}{*}{$\begin{array}{l}\text { Exposure } \\
\text { time (h) }\end{array}$} & \multicolumn{6}{|c|}{ Depth below surface $(\mathrm{F} \mathrm{m})^{a}$} \\
\hline & & 50 & 100 & 150 & 200 & 250 & 300 \\
\hline \multirow[t]{5}{*}{1230} & 0 & 40 (117) & 41 (114) & $53(88)$ & 43 (107) & $59(85)$ & $66(72)$ \\
\hline & 674 & $69(68)$ & $59(78)$ & $57(81)$ & 45 (103) & $54(93)$ & $50(93)$ \\
\hline & 1370 & $64(76)$ & $56(82)$ & $56(82)$ & $50(94)$ & $50(95)$ & $51(92)$ \\
\hline & 2186 & $86(55)$ & $69(68)$ & $65(73)$ & $52(93)$ & $60(78)$ & $64(73)$ \\
\hline & 3000 & $76(61)$ & $80(59)$ & $62(75)$ & $63(75)$ & $69(67)$ & $70(67)$ \\
\hline \multirow{7}{*}{1280} & 0 & $51(94)$ & $48(96)$ & 46 (102) & 45 (107) & $47(100)$ & 43 (107) \\
\hline & 166 & $57(81)$ & $54(86)$ & $59(81)$ & $56(83)$ & $66(71)$ & $55(85)$ \\
\hline & 332 & $59(80)$ & $84(87)$ & $63(82)$ & $64(76)$ & $63(73)$ & $66(73)$ \\
\hline & 696 & $71(65)$ & $68(68)$ & $62(75)$ & $69(68)$ & $79(61)$ & $74(66)$ \\
\hline & 1494 & $88(53)$ & $72(64)$ & $75(61)$ & $70(67)$ & $59(78)$ & $79(62)$ \\
\hline & 2285 & $102(46)$ & $83(61)$ & $69(67)$ & $56(82)$ & $56(81)$ & $49(95)$ \\
\hline & 3000 & $112(44)$ & 107 (47) & $92(54)$ & $72(64)$ & $101(57)$ & $67(69)$ \\
\hline \multirow[t]{4}{*}{1330} & 0 & 49 (203) & 56 (176) & 67 (146) & 70 (134) & $52(179)$ & $55(168)$ \\
\hline & 170 & $58(79)$ & $70(66)$ & $58(82)$ & 70 (67) & $91(54)$ & 79 (61) \\
\hline & 720 & $100(95)$ & 89 (105) & 88 (108) & 82 (114) & 86 (108) & $76(123)$ \\
\hline & 3000 & $122(78)$ & $118(80)$ & $116(82)$ & $130(78)$ & 104 (89) & $86(113)$ \\
\hline
\end{tabular}

${ }^{a}$ Numbers in parentheses indicate number of intercepts counted for grain size determinations. 

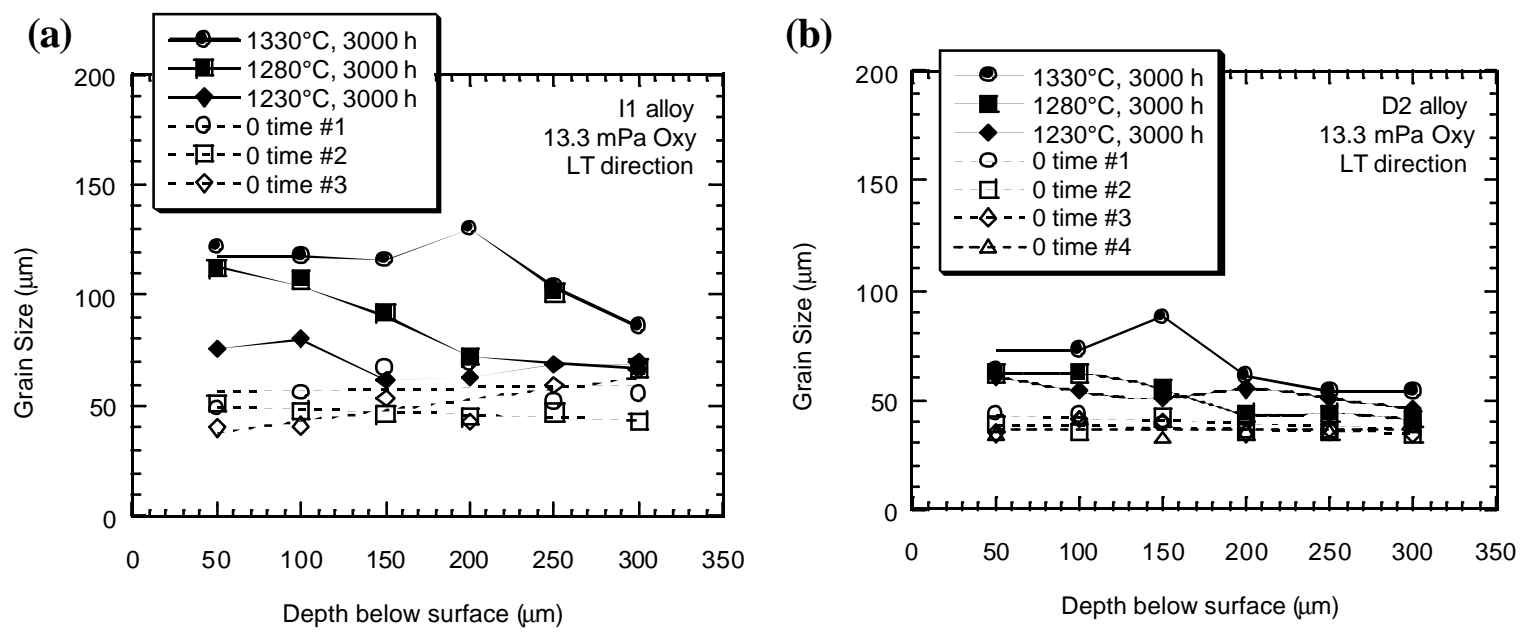

Fig. 25. Grain size in the LT direction as a function of temperature and depth below the surface of the sample for the (a) Ce/Th-doped I-1 and (b) new-process D2 alloy [30] annealed for $3000 \mathrm{~h}$ at 1230EC in an oxygen partial pressure of $13.3 \mathbf{~ m P a}$. Data for the starting grain size ("0 time") are included for comparison.

conducted on samples from heats I-102 through I-105 containing 20-30 ppm Ce and 30-50 ppm Th. Tables XII and XIII show the average grain size in both the ST and LT directions for heats I-102 through I-105 exposed for up to $3000 \mathrm{~h}$ at 1330EC in oxygen partial pressures of 1.3 and $13.3 \mathrm{mPa}$, respectively. These data are plotted in Figs. 26 and 27. Data for the D2 (new process) heat of DOP-26 [30] are included for comparison. Although the $\mathrm{Ce} / \mathrm{Th}$-doped alloys used here were prepared using the old fabrication process, their comparison to new-process D2 material is justified since past studies of old- and newprocess DOP-26 at these temperatures and oxygen levels have shown no difference in their oxygen compatibility [30]. Figures 26(a) and 27(a) show that grain growth of all four Ce/Th-doped alloys in the ST direction is comparable to that of the DOP-26 material. In Figs. 26(b) and 27(b), grain sizes in the LT direction for the Ce/Th-doped alloys are slightly higher than for the DOP-26 alloy. This result was also noted above for the Ce-3 (36 ppm Ce, 0 Th) [Fig. 12(b)] and I-1 (29 ppm Ce, 18 ppm Th) heats [Fig. 22(b)]. In addition, the heat with the largest amount of thorium, I-105 with $50 \mathrm{ppm}$ Th (and $30 \mathrm{ppm} \mathrm{Ce}$ ), exhibited the smallest grain sizes when exposed to $1.3 \mathrm{mPa}$ of oxygen [see Fig. 26(b)]. Together these results suggest that the substitution of cerium for thorium may not affect grain growth at the lower temperatures and oxygen pressures, but may result in larger grain growth for the longer annealing times and higher oxygen pressures. In terms of the grain growth rate, initially the Ce/Th-doped alloys may experience slightly higher grain growth rates than DOP-26 in the LT direction, but after about two weeks time the data indicates that the rates of grain growth are comparable for both the DOP-40 and DOP-26 alloys. The increase in grain size as a function of time at 1330EC for the $13.3 \mathrm{mPa}$ exposure compared to the $1.3 \mathrm{mPa}$ exposure is consistent with results observed previously for the DOP-26 alloy [30]. Optical micrographs of the I-103 and I-105 alloys in the as-recrystallized condition and after 666 and $3000 \mathrm{~h}$ 
Table XII. Grain size of the Ce/Th-doped DOP-40 alloys as a function of exposure time at $1330^{\circ} \mathrm{C}$ in an oxygen partial pressure of $1.3 \mathrm{mPa}$

\begin{tabular}{|c|c|c|c|}
\hline \multirow{2}{*}{ Alloy } & \multirow{2}{*}{ Annealing time (h) } & \multicolumn{2}{|c|}{ Grain size $(\mathrm{Fm})^{a}$} \\
\hline & & ST direction & LT direction \\
\hline \multirow[t]{5}{*}{ D2 } & As $R x n$ & $22(2255)$ & 38 (2981) \\
\hline & 793 & $31(835)$ & $45(525)$ \\
\hline & 1486 & $30(858)$ & $46(519)$ \\
\hline & 2297 & $31(824)$ & $47(503)$ \\
\hline & 3000 & $31(828)$ & $46(508)$ \\
\hline \multirow[t]{7}{*}{ I-102 } & As $\operatorname{Rxn}^{b}$ & $18(2612)$ & 45 (1152) \\
\hline & 168 & $24(752)$ & $54(685)$ \\
\hline & 335 & $26(694)$ & $56(641)$ \\
\hline & 793 & $30(868)$ & $64(378)$ \\
\hline & 1486 & 32 (799) & $60(398)$ \\
\hline & 2297 & $30(864)$ & $60(413)$ \\
\hline & 3000 & $31(828)$ & $65(371)$ \\
\hline \multirow[t]{7}{*}{$\mathrm{I}-103$} & As $\operatorname{Rxn}^{b}$ & $18(1813)$ & 45 (1154) \\
\hline & 168 & $24(774)$ & 39 (897) \\
\hline & 335 & 27 (667) & 57 (629) \\
\hline & 793 & $30(853)$ & $63(420)$ \\
\hline & 1486 & $30(859)$ & $61(394)$ \\
\hline & 2297 & $31(834)$ & 59 (408) \\
\hline & 3000 & $31(834)$ & $66(380)$ \\
\hline \multirow[t]{7}{*}{ I-104 } & As $\operatorname{Rxn}^{b}$ & 17 (3013) & 40 (1293) \\
\hline & 168 & $24(739)$ & $56(635)$ \\
\hline & 335 & $28(657)$ & $69(702)$ \\
\hline & 793 & $30(855)$ & $65(378)$ \\
\hline & 1486 & $32(826)$ & $68(350)$ \\
\hline & 2297 & $32(813)$ & $66(355)$ \\
\hline & 3000 & $31(834)$ & $60(396)$ \\
\hline \multirow[t]{7}{*}{ I- 105} & As $\mathrm{Rxn}^{b}$ & $18(2715)$ & 45 (1114) \\
\hline & 168 & $23(785)$ & $52(744)$ \\
\hline & 335 & $26(698)$ & $48(740)$ \\
\hline & 793 & $30(859)$ & $56(443)$ \\
\hline & 1486 & $28(912)$ & 49 (482) \\
\hline & 2297 & $28(911)$ & $46(516)$ \\
\hline & 3000 & $30(852)$ & $54(449)$ \\
\hline
\end{tabular}

${ }^{a}$ Numbers in parentheses indicate number of intercepts counted for grain size determinations.

${ }^{b}$ Data for as-recrystallized samples were taken from the $1330^{\circ} \mathrm{C}-13.3 \mathrm{mPa}$ oxygen compatibility data of Table XIII. 
Table XIII. Grain size of the Ce/Th-doped DOP-40 alloys as a function of exposure time at $1330^{\circ} \mathrm{C}$ in an oxygen partial pressure of $13.3 \mathrm{mPa}$

\begin{tabular}{|c|c|c|c|}
\hline \multirow{2}{*}{ Alloy } & \multirow{2}{*}{ Annealing time (h) } & \multicolumn{2}{|c|}{ Grain size $(\boldsymbol{F} \mathrm{m})^{a}$} \\
\hline & & ST direction & LT direction \\
\hline \multirow[t]{5}{*}{ D2 } & As $R x n$ & $22(2255)$ & 38 (2981) \\
\hline & 666 & 39 (1264) & 54 (686) \\
\hline & 1502 & 43 (1178) & $60(602)$ \\
\hline & 2315 & 46 (1089) & $65(577)$ \\
\hline & 3000 & $51(948)$ & $69(533)$ \\
\hline \multirow[t]{6}{*}{ I-102 } & As $R x n$ & 18 (2612) & 45 (1152) \\
\hline & 330 & 32 (1619) & $66(563)$ \\
\hline & 666 & 37 (1393) & $65(575)$ \\
\hline & 1502 & 43 (1179) & 83 (469) \\
\hline & 2315 & 48 (1248) & 95 (424) \\
\hline & 3000 & $48(1041)$ & $88(436)$ \\
\hline \multirow[t]{6}{*}{ I-103 } & As $R x n$ & 18 (1813) & 45 (1154) \\
\hline & 330 & 34 (1374) & 73 (533) \\
\hline & 666 & 39 (1210) & 74 (431) \\
\hline & 1502 & 45 (1086) & 81 (507) \\
\hline & 2315 & 53 (2600) & 89 (348) \\
\hline & 3000 & $56(859)$ & $90(345)$ \\
\hline \multirow[t]{6}{*}{ I-104 } & As $R x n$ & 17 (3013) & 40 (1293) \\
\hline & 330 & 31 (1599) & $69(546)$ \\
\hline & 666 & 35 (1412) & 70 (557) \\
\hline & 1502 & 43 (1149) & 77 (493) \\
\hline & 2315 & 45 (1128) & 87 (453) \\
\hline & 3000 & 49 (1028) & $83(460)$ \\
\hline \multirow[t]{6}{*}{ I-105 } & As Rxn & $18(2715)$ & 47 (1114) \\
\hline & 330 & $34(1465)$ & $68(560)$ \\
\hline & 666 & 40 (1269) & $74(514)$ \\
\hline & 1502 & 46 (1117) & 74 (498) \\
\hline & 2315 & 47 (1061) & $86(441)$ \\
\hline & 3000 & $50(978)$ & $80(479)$ \\
\hline
\end{tabular}

${ }^{a}$ Numbers in parentheses indicate number of intercepts counted for grain size determinations.

exposure to $13.3 \mathrm{mPa}$ oxygen at 1330EC are shown in Figs. 28 and 29. These micrographs are typical of the samples from the I-102 through I-105 heats used in this study.

In addition to studies at $1330 \mathrm{EC}$ in two different oxygen partial pressures, samples from DOP-40 heat I-103 (30 ppm Ce, $30 \mathrm{ppm} \mathrm{Th}$ ) were also exposed to $13.3 \mathrm{mPa}$ oxygen at the lower temperature of 1230EC. The results are shown in Table XIV and Fig. 30. Results at this condition are consistent with the results described above. In the ST direction grain sizes were comparable to the DOP-26 D2 material, but in the LT direction grain sizes of the I-103 material were slightly larger than that of the D2 material. 

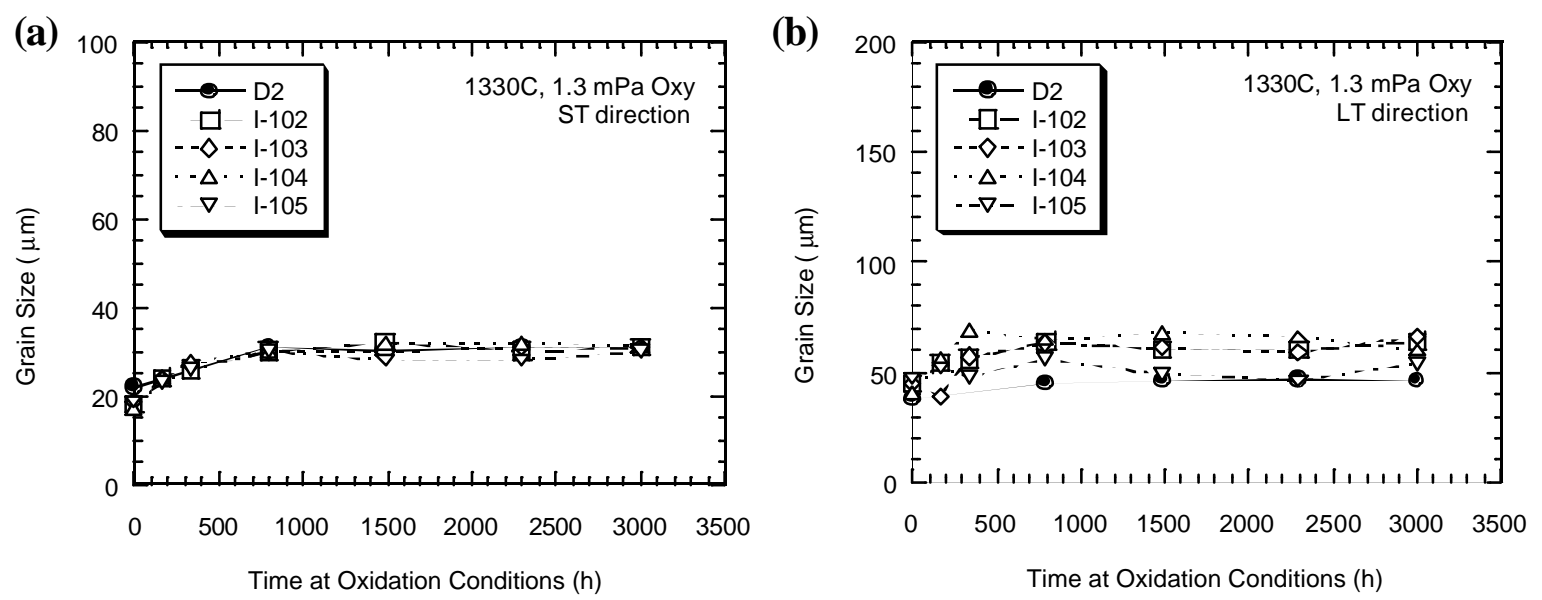

Fig. 26. Comparison of grain size as a function of time of exposure at 1330EC in an oxygen partial pressure of $1.3 \mathrm{mPa}$ for the new-process DOP-26 D2 heat [30] and for Ce/Th-doped heats I-102 through I-105 in the (a) ST and (b) LT direction with respect to the rolling direction.

(a)

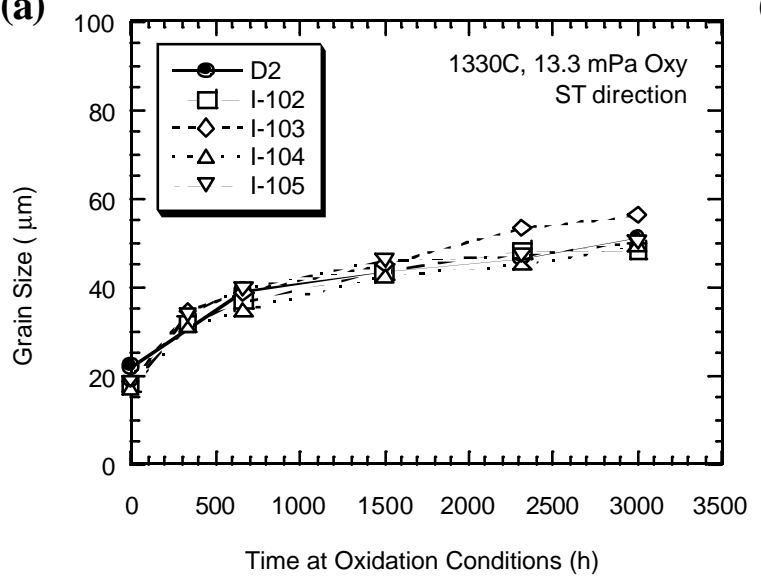

(b)

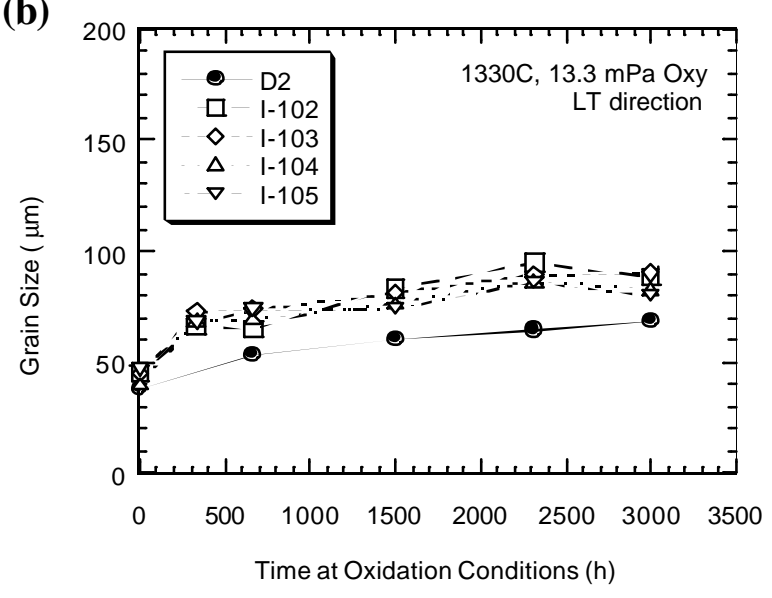

Fig. 27. Comparison of grain size as a function of time of exposure at $1330 \mathrm{EC}$ in an oxygen partial pressure of $13.3 \mathrm{mPa}$ for the new-process DOP-26 D2 heat [30] and for Ce/Th-doped heats I-102 through I105 in the (a) ST and (b) LT direction with respect to the rolling direction.

Tables XV and XVI show grain size data as a function of depth into the specimen for heats I-102 through I-105 exposed at 1330EC to oxygen partial pressures of 1.3 and $13.3 \mathrm{mPa}$, respectively. There was minimal grain growth in $1.3 \mathrm{mPa}$ oxygen, but the data for $13.3 \mathrm{mPa}$ oxygen are shown in Fig. 31, along with results for the D2 heat [30] for comparison. The plot shows that, although the starting grain sizes in the LT direction (0 time in Fig. 31) for all four Ce/Th-doped alloys as a function of depth into the samples were comparable to the D2 DOP-26 alloy, after $3000 \mathrm{~h}$ of exposure the near-surface grains of the $\mathrm{Ce} / \mathrm{Th}$-doped samples were larger than those of the DOP-26 alloy. A possible reason for this is the smaller mass of cerium relative to thorium which would result in faster diffusion. Considering the data at 

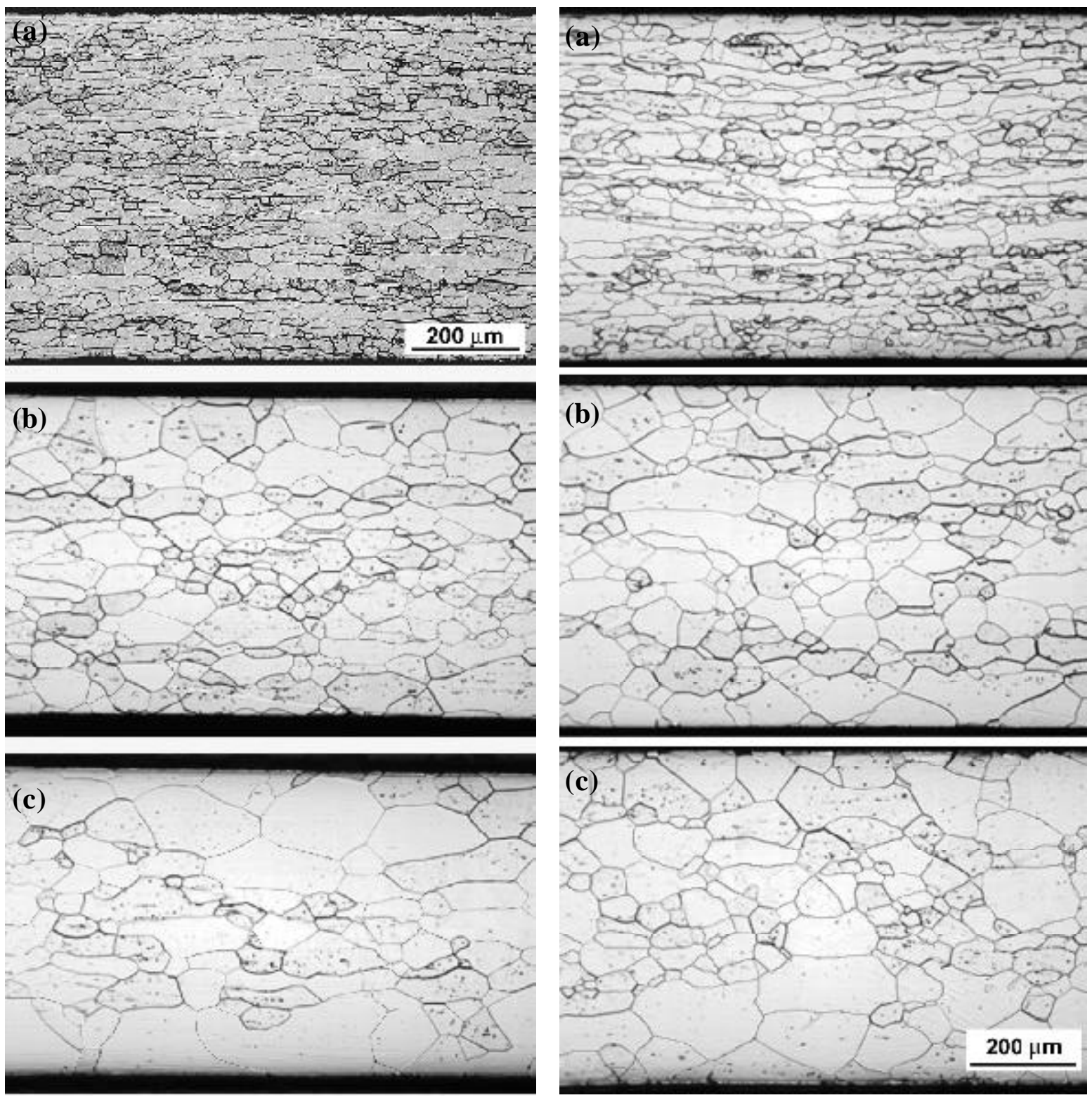

Fig. 28. Optical micrographs of iridium heat I103 (a) in the as-recrystallized condition and after (b) $666 \mathrm{~h}$ and (c) $3000 \mathrm{~h}$ exposure to $13.3 \mathrm{mPa}$ oxygen at 1330EC.

Fig. 29. Optical micrographs of iridium heat I-105 (a) in the as-recrystallized condition and after (b) $666 \mathrm{~h}$ and (c) $3000 \mathrm{~h}$ exposure to 13.3 mPa oxygen at $1330 \mathrm{EC}$.

1330EC in oxygen partial pressures of both 1.3 and $13.3 \mathrm{mPa}$ (and considering the standard deviations of the data), there does not appear to be any difference between these four $\mathrm{Ce} / \mathrm{Th}$-doped alloys in terms of their tendency for near-surface grain growth.

The grain size versus depth data for heat I-103 exposed to $13.3 \mathrm{mPa}$ of oxygen at a temperature of 1230EC are shown in Table XVII and the $3000 \mathrm{~h}$ data are plotted in Fig. 32, along with the data for the 
Table XIV. Grain size of the cerium-doped I-103 alloy as a function of exposure time at $1230^{\circ} \mathrm{C}$ in an oxygen partial pressure of $13.3 \mathrm{mPa}$

\begin{tabular}{ccc}
\hline \multirow{2}{*}{ Length of anneal (h) } & \multicolumn{2}{c}{ Grain size $(\mathrm{Fm})^{a}$} \\
\cline { 2 - 3 } & ST direction & LT direction \\
\hline 0 & $17(848)$ & $38(751)$ \\
170 & $19(730)$ & -- \\
338 & $21(690)$ & -- \\
674 & $25(570)$ & $56(515)$ \\
1370 & $23(603)$ & $49(578)$ \\
2186 & $26(542)$ & $53(528)$ \\
3000 & $28(497)$ & $64(453)$ \\
\hline
\end{tabular}

${ }^{a}$ Numbers in parentheses indicate number of intercepts counted for grain size determinations.

(a)

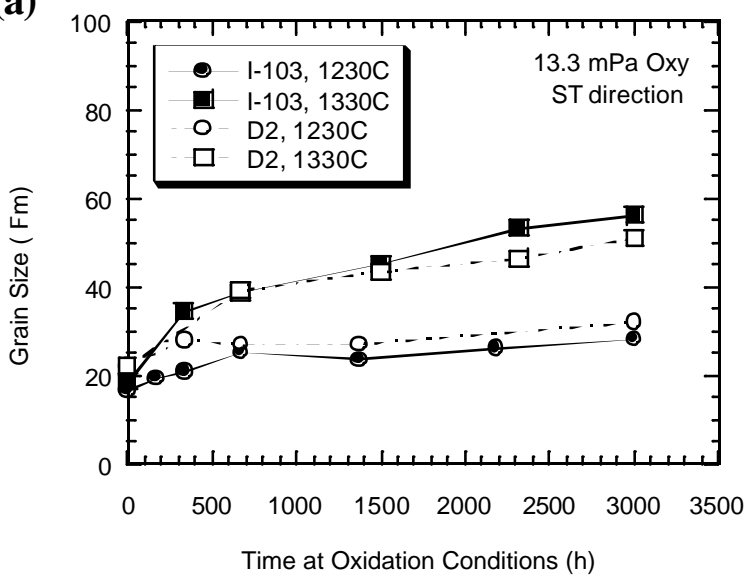

(b)

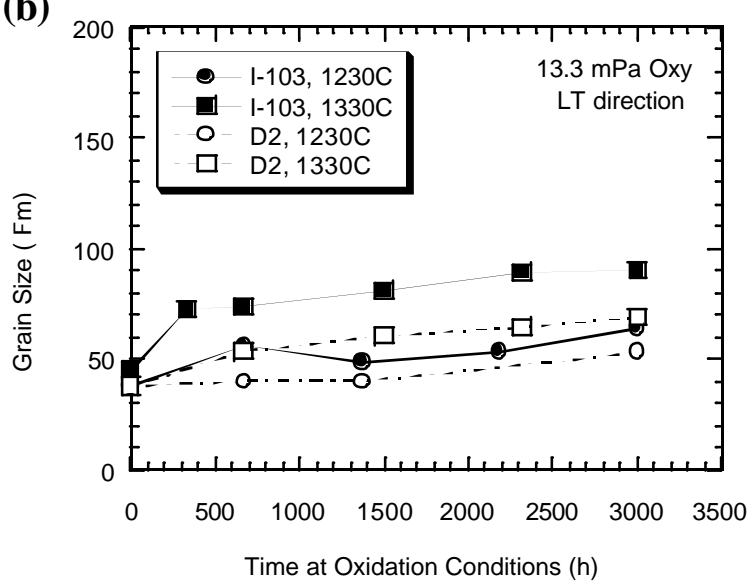

Fig. 30. Comparison of grain size as a function of time of exposure at 1230 and $1330 \mathrm{EC}$ in an oxygen partial pressure of $13.3 \mathrm{mPa}$ for the new-process DOP-26 D2 heat [30] and for cerium-doped heat I-103 in the (a) ST and (b) LT direction with respect to the rolling direction.

3000-h exposures at 1330EC. The data in Fig. 32 show very little grain growth at 1230EC, but it does show a difference in the grain growth at $1330 \mathrm{EC}$ of near-surface grains exposed to $1.3 \mathrm{mPa}$ oxygen versus those exposed at $13.3 \mathrm{mPa}$ oxygen. Indications are that growth of near-surface grains in the Ce/Th-doped samples was much faster in the higher oxygen level than in the lower oxygen level. All of our tests on DOP-26 alloys have shown no difference in the grain growth of near-surface grains for these two oxygen levels [30]. The smaller size of the cerium atom and resulting faster diffusion rates may explain the difference between near-surface grain growth of the DOP-26 and DOP-40 alloys in the two different oxygen levels. 
Table XV. Average grain size (in F $m$ ) as a function of depth below the surface for DOP-40 specimens exposed to an oxygen partial pressure of $1.3 \mathrm{mPa}$ at $1330^{\circ} \mathrm{C}$

\begin{tabular}{|c|c|c|c|c|c|c|c|}
\hline \multirow{2}{*}{ Alloy } & \multirow{2}{*}{$\begin{array}{l}\text { Exposure time } \\
\text { (h) }\end{array}$} & \multicolumn{6}{|c|}{ Depth below surface $(F \mathrm{~m})^{a}$} \\
\hline & & 50 & 100 & 150 & 200 & 250 & 300 \\
\hline \multirow[t]{5}{*}{ D2 } & $0^{b}$ & 44 (108) & 43 (106) & 39 (120) & 39 (118) & 35 (132) & 40 (114) \\
\hline & 793 & $51(75)$ & $53(75)$ & $42(91)$ & $48(81)$ & 40 (99) & 38 (104) \\
\hline & 1486 & $59(65)$ & $50(77)$ & $45(88)$ & $46(83)$ & $42(92)$ & $35(114)$ \\
\hline & 2297 & $55(70)$ & $52(74)$ & $45(85)$ & $44(90)$ & $45(86)$ & $39(98)$ \\
\hline & 3000 & $49(78)$ & $45(85)$ & $48(81)$ & $46(84)$ & $40(100)$ & $49(80)$ \\
\hline \multirow[t]{7}{*}{ I-102 } & $0^{c}$ & $52(163)$ & 47 (184) & 42 (205) & 45 (190) & 41 (205) & $42(205)$ \\
\hline & 168 & 72 (93) & 56 (105) & 44 (133) & 54 (109) & 47 (122) & $48(123)$ \\
\hline & 335 & 54 (108) & 63 (96) & 58 (102) & 50 (117) & 62 (99) & 49 (119) \\
\hline & 793 & 88 (44) & $65(65)$ & $60(65)$ & $60(64)$ & $51(75)$ & $60(65)$ \\
\hline & 1486 & $76(51)$ & $64(61)$ & $57(71)$ & $60(67)$ & $48(81)$ & $57(67)$ \\
\hline & 2297 & 79 (49) & $61(66)$ & $72(59)$ & $49(81)$ & $52(76)$ & $47(82)$ \\
\hline & 3000 & $80(49)$ & $61(66)$ & $72(56)$ & $64(60)$ & $53(73)$ & $59(67)$ \\
\hline \multirow[t]{7}{*}{$\mathrm{I}-103$} & $0^{c}$ & 50 (172) & 46 (189) & 47 (182) & 44 (195) & 46 (192) & 38 (224) \\
\hline & 168 & 46 (129) & 38 (154) & 40 (147) & 38 (152) & 36 (161) & 38 (154) \\
\hline & 335 & $63(95)$ & 70 (88) & 50 (118) & 54 (111) & 51 (113) & $55(104)$ \\
\hline & 793 & 112 (42) & $68(61)$ & $50(77)$ & $50(77)$ & 50 (77) & $44(86)$ \\
\hline & 1486 & $72(54)$ & $69(57)$ & 54 (74) & $61(64)$ & $51(78)$ & $60(67)$ \\
\hline & 2297 & $69(61)$ & $58(74)$ & $70(54)$ & $55(70)$ & $52(74)$ & $51(75)$ \\
\hline & 3000 & $95(46)$ & $72(56)$ & $50(78)$ & $68(59)$ & $56(72)$ & $56(69)$ \\
\hline \multirow[t]{7}{*}{ I-104 } & $0^{c}$ & 45 (187) & 42 (214) & 37 (228) & 42 (206) & 36 (239) & 39 (219) \\
\hline & 168 & $56(102)$ & $59(98)$ & 53 (109) & 56 (106) & 55 (109) & 53 (111) \\
\hline & 335 & 72 (110) & 59 (133) & 73 (107) & 77 (107) & 65 (124) & 70 (121) \\
\hline & 793 & $76(52)$ & $69(58)$ & 68 (61) & $56(71)$ & $62(68)$ & $58(68)$ \\
\hline & 1486 & 79 (49) & $65(60)$ & $67(57)$ & $68(58)$ & $56(72)$ & $71(54)$ \\
\hline & 2297 & $75(52)$ & $58(66)$ & $73(52)$ & $66(58)$ & $69(60)$ & $57(67)$ \\
\hline & 3000 & $69(55)$ & $66(59)$ & $61(63)$ & $52(73)$ & $62(63)$ & $49(83)$ \\
\hline \multirow[t]{7}{*}{ I-105 } & $0^{c}$ & 50 (174) & 51 (169) & 42 (205) & 46 (186) & 40 (212) & $52(168)$ \\
\hline & 168 & 52 (116) & 38 (151) & 58 (105) & 72 (109) & 47 (127) & 44 (136) \\
\hline & 335 & 63 (96) & 48 (123) & 46 (134) & 46 (128) & 46 (125) & 43 (134) \\
\hline & 793 & $77(56)$ & $56(72)$ & $60(70)$ & 46 (82) & $50(80)$ & $46(83)$ \\
\hline & 1486 & $52(78)$ & $46(85)$ & $51(79)$ & $51(78)$ & $44(87)$ & $52(75)$ \\
\hline & 2297 & $60(64)$ & $50(80)$ & $45(86)$ & $46(84)$ & $40(98)$ & 37 (104) \\
\hline & 3000 & $72(54)$ & $50(77)$ & $46(83)$ & $46(84)$ & $58(76)$ & $54(75)$ \\
\hline
\end{tabular}

${ }^{a}$ Numbers in parentheses indicate number of intercepts counted for grain size determinations.

${ }^{b}$ Data taken from Ref. 30.

${ }^{c}$ Data for as-recrystallized samples were taken from the $1330^{\circ} \mathrm{C}-13.3 \mathrm{mPa}$ oxygen compatibility data in Table XVI. 
Table XVI. Average grain Size (in Fm) as a function of depth below the surface for DOP-40 specimens exposed to an oxygen partial pressure of $13.3 \mathrm{mPa}$ at $1330^{\circ} \mathrm{C}$

\begin{tabular}{|c|c|c|c|c|c|c|c|}
\hline \multirow{2}{*}{ Alloy } & \multirow{2}{*}{$\begin{array}{l}\text { Exposure time } \\
\text { (h) }\end{array}$} & \multicolumn{6}{|c|}{ Depth below surface $(\mathrm{Fm})^{a}$} \\
\hline & & 50 & 100 & 150 & 200 & 250 & 300 \\
\hline \multirow[t]{5}{*}{ D2 } & $0^{b}$ & $36(386)$ & $40(355)$ & $38(367)$ & $36(395)$ & $36(387)$ & 35 (393) \\
\hline & 666 & 53 (114) & $63(98)$ & 51 (119) & 52 (114) & $51(121)$ & 51 (120) \\
\hline & 1502 & 67 (90) & $68(88)$ & 57 (106) & 55 (109) & $60(101)$ & 56 (108) \\
\hline & 2315 & $65(92)$ & $72(71)$ & $67(90)$ & 56 (107) & 56 (107) & 57 (110) \\
\hline & 3000 & $73(83)$ & $72(84)$ & 68 (89) & 68 (89) & $65(96)$ & $67(92)$ \\
\hline \multirow[t]{6}{*}{ I-102 } & 0 & $52(163)$ & 47 (184) & 42 (205) & 45 (190) & $41(205)$ & $42(205)$ \\
\hline & 330 & $69(89)$ & $69(93)$ & 60 (101) & $68(93)$ & $68(90)$ & $64(97)$ \\
\hline & 666 & $76(81)$ & $65(95)$ & $66(92)$ & 63 (100) & $62(96)$ & 57 (111) \\
\hline & 1502 & $117(56)$ & $104(62)$ & $63(95)$ & $76(80)$ & $75(82)$ & $65(94)$ \\
\hline & 2315 & $125(53)$ & $109(57)$ & 96 (67) & 98 (72) & $68(92)$ & $73(83)$ \\
\hline & 3000 & $98(65)$ & $108(62)$ & $98(54)$ & 80 (77) & $73(84)$ & $66(94)$ \\
\hline \multirow[t]{6}{*}{ I-103 } & 0 & $50(172)$ & 46 (189) & 47 (182) & 44 (195) & 46 (192) & $38(224)$ \\
\hline & 330 & $83(81)$ & $78(80)$ & $76(85)$ & 67 (93) & 73 (89) & $60(105)$ \\
\hline & 666 & $93(66)$ & $79(85)$ & $65(92)$ & $66(93)$ & $66(95)$ & -- \\
\hline & 1502 & $114(46)$ & 87 (67) & $78(85)$ & $62(101)$ & 59 (102) & 57 (106) \\
\hline & 2315 & $96(63)$ & $101(61)$ & $88(72)$ & $86(71)$ & $75(81)$ & -- \\
\hline & 3000 & $106(57)$ & $100(62)$ & $85(70)$ & 80 (79) & $80(77)$ & -- \\
\hline \multirow[t]{6}{*}{ I-104 } & 0 & 45 (187) & 42 (214) & 37 (228) & 42 (206) & 36 (239) & 39 (219) \\
\hline & 330 & $73(84)$ & $62(97)$ & $76(82)$ & 57 (108) & $70(90)$ & $73(85)$ \\
\hline & 666 & $106(61)$ & $63(95)$ & 63 (97) & 53 (114) & $62(101)$ & $70(89)$ \\
\hline & 1502 & $104(61)$ & $86(72)$ & $66(91)$ & $64(94)$ & $75(81)$ & $64(94)$ \\
\hline & 2315 & 117 (53) & $100(65)$ & $91(67)$ & $73(91)$ & $65(94)$ & $74(83)$ \\
\hline & 3000 & $88(71)$ & 107 (57) & $91(71)$ & 72 (87) & 67 (92) & $74(82)$ \\
\hline \multirow[t]{6}{*}{ I-105 } & 0 & $50(174)$ & $51(169)$ & $42(205)$ & $46(186)$ & $40(212)$ & $52(168)$ \\
\hline & 330 & $68(90)$ & $69(89)$ & $76(88)$ & $69(94)$ & $66(95)$ & 59 (104) \\
\hline & 666 & $81(77)$ & $83(75)$ & $65(94)$ & $76(83)$ & $76(87)$ & $61(98)$ \\
\hline & 1502 & $80(78)$ & $86(71)$ & 68 (89) & $64(95)$ & $68(90)$ & $81(75)$ \\
\hline & 2315 & $83(73)$ & $103(59)$ & $88(71)$ & $77(84)$ & 77 (82) & $88(72)$ \\
\hline & 3000 & $87(71)$ & $108(58)$ & $88(71)$ & $69(87)$ & 67 (89) & $60(103)$ \\
\hline
\end{tabular}

${ }^{a}$ Numbers in parentheses indicate number of intercepts counted for grain size determinations.

${ }^{b}$ Data taken from Ref. 30.

Fig. 31. Grain size in the LT direction as a function of depth below the surface of the samples for the new-process DOP-26 D2 heat [30] and for Ce/Th-doped heats I-102 through $\mathrm{I}-105$ annealed for $3000 \mathrm{~h}$ at 1330EC in an oxygen partial pressure of $13.3 \mathrm{mPa}$. Data for the starting grain size ("0 time") are included for comparison.

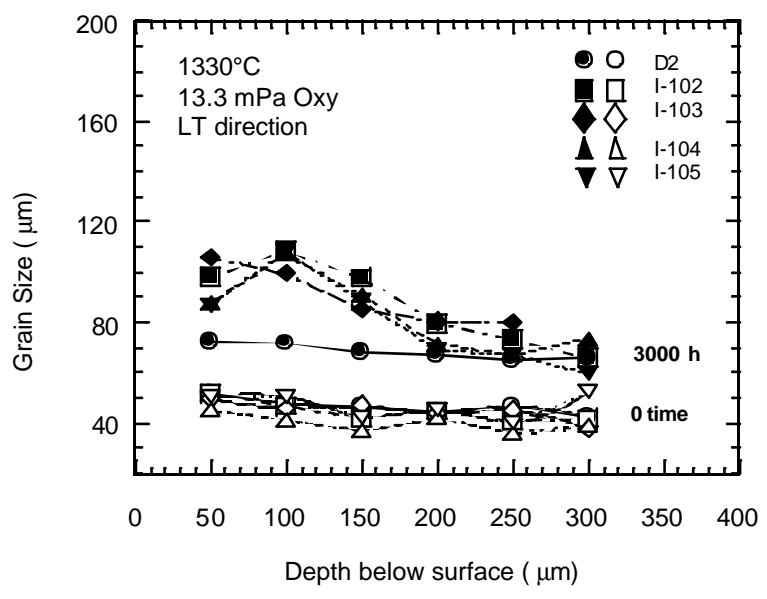


Table XVII. Average grain size (in F $\mathrm{m}$ ) as a function of depth below the surface for I-103 specimens exposed to an oxygen partial pressure of $13.3 \mathrm{mPa}$ at $1230^{\circ} \mathrm{C}$

\begin{tabular}{|c|c|c|c|c|c|c|}
\hline \multirow{2}{*}{$\begin{array}{l}\text { Exposure time } \\
\text { (h) }\end{array}$} & \multicolumn{6}{|c|}{ Depth below surface $(\mathrm{Fm})^{a}$} \\
\hline & 50 & 100 & 150 & 200 & 250 & 300 \\
\hline 0 & 40 (116) & $34(136)$ & 34 (138) & 39 (126) & 39 (117) & 39 (118) \\
\hline 674 & $50(95)$ & $52(89)$ & $54(87)$ & $60(79)$ & $69(72)$ & $50(93)$ \\
\hline 1370 & $48(97)$ & $49(94)$ & $50(94)$ & $50(93)$ & $50(98)$ & $46(102)$ \\
\hline 2186 & $60(78)$ & $60(80)$ & $46(99)$ & $46(99)$ & $57(81)$ & $51(91)$ \\
\hline 3000 & $81(57)$ & $58(81)$ & $60(79)$ & $56(84)$ & $68(69)$ & $59(83)$ \\
\hline
\end{tabular}

${ }^{a}$ Numbers in parentheses indicate number of intercepts counted for grain size determinations.

Fig. 32. Comparison of grain size as a function of depth below the surface of samples of the Ce/Th-doped I-103 heat annealed for $3000 \mathrm{~h}$ in $13.3 \mathrm{mPa}$ oxygen at $1230 \mathrm{EC}$ and at $1330 \mathrm{EC}$ in 1.3 and $13.3 \mathrm{mPa}$ oxygen.

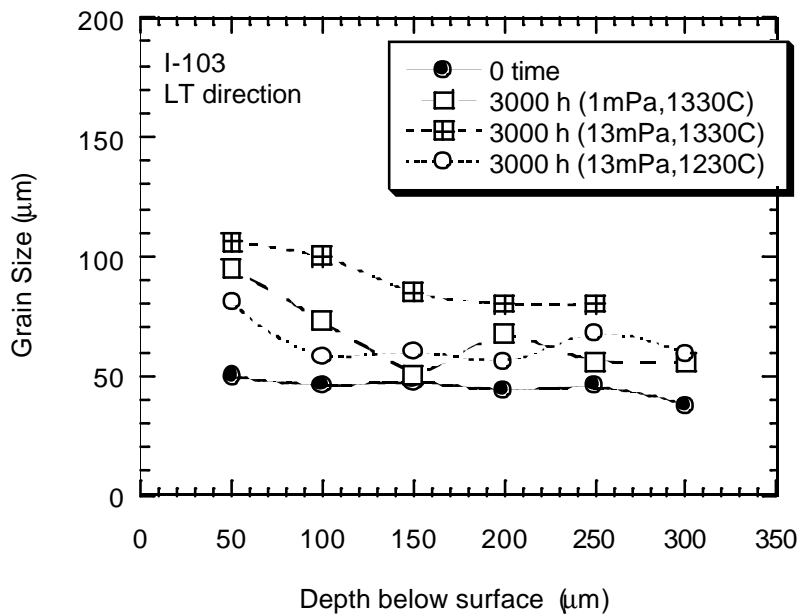

\section{TENSILE IMPACT PROPERTIES}

Table XVIII and Fig. 33 show the variation in impact ductility (at 980EC) as a function of the annealing temperature for the first series of cerium-doped alloys listed in Table I (Ce-2 through Ce-7) [37]. The graph shows that the data can be grouped into two categories. Within experimental scatter, the alloys doped with only cerium (Ce-3 and $\mathrm{Ce}-4)$ exhibited ductilities that were lower at all annealing temperatures than the alloys doped with thorium or thorium plus cerium. There does not appear to be any difference in ductility between the Ce-3 and Ce-4 heats containing $36 \mathrm{ppm} \mathrm{Ce}$ and $73 \mathrm{ppm} \mathrm{Ce}$, respectively. Likewise, there is no discernable difference in ductility between the Ce/Th-doped heats Ce-2 containing 36 ppm Ce and 60 ppm Th and Ce-6 containing 29 ppm Ce and 12 ppm Th. Both of these heats also have ductilities comparable to that of the DOP-26 alloy.

Figure 34 shows the impact ductility as a function of the grain size of these six alloys. All exhibited a decrease in ductility with increasing grain size. All the alloys failed, in general, in a ductile transgranular mode at low annealing temperatures (i.e., below 1400EC) and in a brittle intergranular 
Table XVIII. Effect of annealing temperature on tensile impact ductility of Ce/Th-doped heats Ce-2 through Ce-7

\begin{tabular}{|c|c|c|c|c|c|c|c|}
\hline \multicolumn{2}{|c|}{ Annealing temperature } & \multicolumn{6}{|c|}{ Elongation to fracture $(\%)^{a}$} \\
\hline${ }^{\circ} \mathrm{C}$ & $\mathrm{K}$ & DOP- $26^{b}$ & $\mathrm{Ce}-2$ & $\mathrm{Ce}-3$ & $\mathrm{Ce}-4$ & $\mathrm{Ce}-6$ & $\mathrm{Ce}-7$ \\
\hline 1200 & 1473 & -- & -- & 33.7 & 34.7 & -- & -- \\
\hline 1300 & 1573 & 54.9 & -- & 30.8 & 21.2 & 48.5 & 44.8 \\
\hline 1350 & 1623 & 33.7 & 38.4 & -- & -- & -- & -- \\
\hline 1400 & 1673 & 35.9 & 38.4 & 14.0 & 16.5 & 40.0 & 44.7 \\
\hline 1500 & 1773 & 35.4 & 25.0 & 12.8 & 12.5 & 26.5 & 16.8 \\
\hline 1600 & 1873 & 16.9 & 19.8 & 5.5 & 6.8 & 19.2 & 10.8 \\
\hline 1700 & 1973 & 7.7 & 9.2 & 4.9 & 3.8 & 10.2 & 11.0 \\
\hline 1800 & 2073 & 4.7 & 2.5 & 2.5 & 0.8 & 3.8 & -- \\
\hline
\end{tabular}

${ }^{a}$ Tensile impact tested at $980^{\circ} \mathrm{C}$ at a strain rate of $\sim 10^{3} \mathrm{~s}^{-1}$.

${ }^{b}$ Data for DOP-26 was taken from Refs. 30 and 37.

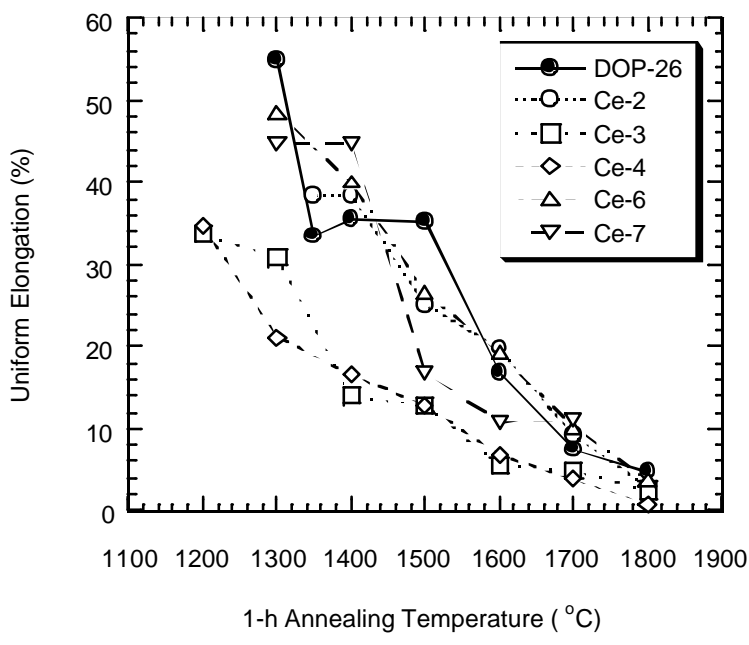

Fig. 33. Variation of impact ductility with annealing temperature (impact test temperature was 980EC).

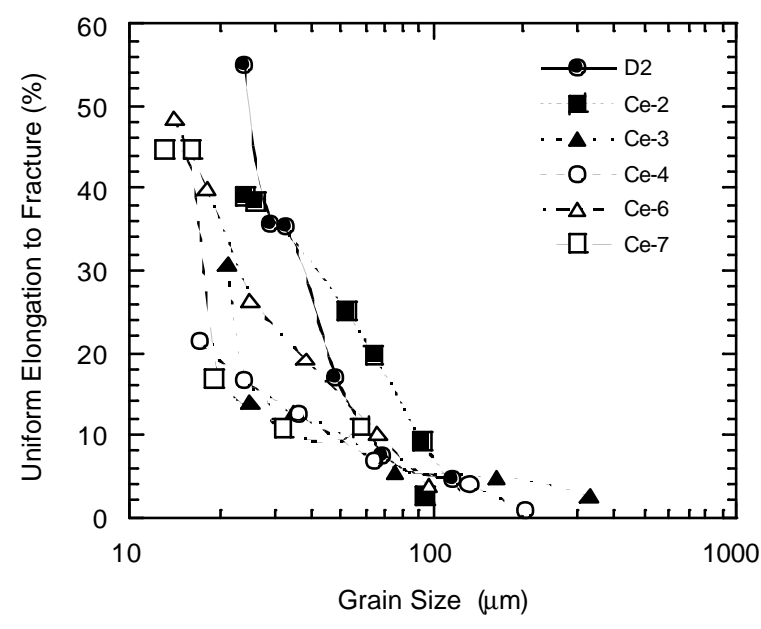

Fig. 34. Variation of impact ductility with grain size (impact test temperature was $980 \mathrm{EC}$ ).

mode at high annealing temperatures (i.e., 1700EC and above). Figure 35 shows the typical fracture surfaces of all six alloys after a 1-hour anneal at 1500EC and tensile impact testing at 980EC. In the intermediate temperature range, the fracture mode for all the alloys changed from mixed intergranular and transgranular cleavage to predominantly intergranular fracture with increasing annealing temperature.

Figure 36 is a plot of the change in the amount of transgranular fracture with impact ductility. It shows a broad correlation between fracture mode and impact ductility. In general, higher ductilities at low annealing temperatures were associated with transgranular fracture, and lower ductilities at high annealing temperatures were associated with intergranular fracture. 
(a)

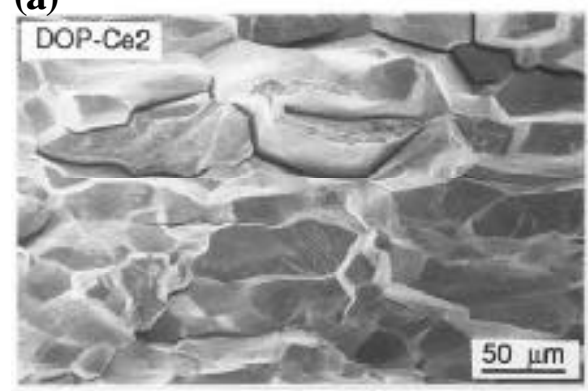

(c)

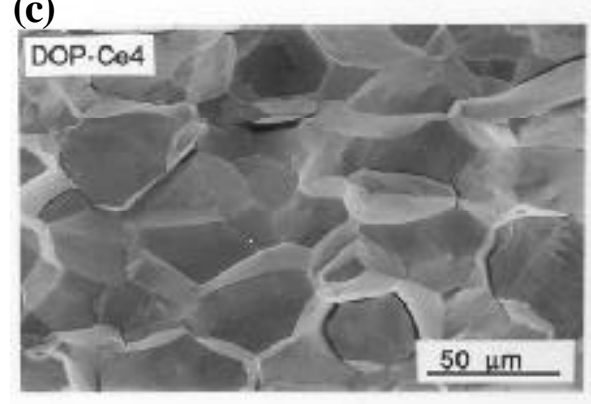

(e)

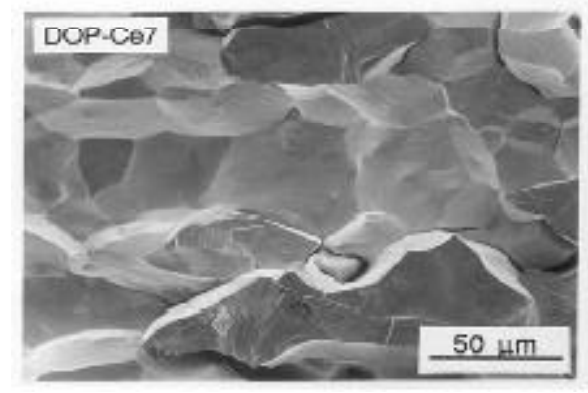

(b)

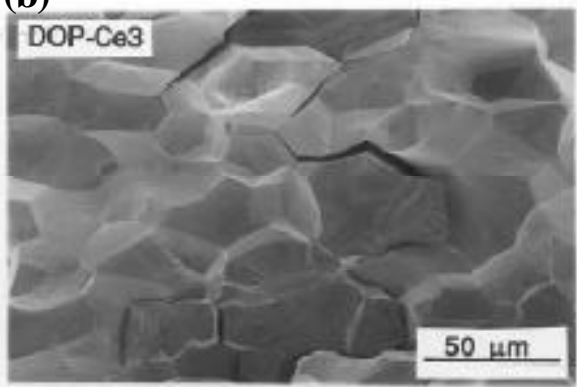

(d)

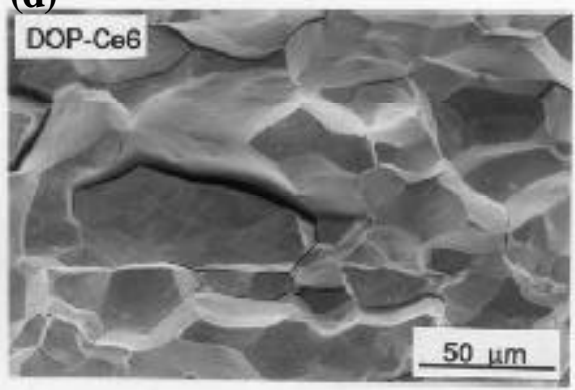

(f)

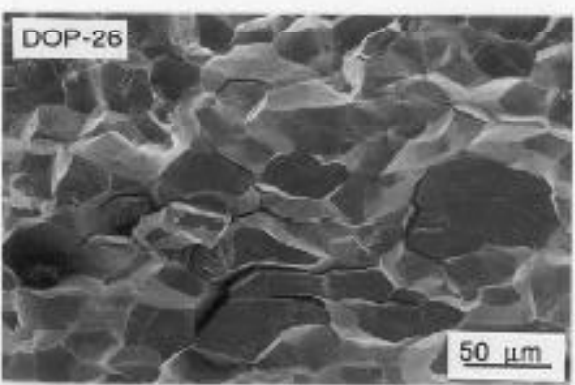

Fig. 35. Fracture surfaces of (a) Ce-2, (b) Ce-3, (c) Ce-4, (d) Ce-6, (e) Ce-7, and (f) DOP-26 annealed for $1 \mathrm{~h}$ at $1500 \mathrm{EC}$ and impact tested at $980 \mathrm{EC}$.

Fig. 36. Amount of transgranular fracture area as a function of impact ductility.

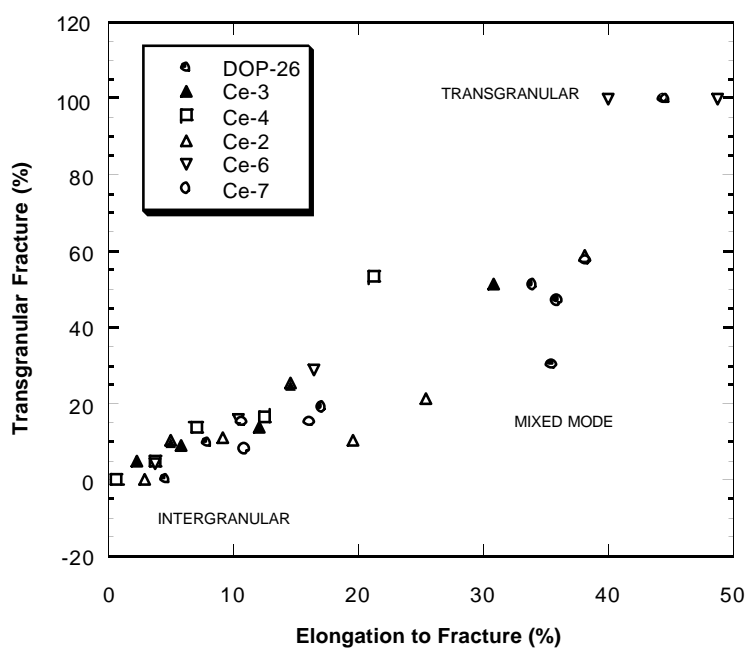


As shown earlier in Fig. 3, DOP-26, Ce-3, Ce-4, and Ce-6 had similar grain sizes after a 1-hour anneal at $1500 \mathrm{EC}$. The measured values of grain size (transverse to the rolling direction) ranged from 25 to $36 \mathrm{Fm}$. Figure 37 and Table XIX show the variation of impact ductility with test temperature for these alloys. The two cerium-doped alloys (Ce-3 and Ce-4) exhibited similar variations in ductility with temperature (although Ce-4 had somewhat higher ductilities than Ce-3). For both alloys there was a steep increase in ductility with test temperatures between 1000 and 1200EC (i.e., a BDTT at around 1000EC). The impact ductility became less sensitive to test temperatures below $\sim 1000 \mathrm{EC}$ and above $\sim 1200 \mathrm{EC}$. A broadly similar behavior was observed in the thorium-doped alloy (DOP-26), and the (Ce+Th)-doped alloy (Ce-6); however, the BDTT in these alloys occurred at approximately 800EC, about 200EC lower than that of the ceriumdoped alloys. Below this transition temperature, the ductilities of DOP-26 and Ce-6 were comparable to that of the ceriumdoped $\mathrm{Ce}-3$ and $\mathrm{Ce}-4$ iridium. Above the transition temperature, the ductilities of DOP-26 and Ce-6 were consistently higher than those of $\mathrm{Ce}-3$ and $\mathrm{Ce}-4$.

Figure 38 shows the typical fracture surfaces of the four alloys at low and high test temperatures. In general, the fracture mode changed from predominantly intergranular at low temperatures $(800 \mathrm{EC}$ and

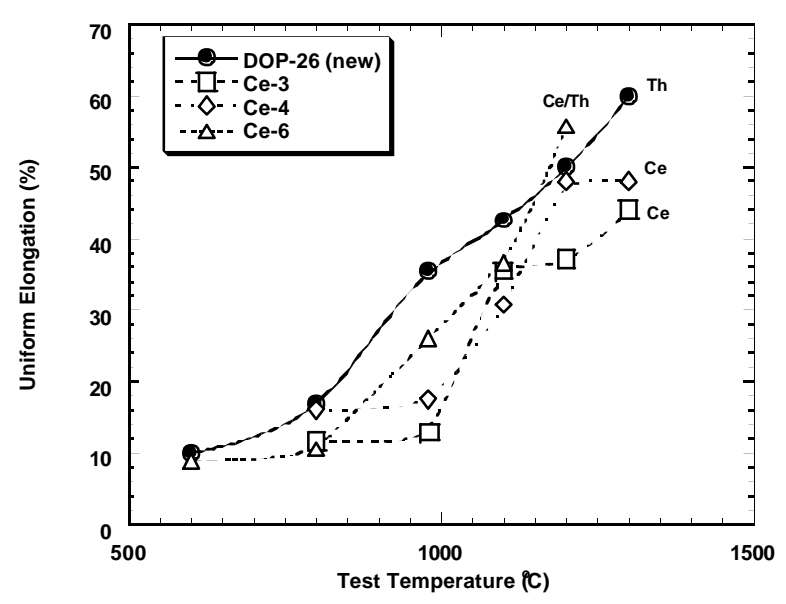

Fig. 37. Variation of impact ductility with test temperature for cerium-, thorium-, and $\mathrm{Ce} / \mathrm{Th}$ doped alloys (all alloys possess a similar grain size of 30 to 35 Fm).

Table XIX. Effect of test temperature on tensile impact ductility of Ce/Th-doped alloys

\begin{tabular}{|c|c|c|c|c|c|c|}
\hline \multicolumn{2}{|c|}{ Test temperature } & \multicolumn{5}{|c|}{ Elongation to fracture $(\%)^{a}$} \\
\hline${ }^{\circ} \mathrm{C}$ & $\mathrm{K}$ & $\begin{array}{c}\text { DOP-26 } \\
\text { (new process) }\end{array}$ & $\begin{array}{c}\text { DOP- } 26^{b} \\
\text { (old process) }\end{array}$ & $\mathrm{Ce}-3$ & $\mathrm{Ce}-4$ & $\mathrm{Ce}-6$ \\
\hline 600 & 873 & 10.0 & -- & -- & -- & 8.8 \\
\hline 800 & 1073 & 16.4 & 10.5 & 11.5 & 16.0 & 10.6 \\
\hline 850 & 1123 & 16.5 & 13.0 & -- & -- & -- \\
\hline 980 & 1253 & 35.9 & 20.7 & 12.8 & 17.5 & 26.0 \\
\hline 1050 & 1323 & 32.2 & 27.9 & -- & -- & -- \\
\hline 1100 & 1373 & 39.9 & 43.2 & 35.4 & 30.7 & 36.6 \\
\hline 1200 & 1473 & 50.0 & -- & 37.0 & 48.0 & 55.8 \\
\hline 1300 & 1573 & 59.8 & -- & 44.0 & 48.0 & -- \\
\hline
\end{tabular}

${ }^{a}$ Tensile impact tested at a strain rate of $\sim 10^{3} \mathrm{~s}^{-1}$.

${ }^{b}$ Data for DOP-26 was taken from Refs. 30 and 37. 

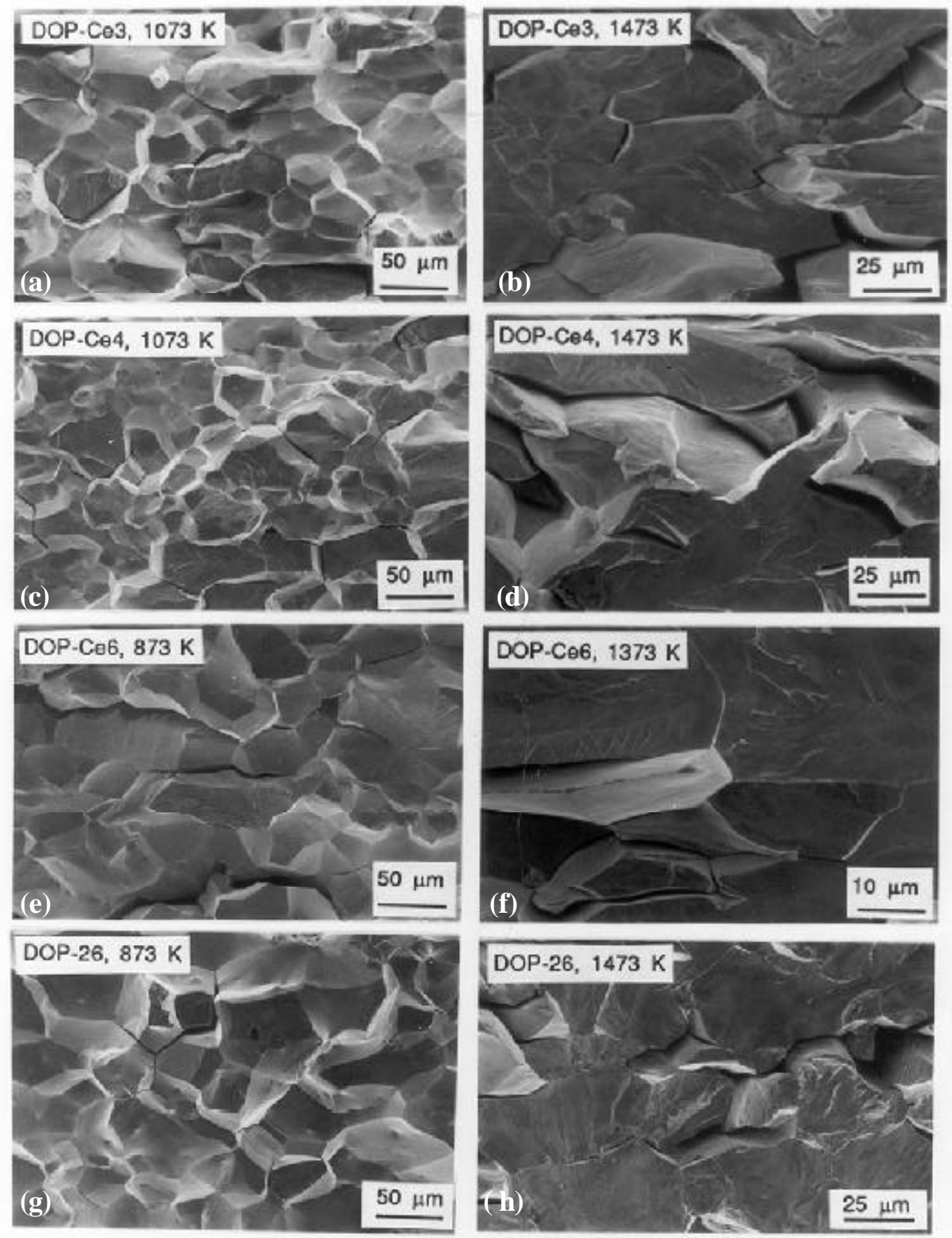

Fig. 38. Fracture surfaces of (a,b) Ce-3, (c,d) Ce-4, (e,f) Ce-6, and (g,h) DOP-26 at low and high test temperatures, all annealed $1 \mathrm{~h}$ at 1500EC.

below) to transgranular at high temperatures (1200EC in DOP-26, Ce-3, and Ce-4, and 1100EC in Ce-6). In the intermediate temperature range, the fracture mode changed from mixed intergranular and transgranular cleavage to predominantly transgranular cleavage with increasing test temperatures. Figure 39 shows this change in the amount of transgranular fracture with test temperature. There is a good correlation between fracture mode and test temperature. As observed before, low ductilities were associ- 
ated with intergranular fracture at low test temperatures and high ductilities with transgranular fracture at elevated temperatures.

Figure 40 summarizes the temperature dependence of the yield and ultimate strengths of the I-1 alloy (containing 29 ppm Ce and 18 ppm $\mathrm{Th}$ ) tensile tested at a conventional strain rate of $\sim 10^{-3} \mathrm{~s}^{-1}$. Also included in the figure are data for DOP-26 iridium [20] which, as mentioned before, is the currently used alloy.

Within experimental scatter, the temperature dependencies of the strengths of the two alloys aresimilar. Below $\sim 20 \bar{E} \mathrm{C}$, the yield and

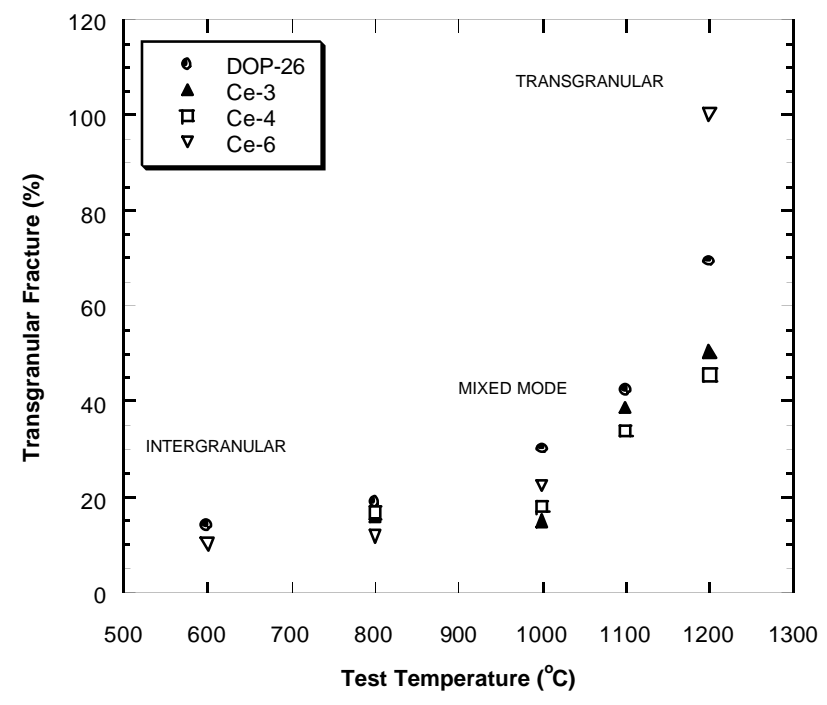

Fig. 39. Amount of transgranular fracture area as a function of test temperature.

ultimate strengths are roughly independent of temperature. The work hardening rate is high, as evidenced by the large difference between the yield and ultimate strengths. Above 200EC, the yield strength drops only moderately, but the ultimate strength drops sharply. As a result, the work hardening rate decreases dramatically with increasing temperature.

Figure 41 shows the temperature dependencies of the ductilities of the I-1 and DOP-26 alloys. For comparison, ductilities of pure iridium and Ir-0.3W alloys, measured in earlier studies [20], are also

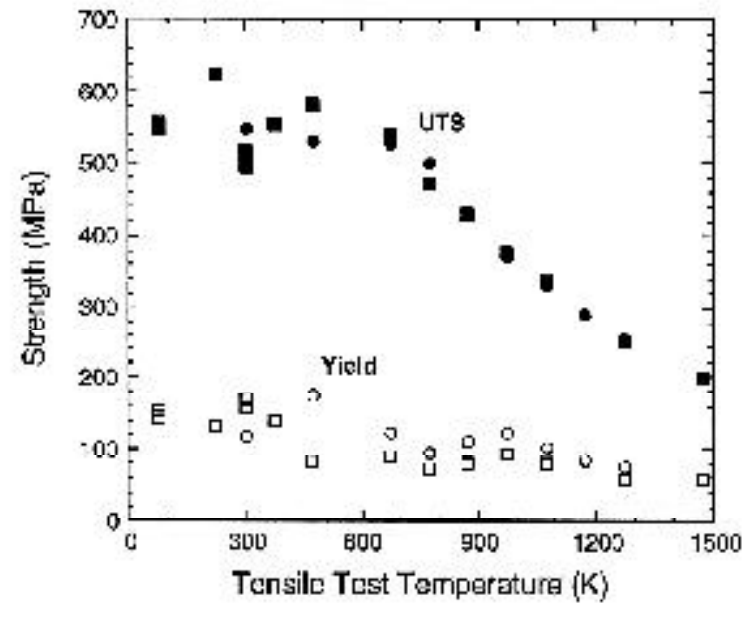

Fig. 40. Temperature dependence of the yield and ultimate tensile strengths of $\mathrm{Ce} / \mathrm{Th}$ doped alloy I-1 (squares) and DOP-26 (circles), tensile tested at a conventional strain rate $\left(\sim 10^{-3} \mathrm{~s}^{-1}\right)$.

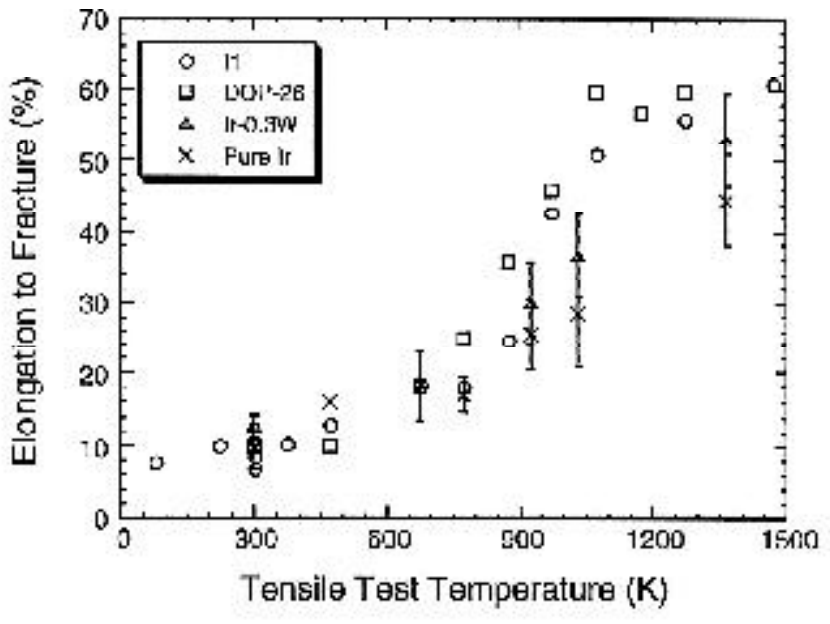

Fig. 41. Temperature dependence of the ductilities of Ce/Th-doped alloy I-1 (squares) and DOP-26 (circles) compared to Ir-0.3W [20] and pure iridium [20], tensile tested at a conventional strain rate $\left(\sim 10^{-3} \mathrm{~s}^{-1}\right)$. 
included. Below $\sim 200 \mathrm{EC}$ the ductilities of all four alloys are comparable; they are all relatively brittle, independent of temperature and composition. Above this temperature ductility increases sharply, from $<10 \%$ at temperatures below $200 \mathrm{EC}$ to $\sim 60 \%$ at temperatures above $700 \mathrm{EC}$, with the I-1 and DOP-26 alloys exhibiting somewhat more ductility at elevated temperatures than pure iridium and Ir- $0.3 \mathrm{~W}$. Pure iridium and Ir- $0.3 \mathrm{~W}$ behave similarly, indicating that macroalloying with $0.3 \% \mathrm{~W}$ does not degrade the ductility of iridium. However, since the ductilities of I-1 and DOP-26 are higher, it suggests that microalloying with thorium (DOP-26) or thorium plus cerium (I-1) is beneficial for ductility. Below the BDTT, fracture is mixed intergranular/transgranular [as shown in Fig. 42(a) for I-1 tested at 400EC], whereas above it there is a change in the fracture mode to almost 100\% transgranular [Fig. 42(b)], along with some necking of the cross section. This brittle-to-ductile transition we believe is a result mainly of the dramatically lower work hardening rate at elevated temperatures, rather than the modestly lower yield strength (especially since much of the ductility improvement takes place above the temperature at which most of the yield strength drop occurs).

Figure 43 and Table XX show the temperature dependence of the ductilities of the cerium-doped I101 through I-107 heats of DOP-40 tensile tested at the high strain rate $\left(\sim 10^{3} \mathrm{~s}^{-1}\right)$ after 1-h anneals at $1500 \mathrm{EC}$. At tensile test temperatures $<900 \mathrm{EC}$, the alloys are all relatively brittle and fracture predominantly intergranularly [Fig. 44(a)]. At elevated temperatures (above 1100 EC) the alloys are ductile and fracture transgranularly with considerable necking [Fig. 44(c)]. In the intermediate temperature regime, the alloys undergo a brittle-to-ductile transition and fracture by mixed intergranular/transgranular cleavage [Fig. 44(b)]. The increase in the BDTT is $\sim 400 \mathrm{EC}$ for a $10^{6}$ increase in strain rate (cf. Figs. 41 and 43).

Figure 45 and Table XXI show the effect of annealing temperature on the ductility of the I-101 to I107 heats of DOP-40 tensile tested at 1000EC and DOP-26 alloys tensile tested at 980EC [30] at a strain
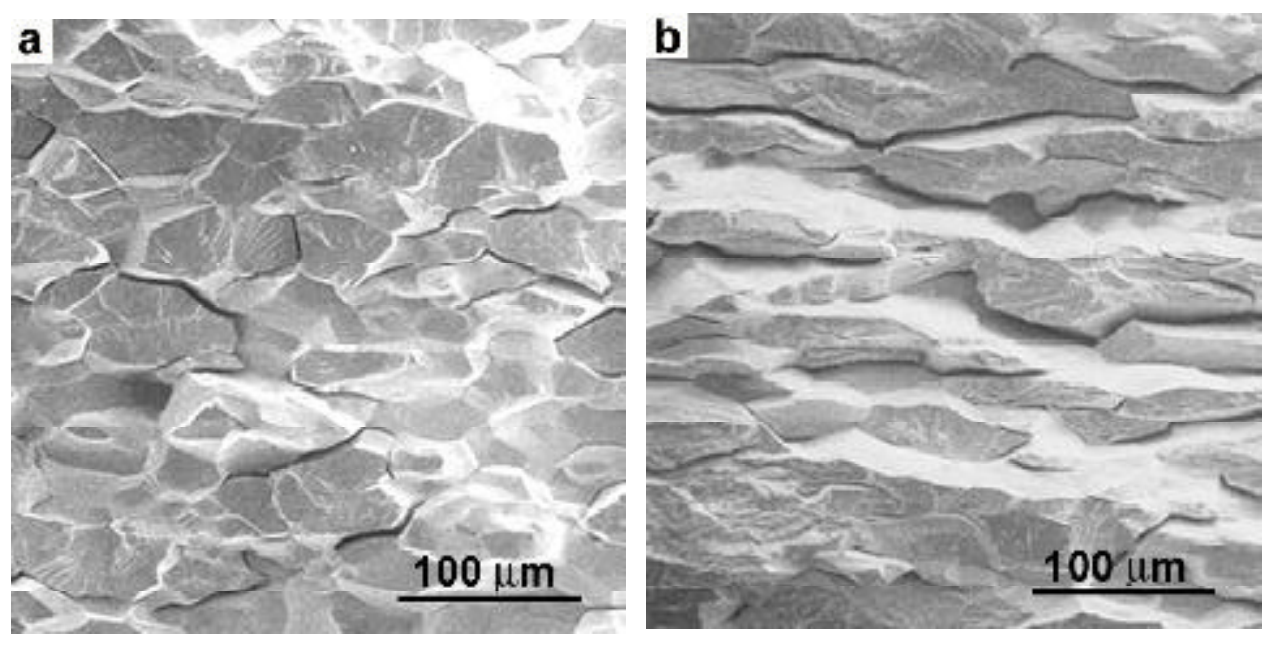

Fig. 42. Fracture surface of $I-1$ alloy tensile tested at the conventional strain rate $\left(\sim 10^{-3} \mathrm{~s}^{-1}\right)$ at (a) 400 and (b) $700 \mathrm{EC}$. 
rate of $\sim 10^{3} \mathrm{~s}^{-1}$. The sharp drop in ductility is the result of increasing grain size with increasing annealing temperature. For both DOP-26 and DOP-40 significant grain growth begins at approximately 1400EC .

For annealing temperatures below $1500 \mathrm{EC}$, ductility of the DOP-26 alloy falls roughly within the scatter band of the DOP-40 data but, at higher temperatures, its ductility is at the lower end of the ductility range of the DOP-40 alloys.

Liu et al. [5,44] derived the following expression for fracture strain using a dislocation pile-up model for the stress concentration at grain boundaries:

$$
\varepsilon_{\mathrm{f}}=\left(\sigma_{\mathrm{o}}-\sigma_{\mathrm{i}}\right) / k+\left(\sigma_{\mathrm{c}} / k\right)(s / d)^{1 / 2}
$$

where $\varepsilon_{\mathrm{f}}$ is the true fracture strain, $\sigma_{\mathrm{o}}$ is the frictional stress against the motion of dislocations on slip planes, $k$ and $\sigma_{\mathrm{i}}$ are materials constants in the constitutive stress-strain relationship, $d$ is the grain diameter, $s$ is the distance to the tip of the pile-up, and $\sigma_{c}$ is the grain-boundary cohesive strength. According to this expression, a plot of fracture strain versus the reciprocal square root of grain size will be a straight line whose slope is proportional to the grain-boundary cohesive

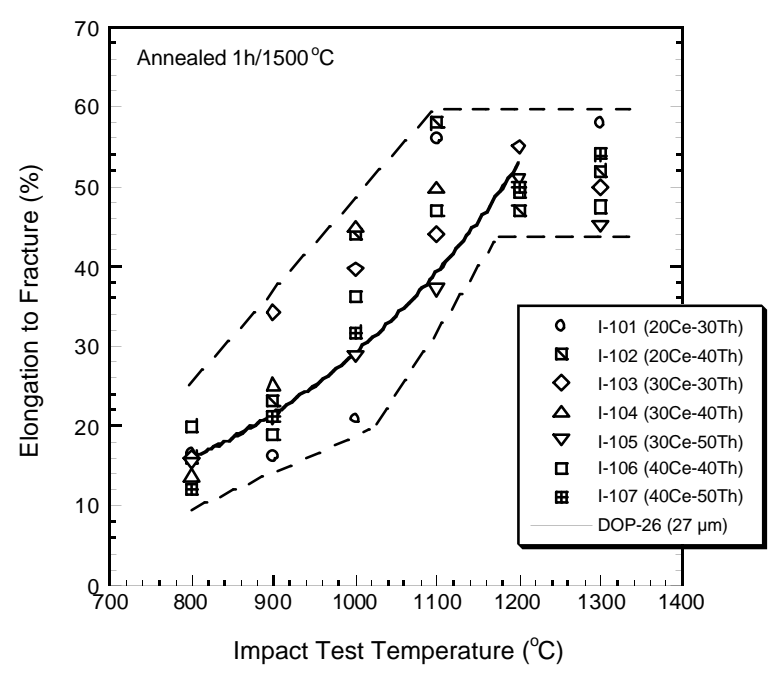

Fig. 43. Temperature dependence of the ductilities of DOP-40 alloys and DOP-26 [30] tensile tested at the high strain rate $\left(\sim 10^{3} \mathrm{~s}^{-1}\right)$.

Table XX. Effect of test temperature on tensile impact ductility of Ce/Th-doped heats I-101 through I-107

\begin{tabular}{|c|c|c|c|c|c|c|c|c|c|}
\hline \multicolumn{2}{|c|}{ Test temperature } & \multicolumn{8}{|c|}{ Elongation to fracture $(\%)^{a}$} \\
\hline${ }^{\circ} \mathrm{C}$ & $\mathrm{K}$ & DOP- $26^{b}$ & $\mathrm{I}-101$ & I-102 & $\mathrm{I}-103$ & $\mathrm{I}-104$ & $\mathrm{I}-105$ & I-106 & I-107 \\
\hline 800 & 1073 & 16.4 & 16.5 & 16.1 & 16.1 & 13.9 & 15.3 & 20.0 & 12.2 \\
\hline 850 & 1123 & 16.5 & -- & -- & -- & -- & -- & -- & -- \\
\hline 900 & 1173 & 19.6 & 16.2 & 23.1 & 34.3 & 25.3 & 21.0 & 18.9 & 21.2 \\
\hline 980 & 1253 & 35.9 & -- & -- & -- & -- & -- & -- & -- \\
\hline 1000 & 1273 & -- & 21.0 & 44.0 & 39.7 & 45.0 & 28.8 & 36.3 & 31.8 \\
\hline 1050 & 1323 & 32.2 & -- & -- & -- & -- & -- & -- & -- \\
\hline 1100 & 1373 & 39.9 & 56.0 & 58.0 & 40.0 & 50.0 & 37.0 & 47.0 & -- \\
\hline 1200 & 1473 & 50.0 & 49.0 & 47.0 & 55.0 & -- & 51.0 & 49.2 & 50.0 \\
\hline 1300 & 1573 & 59.8 & 58.0 & 52.0 & 50.0 & -- & 45.0 & 47.5 & 54.0 \\
\hline
\end{tabular}

${ }^{a}$ Tensile impact tested at a strain rate of $\sim 10^{3} \mathrm{~s}^{-1}$.

${ }^{b}$ Data for DOP-26 (new process) was taken from Refs. 30 and 37. 

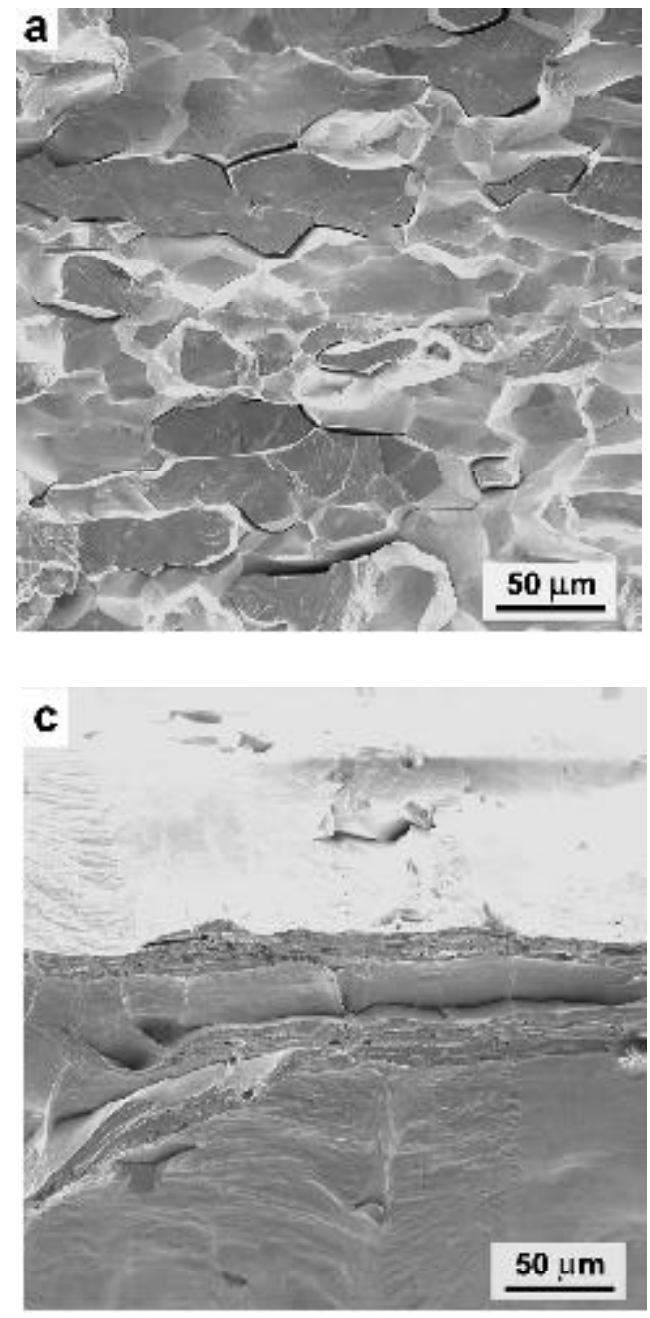

strength. In addition, the effectiveness with which different dopants affect the grain boundary cohesion can be inferred from the plot by comparing the slopes obtained for different alloys.

Figure 46 shows such a plot for the $\mathrm{Ce}-2$ through Ce-7 heats of DOP-40 and for the D2 heat of DOP-26. The plot shows that alloys doped with only cerium (Ce-3 and $\mathrm{Ce}-4)$ have lower slopes than alloys doped with either thorium (DOP-26) or cerium plus thorium (Ce2, Ce-6, and $\mathrm{Ce}-7)$. This indicates that cerium

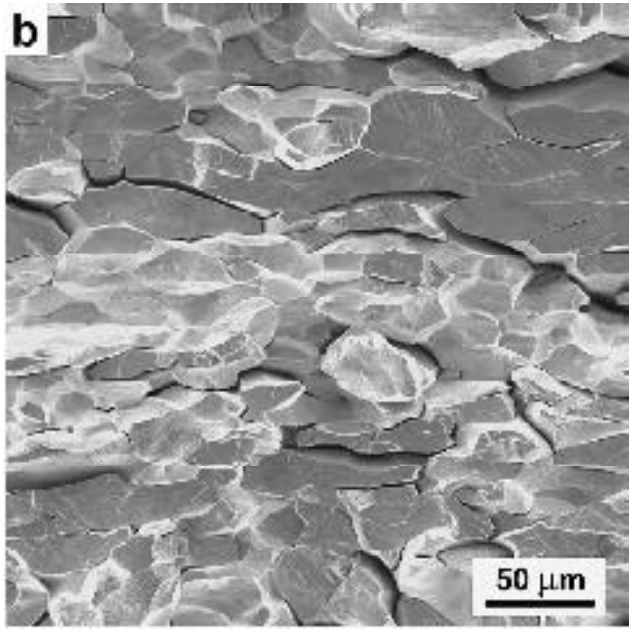

Fig. 44. Fracture surfaces of the I-106 alloy tensile tested at high strain rate $\left(\sim 10^{3} \mathrm{~s}^{-1}\right)$ at (a) 800, (b) 1000, and (c) 1300EC (the other DOP40 alloys looked similar).

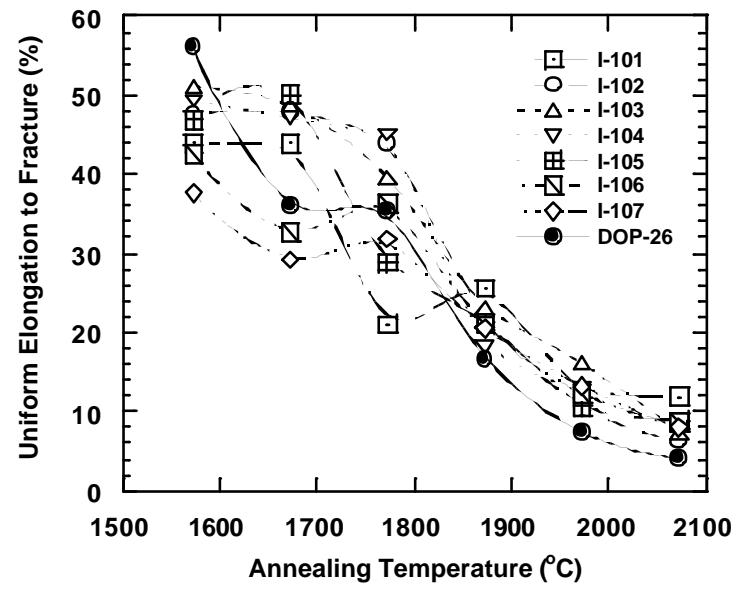

Fig. 45. Effect of annealing temperature on the ductility of DOP-40 alloys and DOP-26 [30] tensile tested at 1000EC at a strain rate of $\sim 10^{3} \mathrm{~s}^{-1}$. 
Table XXI. Effect of annealing temperature on tensile impact ductility of Ce/Th-doped heats I-101 through I-107

\begin{tabular}{|c|c|c|c|c|c|c|c|c|c|}
\hline \multicolumn{2}{|c|}{$\begin{array}{l}\text { Annealing } \\
\text { temperature }\end{array}$} & \multicolumn{8}{|c|}{ Elongation to fracture $(\%)^{a}$} \\
\hline${ }^{\circ} \mathrm{C}$ & $\mathrm{K}$ & DOP- $26^{b}$ & $\mathrm{I}-101$ & $\mathrm{I}-102$ & $\mathrm{I}-103$ & $\mathrm{I}-104$ & $\mathrm{I}-105$ & I-106 & $\mathrm{I}-107$ \\
\hline 1300 & 1573 & 56.0 & 43.9 & 47.4 & 51.1 & 49.3 & 46.8 & 42.5 & 37.7 \\
\hline 1400 & 1673 & 35.9 & 43.9 & 47.8 & 48.8 & 47.2 & 50.1 & 32.7 & 29.2 \\
\hline 1500 & 1773 & 35.4 & 21.0 & 44.0 & 39.7 & 45.0 & 28.8 & 36.3 & 31.8 \\
\hline 1600 & 1873 & 16.9 & 25.6 & 22.0 & 23.0 & 18.1 & 21.2 & 21.0 & 20.5 \\
\hline 1700 & 1973 & 7.7 & 12.7 & 10.6 & 16.1 & 12.3 & 10.6 & 12.2 & 13.2 \\
\hline 1800 & 2073 & 4.7 & 11.9 & 6.2 & 7.3 & 8.0 & 8.9 & 8.6 & 8.0 \\
\hline
\end{tabular}

${ }^{a}$ Tensile impact tested at $1000^{\circ} \mathrm{C}$ at a strain rate of $\sim 10^{3} \mathrm{~s}^{-1}$.

${ }^{b}$ Data for DOP-26 was taken from Ref. 30 for specimens tested at $980^{\circ} \mathrm{C}$.

is not as effective as thorium in improving the grain boundary cohesion of iridium. The slopes of Ce-2, Ce-6 and Ce-7 are comparable to that of DOP-26. Therefore, variations in the thorium content between 12 and 60 wppm (10-50 appm) have no significant effect on the grain boundary cohesion of iridium alloys. This is not surprising since it was earlier shown that as little as 5 wppm thorium can saturate the grain boundaries of iridium [45]. Thus, additional thorium beyond that needed for saturating the grain boundaries may not significantly improve the grain boundary cohesion. The role of additional thorium (or cerium) beyond the saturation limit is principally to refine the grain size. In DOP-26, thorium performs both functions [5,18,31]. In the DOP-40 alloys, thorium is still required to provide adequate grain boundary cohesion, but, as shown in Fig. 46, its level can be reduced to as low as 12 wppm (10 appm). Grain refinement results mainly from the addition of cerium, which precipitates as $\operatorname{Ir}_{5} \mathrm{Ce}$ and pins the grain boundaries.

Table XXII gives the impact results obtained from testing of heats Ce- 6 and Ce-7 under conditions used for qualifying the current generation of DOP-26 iridium alloys. Also included in the table are the data previously obtained on DOP-26 (with 60 wppm Th) [46]. All test samples were given a 19-h anneal at $1500 \mathrm{EC}$ and were impact tested at $980 \pm 10 \mathrm{EC}$ with a bullet velocity of $61 \pm 3 \mathrm{~m} / \mathrm{s}$. The average impact 
Table XXII. Results from impact testing of Ce/Th-doped iridium alloys ${ }^{a}$

\begin{tabular}{|c|c|c|c|c|}
\hline \multirow{2}{*}{ Alloy } & \multicolumn{2}{|c|}{ Bulk Dopant Concentration } & \multirow{2}{*}{ Number of Tests } & \multirow{2}{*}{$\begin{array}{l}\text { Avg. Impact Ductility } \\
(\%)\end{array}$} \\
\hline & wppm & appm & & \\
\hline $\mathrm{Ce}-6$ & $29 \mathrm{Ce}+12 \mathrm{Th}$ & $40 \mathrm{Ce}+10 \mathrm{Th}$ & 9 & $20 \pm 4$ \\
\hline $\mathrm{Ce}-7$ & $22 \mathrm{Ce}+24 \mathrm{Th}$ & $30 \mathrm{Ce}+20 \mathrm{Th}$ & 6 & $18 \pm 3$ \\
\hline DOP-26 & 60Th & $50 \mathrm{Th}$ & 31 & $23 \pm 5$ \\
\hline
\end{tabular}

${ }^{a}$ Test conditions: specimens vacuum annealed $19 \mathrm{~h}$ at $1500^{\circ} \mathrm{C}$, tested at $980^{\circ} \mathrm{C}$, bullet velocity of $61 \mathrm{~m} / \mathrm{s}$.

ductilities of Ce-6 and Ce-7 are comparable to that of the DOP-26 alloy, consistent with our conclusion that as little as 12 wppm (10 appm) Th is all that is needed for adequate grain boundary cohesion and that grain refinement can be achieved by cerium additions.

Figure 47 shows a separate plot of grain size versus elongation to fracture for the I-101 through I-107 heats of DOP-40 containing 20-40 wppm Ce and 30-50 wppm Th. Within experimental scatter, a single straight line can be used to fit the data for these seven DOP-40 alloys. The slope of this line is similar to that for DOP-26 iridium [30], suggesting (as above) that the grain-boundary cohesive strength of DOP-40 is similar to that of DOP-26. In these most recent DOP-40 alloys, the radioactive thorium content in DOP-26 has been reduced (by a third), without sacrificing high-temperature strength or ductility. Cerium additions provide the beneficial effect of grain refinement, which compensates for the reduced thorium in these alloys. Based on these results, DOP-40 alloys containing $30 \pm 10 \mathrm{wppm} \mathrm{Ce}$ and $40 \pm 10 \mathrm{wppm}$ Th are expected to behave comparably to currently used DOP-26 iridium.

Table XXIII gives the results of Auger analyses from the grain boundary segregation studies conducted by earlier investigators [3437] of heats $\mathrm{Ce}-2, \mathrm{Ce}-3, \mathrm{Ce}-6$, and Ce-7. The grain boundary concentrations of cerium and thorium given in Table XXIII show that the cerium level at the grain boundaries drops significantly with small additions of thorium, whereas the thorium level is not affected by adding cerium. Cerium was found to segregate more strongly than thorium to the grain boundaries. In addition, cerium, when added together with thorium, segregates and saturates the grain boundaries at a lower level than when it is added alone. In contrast, thorium segregates independently irrespective of the bulk cerium

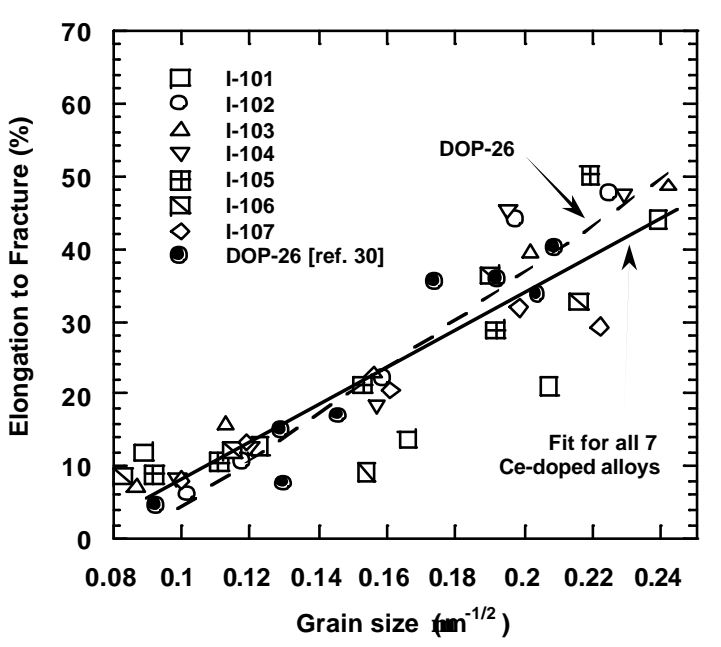

Fig. 47. Tensile ductility of the I-101 through I107 DOP-40 alloys and DOP-26 as a function of the inverse square root of grain size (tensile tested at $1000 E C$ and a strain rate of $\sim 10^{3} \mathrm{~s}^{-1}$ ). 
Table XXIII. Results from Auger analysis of grain boundaries in various iridium alloys

\begin{tabular}{|c|c|c|c|c|c|c|}
\hline \multirow{2}{*}{ Alloy } & \multicolumn{2}{|c|}{ Bulk dopant concentration } & \multicolumn{2}{|c|}{ Heat treatment } & \multicolumn{2}{|c|}{ Grain boundary concentration } \\
\hline & wppm & appm & Duration (h) & Temperature $\left({ }^{\circ} \mathrm{C}\right)$ & Th (at.\%) & Ce (at.\%) \\
\hline DOP-26 & $60 \mathrm{Th}$ & $50 \mathrm{Th}$ & 24 & 1227 & $2.0 \pm 0.4$ & -- \\
\hline $\mathrm{Ce}-3$ & $36 \mathrm{Ce}$ & $50 \mathrm{Ce}$ & 24 & 1227 & -- & $12.4 \pm 2.5$ \\
\hline $\mathrm{Ce}-2$ & $36 \mathrm{Ce}+60 \mathrm{Th}$ & $50 \mathrm{Ce}+50 \mathrm{Th}$ & 10 & 1327 & $0.9 \pm 0.3$ & $8.3 \pm 1.1$ \\
\hline $\mathrm{Ce}-6$ & $29 \mathrm{Ce}+12 \mathrm{Th}$ & $40 \mathrm{Ce}+10 \mathrm{Th}$ & 21 & 1227 & $1.2 \pm 0.3$ & $7.6 \pm 1.2$ \\
\hline $\mathrm{Ce}-7$ & $22 \mathrm{Ce}+24 \mathrm{Th}$ & $30 \mathrm{Ce}+20 \mathrm{Th}$ & 21 & 1227 & $1.7 \pm 0.4$ & $7.4 \pm 1.6$ \\
\hline
\end{tabular}

concentration. Results of the Auger analyses, in conjunction with the impact results, show that as little as 12 wppm of thorium in the bulk is sufficient to saturate the grain boundaries, and that thorium concentration at the grain boundaries of around 1 at.\% is sufficient to obtain adequate grain boundary cohesion.

\section{WELDABILITY}

The results of Sigmajig weldability tests on cerium-doped alloys are given in Table XXIV. Also included for comparison are the results for average values of threshold stresses for old- and new-process DOP-26 [47]. The Ce-3 heat, which has nominally the same atomic percent of cerium (50 appm or 36 wppm) as the amount of thorium in DOP-26 (50 appm or $60 \mathrm{wppm}$ ), has a threshold stress for cracking in excess of $170 \mathrm{MPa}$. This compares very favorably with the average threshold stresses obtained for oldand new-process DOP-26 (100 and $130 \mathrm{MPa}$, respectively). A possible explanation for this can be found by comparing the iridium-cerium and iridium-thorium phase diagrams (Fig. 48 [31]), which are quite similar at the iridium-rich end. Therefore, one would expect the microstructures of cerium-containing and thorium-containing alloys to be similar: both would contain $\operatorname{Ir}_{5} \mathrm{X}(\mathrm{X}=\mathrm{Ce}$ or $\mathrm{Th})$ intermetallic precipitates in the recrystallized state, and both would form $\operatorname{Ir}_{-} \operatorname{Ir}_{5} \mathrm{X}$ eutectics during welding. And, indeed, transmission electron microscopy has identified the precipitates in an Ir- $0.3 \mathrm{~W}$ alloy doped with 50 appm $\mathrm{Ce}(36 \mathrm{wppm})$ as $\mathrm{Ir}_{5} \mathrm{Ce}$ [34]. It is likely, therefore, that the mechanism of hot cracking in cerium-doped iridium alloys is similar to that which has been proposed for thorium-doped iridium alloys, namely the formation of a low-melting eutectic. Thus, a possible explanation for the better weldability of heats Ce-3, -6 , and -7 (each containing little or no thorium) as compared to DOP-26 is that the $\operatorname{Ir}_{-} \mathrm{Ir}_{5}$ Ce eutectic

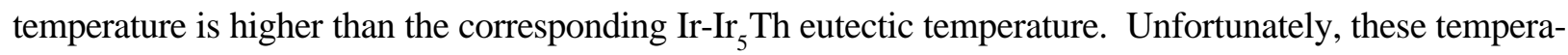
tures are not currently known (see dotted lines in Fig. 48), and we can only speculate at this time.

Interestingly, increasing the amount of cerium to 100 appm (73 wppm) dramatically lowers the threshold stress for cracking to below $70 \mathrm{MPa}$ (Ce-4 in Table XXIV). A similar drop in weldability is seen in heat Ce-2 when 50 appm Ce (36 wppm) is added in combination with 50 appm Th (60 wppm). In 
Table XXIV. Threshold stresses for weld cracking in cerium- and Ce/Th-doped iridium alloys

\begin{tabular}{|c|c|c|c|c|c|}
\hline \multirow{2}{*}{ Alloy } & \multicolumn{2}{|c|}{ Ce concentration } & \multicolumn{2}{|c|}{ Th concentration } & \multirow{2}{*}{$\begin{array}{l}\text { Threshold stress for } \\
\text { cracking (MPa) }\end{array}$} \\
\hline & wppm & appm & wppm & appm & \\
\hline Ce-2 (13935) & 36 & 50 & 60 & 50 & $<70$ \\
\hline Ce-3 (E809) & 36 & 50 & 0 & 0 & $>170$ \\
\hline Ce-4 (E808) & 73 & 100 & 0 & 0 & $<70$ \\
\hline Ce-6 (E814) & 29 & 40 & 12 & 10 & $>210$ \\
\hline Ce-7 (E815) & 22 & 30 & 24 & 20 & $>210$ \\
\hline E818 (+100 appm B) & 22 & 30 & 24 & 20 & $>10,<100$ \\
\hline E819 (+10 appm Y) & 15 & 20 & 24 & 20 & $<140$ \\
\hline $\begin{array}{c}\mathrm{E} 820(+10 \text { appm Y }+ \\
100 \text { appm B })\end{array}$ & 15 & 20 & 24 & 20 & $>10,<100$ \\
\hline I-101 & 20 & 27 & 30 & 25 & $85-100$ \\
\hline $\mathrm{I}-102$ & 20 & 27 & 40 & 33 & $\sim 75$ \\
\hline $\mathrm{I}-103$ & 30 & 41 & 30 & 25 & $\sim 75$ \\
\hline $\mathrm{I}-104$ & 30 & 41 & 40 & 33 & $>70,<100$ \\
\hline $\mathrm{I}-105$ & 30 & 41 & 50 & 41 & $\sim 70$ \\
\hline $\mathrm{I}-106$ & 40 & 55 & 40 & 33 & $<55$ \\
\hline $\mathrm{I}-107$ & 40 & 55 & 50 & 41 & $>55,<80$ \\
\hline DOP-26 (old process) & 0 & 0 & 60 & 50 & 100 \\
\hline DOP-26 (new process) & 0 & 0 & 60 & 50 & 130 \\
\hline
\end{tabular}

other words, although cerium is better than thorium at levels of around 50 appm (which is the level of thorium in DOP-26), at higher levels of around 100 appm it appears to become deleterious (like thorium [48]). To have good weldability, therefore, cerium plus thorium should be kept around 50 appm. And, indeed, when that is done (heats Ce-6 and -7), the threshold stress for cracking is found to be >210 MPa, which is significantly higher than that for DOP-26. These results, along with the effects of thorium content on weldability, are plotted in Fig. 49. While the same trend appears to hold at higher dopant concentrations, additional data are required before the precise dependence of threshold stresses on cerium (and cerium plus thorium) content can be determined. Clearly, however, alloys doped with cerium and thorium should be investigated further, especially since their impact ductilities are comparable to those of DOP-26.

Only one or two blanks were available for weldability testing of the I-101 through I-107 series of DOP-40 heats. The results on these compositions are also included in Table XXIV and Fig. 49. Arrows in Fig. 49 indicate the trends of the data at compositions where there were not enough blanks available to pinpoint accurately the range of the threshold cracking stress. The results on this series of alloys were qualitatively in agreement with the results described above for the Ce-2 to $\mathrm{Ce}-7$ series.

Finally, consider the weldability of Ir- $0.3 \mathrm{~W}$ alloys doped with $\mathrm{Ce}+\mathrm{Th}+\mathrm{Y}, \mathrm{Ce}+\mathrm{Th}+\mathrm{B}$, and $\mathrm{Ce}+\mathrm{Th}+\mathrm{Y}+\mathrm{B}$ (E819, E818, and E820, respectively, in Table XXIV). The threshold stress for cracking in 
(a)

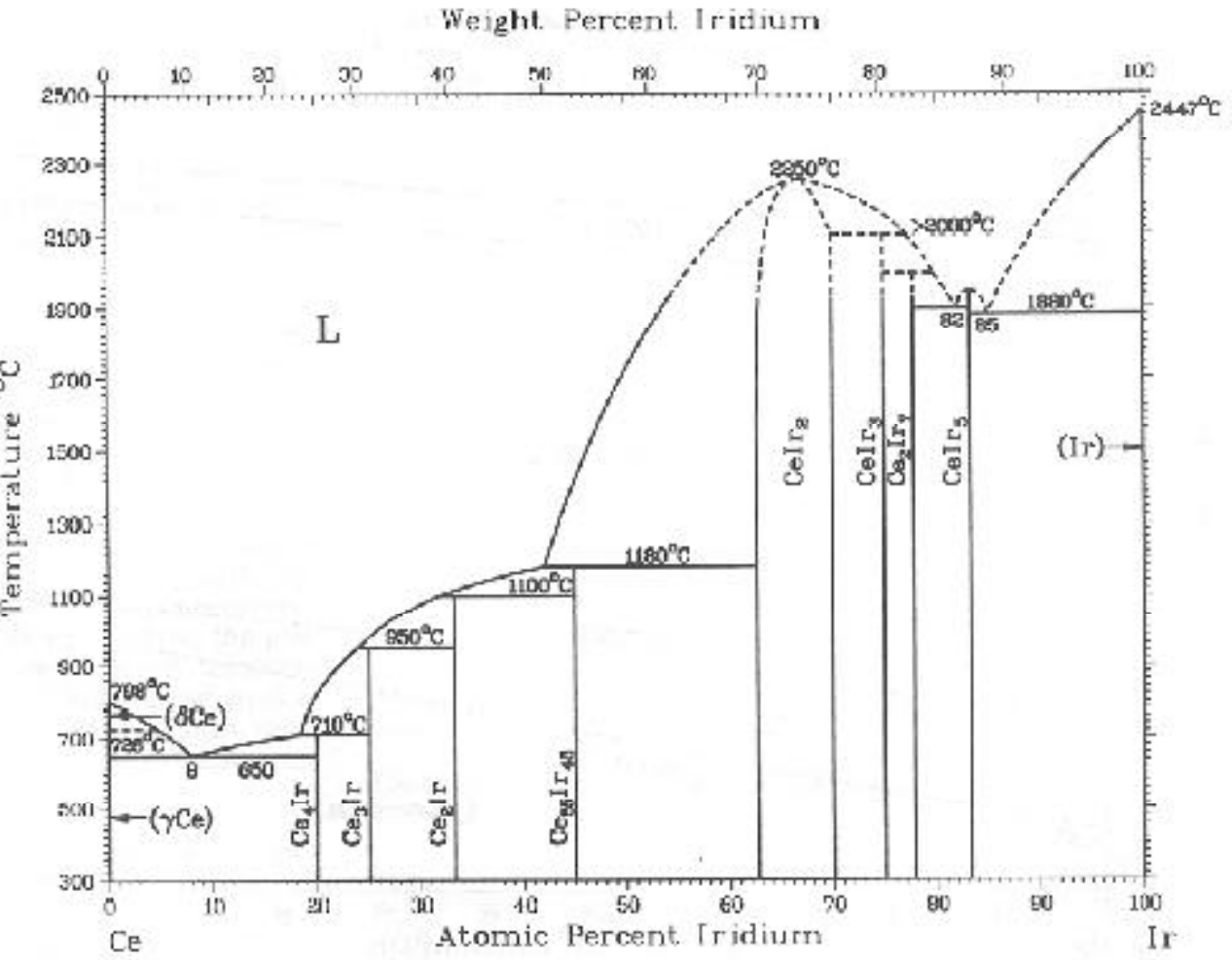

(b)

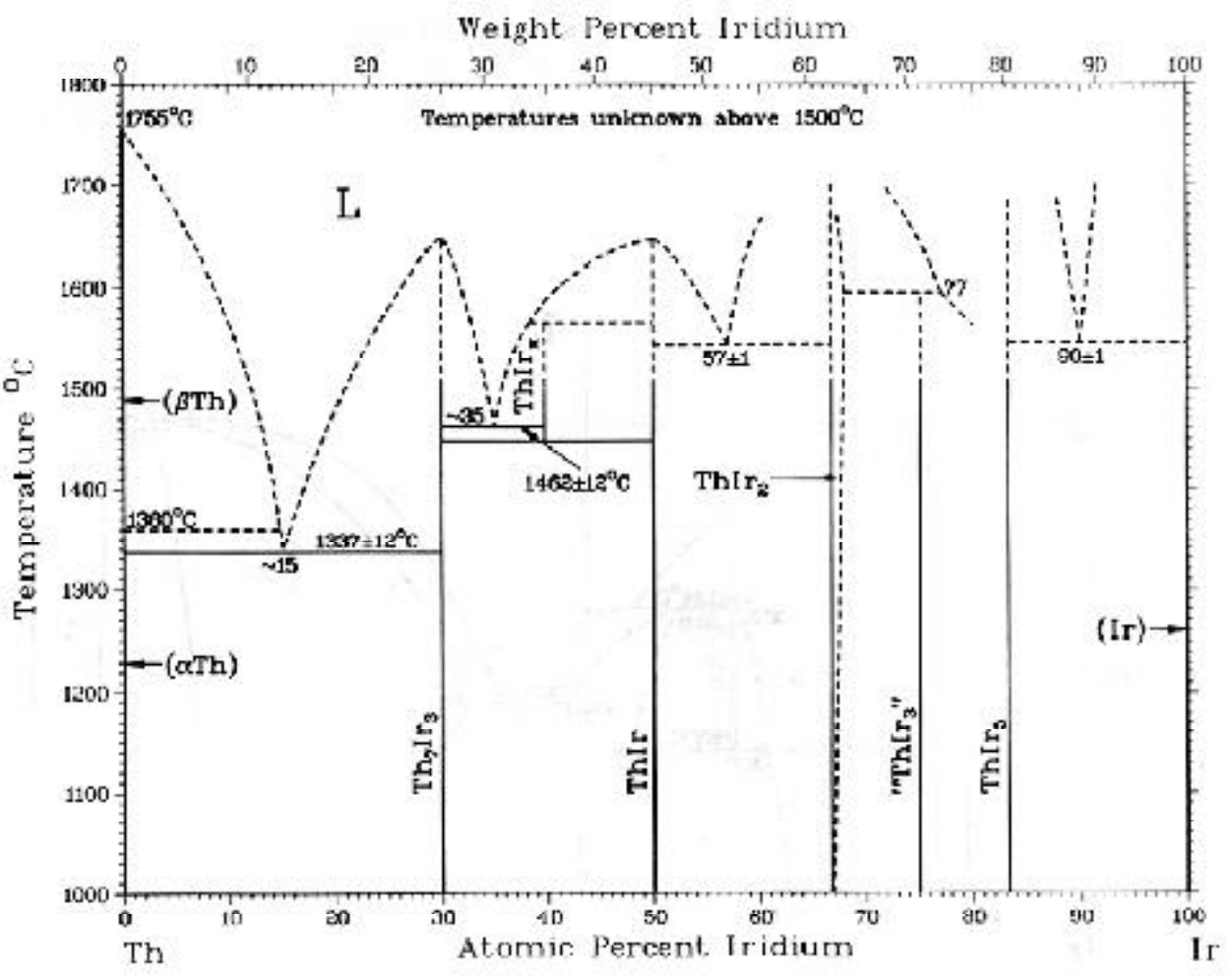

Fig. 48. Phase diagrams of (a) Ir-Ce and (b) Ir-Th [31]. 
the latter two alloys is less than the average cracking stress for both old- and new-proces DOP-26 alloys. In the case of E819, we did not have enough material to determine a precise cracking stress; all we can conclude at present is that $\mathrm{F}_{0}<140 \mathrm{MPa}$. Based on these preliminary results, it appears that boron at a level of 100 appm is quite harmful and its level in the alloy needs to be reduced. However, 100 appm B in the iridium alloys is only $6 \mathrm{ppm}$ by weight, and it would be difficult to consistently make (and chemically analyze) alloys containing lower boron concentrations. Therefore, boron-doped alloys should prob-

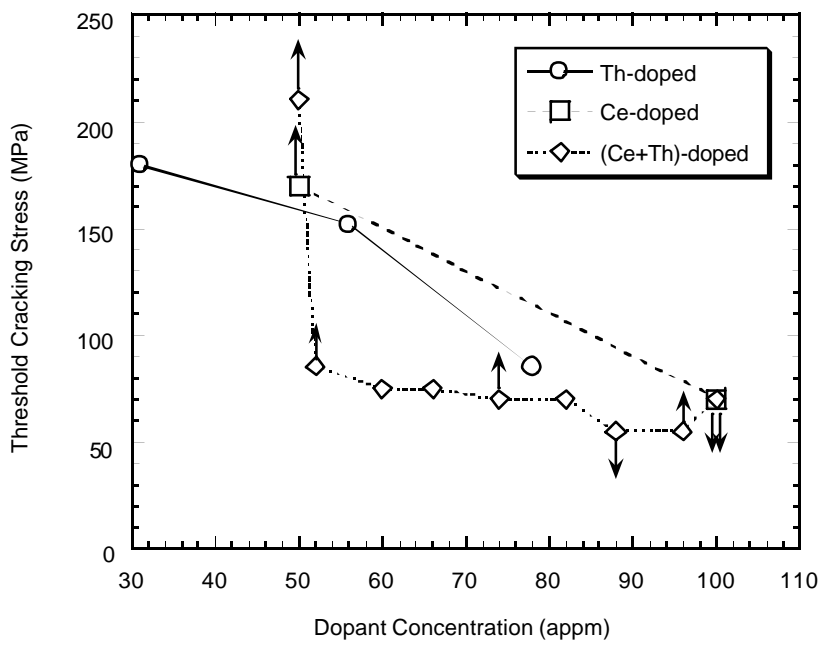

Fig. 49. Effect of doping with cerium and thorium, individually and together, on weldability of iridium alloys. ably not be considered further. In the case of yttrium, although additional data are needed before its effect on weldability is definitively known, it is clearly inferior to cerium. Therefore, unless its effect on impact ductility is far superior to that of cerium, it should probably not be considered further.

\section{SUMMARY AND CONCLUSIONS}

This report summarizes results of studies conducted to date to characterize the properties of Ir- $0.3 \%$ W alloys doped with cerium or cerium plus thorium. The properties investigated included grain growth in both vacuum and low-pressure oxygen environments, weldability, and the effect of grain size and test temperature on tensile properties.

Grain sizes were determined for eleven Ce/Th-doped alloys and two cerium-doped alloys after annealing at temperatures of 1200 to $1800 \mathrm{EC}$. All of the Ce/Th-doped alloys have essentially identical grain sizes after 1-h anneals at these temperatures and their grain sizes are comparable to grain sizes for DOP-26 annealed under the same conditions (see Figs. 2, 5 and 9). The alloys doped only with cerium also have grain sizes comparable to DOP-26 for annealing temperatures below 1600EC. However, at temperatures above $1600 \mathrm{EC}$, they show greater grain growth than the thorium-doped or Ce/Th-doped alloys. In general, the greater the amount of dopant (cerium or cerium plus thorium) the smaller the grain size, especially at higher temperatures. The grain growth kinetics (for anneals up to $1000 \mathrm{~h}$ ) of alloys containing both cerium and thorium are comparable to those of new- and old-process DOP-26 containing 60 ppm Th (see Figs. 4, 6, and 8). 
Oxygen compatibility studies were conducted on specimens taken from several cerium-doped heats of the DOP-40 iridium alloy. These heats contained various combinations of cerium and thorium ranging from 20 ppm Ce-40 ppm Th and 29 ppm Ce-18 ppm Th to 36 ppm Ce-60 ppm Th and included one heat with only $36 \mathrm{ppm} \mathrm{Ce}$ (no thorium). The tests were conducted in oxygen partial pressures of 1.3 and 13.3 $\mathrm{mPa}$ at temperatures of 1230,1280 , and $1330 \mathrm{EC}$ for times up to $3000 \mathrm{~h}$. Specimens from the ZR and D2 heats of DOP-26 material (containing nominally $60 \mathrm{wppm}$ Th but no cerium) were included for comparison purposes. In terms of average grain size and grain growth rates as a function of time, the DOP-40 alloys are comparable to DOP-26 as long as the alloys contain at least approximately 20-30 ppm Th. Heats that contained only cerium (no thorium) experienced greater grain growth than DOP-26, especially at longer times and higher temperatures. In addition, the data suggest a slight difference between DOP-26 and Ce/Th-doped DOP-40 alloys in their tendency to form larger near-surface grains under these annealing conditions. This difference may be related to the possible faster diffusion rate of cerium in iridium as compared to thorium. The data also show a difference in the grain growth of near surface grains exposed to $1.3 \mathrm{mPa}$ oxygen versus those exposed to $13.3 \mathrm{mPa}$ oxygen, with grain sizes of the specimens exposed to $13.3 \mathrm{mPa}$ oxygen being larger. All of our tests on DOP-26 alloys have shown no difference in the grain growth of near surface grains in these two oxygen levels.

The effects of cerium and thorium microalloying additions on the mechanical properties of iridium alloys were investigated. The base alloy to which the dopants were added was Ir-0.3W. At low strain rates $\left(\sim 10^{-3} \mathrm{~s}^{-1}\right)$, the strength and ductility of alloys doped with thorium were similar to those of alloys doped with both thorium and cerium. The alloys all exhibited high work hardening rates and brittle mixed-mode fracture (intergranular + transgranular) at low temperatures and low work hardening plus ductile transgranular fracture at elevated temperatures. The brittle-to-ductile transition occurred at around $600 \mathrm{EC}$. Both thorium and $\mathrm{Ce} / \mathrm{Th}$ additions produced a slight improvement in ductility compared to the undoped alloys.

At high strain rates $\left(\sim 10^{3} \mathrm{~s}^{-1}\right)$, the Ce/Th-doped alloys exhibited brittle intergranular fracture at low temperatures and ductile transgranular fracture at elevated temperatures. The brittle-to-ductile transition occurred at around 1000EC. Compared to the lower strain rate, there was an increase in the BDTT of $\sim 400 \mathrm{EC}$ at this higher strain rate. For a fixed tensile test temperature (1000EC), ductility dropped sharply with increasing annealing temperature because of increasing grain size. The Ce/Th-doped alloys appeared to have somewhat higher ductilities than the thorium-doped alloy when annealed at temperatures higher than 1500EC. The grain-boundary cohesive strengths of the Ce/Th-doped alloys were similar to that of the thorium-doped alloy. Based on the results of the present study, Ir-0.3W alloys containing $30 \pm 10 \mathrm{ppm}$ Ce and $40 \pm 10 \mathrm{ppm}$ Th are expected to behave similarly to the currently used DOP-26 alloy (containing nominally $60 \mathrm{ppm}$ Th plus $50 \mathrm{ppm} \mathrm{Al}$ ) in space power applications.

Threshold cracking stresses for several cerium-doped alloys were determined using the Sigmajig weldability test. At dopant levels of around 50 appm, cerium or combinations of cerium and thorium 
were significantly better for weldability than thorium by itself. We speculate that the reason for this is

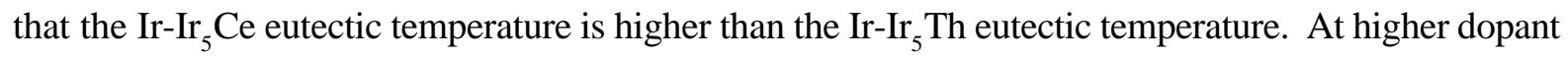
levels (around 100 appm), cerium also becomes deleterious to weldability, but preliminary indications are that it is not as harmful as thorium. Yttrium, boron, and a combination of the two, when added to Ir- $0.3 \mathrm{~W}$ alloys containing cerium and thorium, lower the threshold stresses considerably. Therefore, unless these elements are found to improve impact ductility dramatically, they should probably not be considered further.

The general conclusion from these studies is that cerium can be used to replace some of the radioactive thorium currently used in DOP-26 while maintaining or improving its metallurgical properties. The

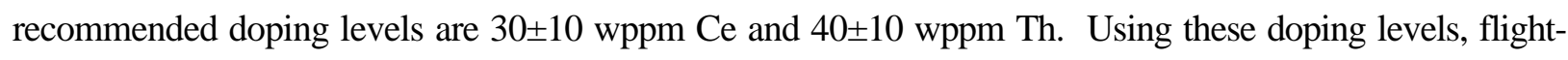
quality clad vent set cups were fabricated and were shown in this study to have the necessary metallurgical properties. Qualification of DOP-40 for encapsulation of Pu- 238 should be completed by conducting impact tests of several fuel clads. The current DOP-26 alloy meets all requirements for cladding the radioactive fuel in the RTG heat source, but the new DOP-40 alloy could serve as a back-up alloy to be used if the costs of refining, handling, and transporting DOP-26 become prohibitively high.

\section{ACKNOWLEDGEMENTS}

This effort was sponsored by the Office of Space and Defense Power Systems of the U. S. Department of Energy. The authors gratefully acknowledge the support and technical guidance of Dr. W. J. Barnett of the U. S. Department of Energy. His foresight was instrumental in the development, production, and evaluation of materials for radioisotope power systems.

\section{REFERENCES}

1. A. H. Cottrell, The Mechanical Properties of Matter, Wiley, New York, NY, 1964.

2. B. L. Mordike and C. A. Brookes, Platinum Metals Rev., 4 (1960) 94.

3. H. Jehn, J. Less Common Met., 100 (1984) 321.

4. Metals Handbook, Vol. 2, 9th edition, American Society for Metals, Metals Park, OH, 1979.

5. C. T. Liu, H. Inouye and A. C. Schaffhauser, Metall. Trans. A, 12 (1981) 993.

6. S. S. Hecker, D. L. Rohr and D. F. Stein, Metall. Trans. A, 9 (1978) 481.

7. D. L. Rohr, L. E. Murr and S. S. Hecker, Metall. Trans. A, 10 (1979) 399.

8. C. Gandhi and M. F. Ashby, Scripta Metall., 13 (1979) 371.

9. T. G. George and M. F. Stevens, JOM, 40 (10) (1988) 32.

10. P. Panfilov, A. Yermakov, V. Dimitriev, and N. Timofeev, Platinum Metals Rev., 35 (1991) 196.

11. P. Haasen, H. Hieber, and B. L. Mordike, Z. Metallkd., 56 (1965) 832.

12. C. N. Reid and J. L. Routbort, Metall. Trans. A, 3 (1972) 2257.

13. A. Yermakov, P. Panfilov, and R. Adamesku, J. Mater. Sci. Lett., 9 (1990) 696.

14. M. A. Fortes and B. Ralph, Acta Metall., 15 (1967) 707.

15. C. A. Brookes, J. H. Greenwood and J. L. Routbort, J. Inst. Metals, 98 (1970) 27. 
16. C. L. White and C. T. Liu, Scripta Metall., 12 (1978) 727.

17. C. T. Liu and H. Inouye, Development and Characterization of an Improved Ir-0.3\% W Alloy for Space Radioisotopic Heat Sources, ORNL-5290, Oak Ridge National Laboratory, Oak Ridge, TN, October 1977.

18. C. L. White, R. E. Clausing and L. Heatherly, Metall. Trans. A, 10 (1979) 683.

19. C. T. Liu, H. Inouye and A. C. Schaffhauser, Metallurgical and Mechanical Properties of Thorium-Doped Ir-0.3\% W Alloys, ORNL-5616, Oak Ridge National Laboratory, Oak Ridge, TN, April 1980.

20. C. T. Liu and H. Inouye, Study of Iridium and Iridium-Tungsten Alloys for Space Radioisotopic Heat Sources, ORNL-5240,Oak Ridge National Laboratory, Oak Ridge, TN, December 1976.

21. T. Takasugi, E. P. George, D. P. Pope and O. Izumi, Scripta Metall., 19 (1985) 551.

22. T. Ogura, S. Hanada, T. Masumoto and O. Izumi, Metall Trans. A, 16 (1985) 441.

23. E. P. George, C. T. Liu, and D. P. Pope, Scripta Metall. Mater., 28 (1993) 857.

24. E. P. George, C. T. Liu, and D. P. Pope, Scripta Metall. Mater., 30 (1994) 37.

25. E. P. George, C. T. Liu, and D. P. Pope, Acta. Mater., 44 (1996) 1757.

26. J. W. Cohron, E. P. George, L. Heatherly, C. T. Liu, and R. H. Zee, Intermetallics, 4 (1996) 497.

27. C. T. Liu, C. L. White, and E. H. Lee, Scripta Metall., 19 (1985) 1247.

28. A. I. Taub, K.-M. Chang, and C. T. Liu, Scripta Metall., 20 (1986) 1613.

29. http://www.jpl.nasa.gov/cassini/rtg/

30. C. G. McKamey, A. N. Gubbi, Y. Lin, J. W. Cohron, E. H. Lee, and E. P. George, Grain Growth Behavior and High-Temperature High-Strain-Rate Tensile Ductility of Iridium Alloy DOP-26, ORNL6935, Oak Ridge National Laboratory, Oak Ridge, TN, April 1998.

31. T. B. Massalski, editor-in-chief, Binary Alloy Phase Diagrams, Second Edition, ASM International, Materials Park, OH, 1990.

32. C. T. Liu and S. A. David, Weld Metal Grain Structure and Mechanical Properties of Iridium Alloy DOP-26, ORNL-5857, Oak Ridge National Laboratory, Oak Ridge, TN, August 1982.

33. D. McLean, Grain Boundaries in Metals, Clarendon Press, Oxford, United Kingdom, 1957.

34. J. J. Liao, Ph.D. Thesis, Auburn University, Auburn, AL, 1991.

35. A. N. Gubbi, "Grain Boundary Segregation, Microstructure, Impact Ductility and Fracture Behavior of Iridium Alloys," Ph.D. Thesis, Auburn University, 1994.

36. A. N. Gubbi, E. P. George, E. K. Ohriner and R. H. Zee, Acta Mater., 46 (1998) 893.

37. A. N. Gubbi, E. P. George, E. K. Ohriner and R. H. Zee, Metall. Mater. Trans. A, 28 (1997) 2049.

38. E. K. Ohriner, pp. 1093-98 in Proc. Tenth Symposium on Space Nuclear Power and Propulsion, eds. M. S. El-Genk and M. D. Hoover, American Inst. of Physics Conf. Proc. 271 (1993).

39. E. K. Ohriner, p. 605 in Proc. Int. Conf. on Tungsten and Refractory Metals, Metal Powder Industries Federation, Princeton, NJ, 1995.

40. D. J. McGuire, J. P. Moore, E. K. Ohriner, and G. B. Ulrich, Production of Iridium Alloy and Carbon-Bonded Carbon Fiber Components for the Cassini Mission to Saturn, ORNL-6933, Oak Ridge National Laboratory, Oak Ridge, TN, 1998.

41. C. L. White and C. T. Liu, Acta Metall. 29, (1981) 301.

42. G. M. Goodwin, Welding Research 33-s (1987) .

43. C. G. McKamey, E. H. Lee, J. W. Cohron, and E. P. George, Scripta Mater. 35(2) (1996) 181-85.

44. C. T. Liu and H. Inouye, page 1149 in Proc. 2nd Intl. Conf. Mech. Behav. Mater., American Society for Metals, Metals Park, OH, 1976.

45. C. L. White, L. Heatherly, and R. A. Padgett, Acta Metall. 31 (1983) 111-19.

46. E. K. Ohriner, unpublished results, 1994.

47. G. M. Goodwin and E. K. Ohriner, unpublished results, 1993.

48. S. A. David and C. T. Liu, High-Power Laser and Arc Welding of Thorium-Doped Iridium Alloys, ORNL/TM-7258, Oak Ridge National Laboratory, Oak Ridge, TN, May 1980. 


\section{INTERNAL DISTRIBUTION}

1. E. E. Bloom

2. E. P. George

3. L. L. Horton

4. J. F. King

5. E. H. Lee

6. C. T. Liu

7-8. C. G. McKamey
9-11. J. P. Moore
12. E. K. Ohriner
13-15. G. B. Ulrich
16. J. L. Wright
17. Central Research Library
18. ORNL Laboratory Records -- RC
19-20. ORNL Laboratory Records -- OSTI

\section{EXTERNAL DISTRIBUTION}

21. R. T. Carpenter, Orbital Sciences Corp., 20030 Century Boulevard, Suite 102, Germantown, Maryland 20874

22. L. E. DeFillippo, Lockheed Martin Astronautics, P. O. Box 8555, Philadelphia, Pennsylvania 19101

23. E. M. Foltyn, Los Alamos National Laboratory, NMT-9, Mail Stop E502, P. O. Box 1663, Los Alamos, New Mexico 87545

24. D. M. Gabriel, BWXT of Ohio, Inc., 1 Mound Road, P. O. Box 3030, Miamisburg, Ohio 453433030

25. D. P. Kramer, BWXT of Ohio, Inc., 1 Mound Road, P. O. Box 3030, Miamisburg, Ohio 453433030

26. S. R. Martin, Jr., Department of Energy, Oak Ridge Operations Office, P. O. Box 2001, Oak Ridge, Tennessee 37831

27. D. C. McNeil, BWXT of Ohio, Inc., 1 Mound Road, P. O. Box 3030, Miamisburg, Ohio 453433030

28. A. S. Mehner, Department of Energy, Space and National Security Programs (NE-50), Germantown Building, 19901 Germantown Road, Germantown, Maryland 20874-1290

29. R. M. Reinstrom, Lockheed Martin Astronautics, P. O. Box 8555, Philadelphia, Pennsylvania 19101

30. E. A. Skrabek, Orbital Sciences Corp., 20030 Century Boulevard, Suite 102, Germantown, Maryland 20874

31. J. G. Teague, Los Alamos National Laboratory, NMT-9, Mail Stop E502, P. O. Box 1663, Los Alamos, New Mexico 87545

32. R. L. Wiley, Department of Energy, Space and National Security Programs (NE-50), Germantown Building, 19901 Germantown Road, Germantown, Maryland 20874-1290 